\title{
DEAF NI-VANUATU AND THEIR SIGNS: \\ A SOCIOLINGUISTIC STUDY
}

\author{
BY \\ JACQUELINE GEORGA ISELI

\begin{abstract}
A Thesis
submitted to Victoria University of Wellington

In fulfilment of the requirements for the degree of

Master of Arts in Linguistics by Thesis
\end{abstract}

Victoria University of Wellington

2018 


\section{Abstract}

This thesis provides the first documentation and description of the signs created and used by deaf individuals in Vanuatu. The specific aims of this research were as follows: to establish the sociolinguistic context experienced by deaf people in Vanuatu; to identify the repertoire and characteristics of signs used by the deaf participants; to compare features of participants' individual signs with the characteristics of home signs and emerging sign languages; and to consider the degree of similarity and potential similarity of signs between participants and how this reflects individuals' opportunities for contact with other deaf people and signing interlocutors. The limitations of this study are that field methodology for data collection was developed in situ as conditions allowed. The sociolinguistic context for deaf $\mathrm{Ni}$-Vanuatu confirms that language isolation leads to marginalisation from community and society. The study established that these home sign lexicons were limited in quantity and conceptual range, and that shared background knowledge was essential for comprehension. Overall, 22 handshapes were documented, and the predominant handshapes unmarked. Most participants preferred handling strategy for depicting signs. Some evidence of noun-verb distinction was noted in the repertoire of some participants. However, across this range of formational characteristics, results showed significant individual variations. Furthermore, multiple barriers have precluded development of a shared sign language and any form of deaf community. 


\section{Acknowledgements}

Firstly, I would like to thank my supervisor Rachel McKee who encouraged me; firstly, in Vanuatu while I was living in the remoteness of Malakula creating the small lexicon; and secondly, in the value of pursuing this research. Rachel has provided invaluable advice and questions to head me in the right directions, particularly when the way ahead seemed rather elusive.

Secondly, I would like to thank Volunteer Service Abroad for my two years in Vanuatu. For me it was an amazing opportunity, full of new experiences, and wonderful to meet the people of Vanuatu. Also, my appreciation to Mrs Doriane Naliupis of SANMA Frangipani Association for her support and enthusiasm.

Thirdly, I would like to thank my husband, Howard Iseli, for his continuous support during this time to work on my thesis.

Finally, my grateful thanks to the remarkable deaf people of Vanuatu who shared their creative home signs with me. 


\section{Table of Contents}

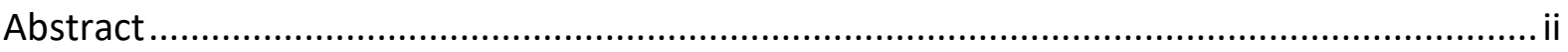

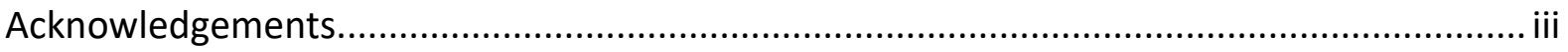

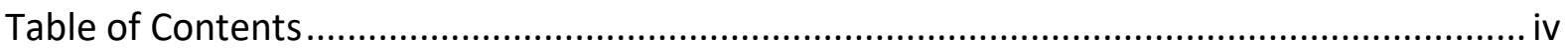

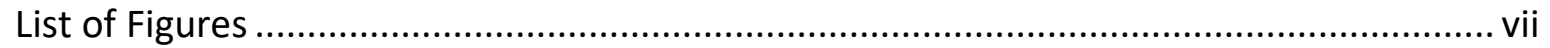

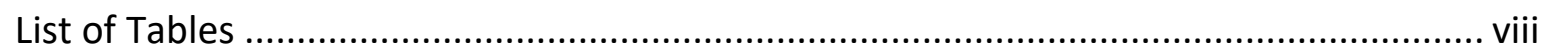

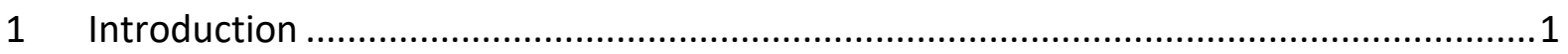

1.1 Geography, Demographics and Languages of Vanuatu ........................................2

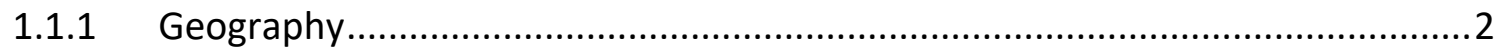

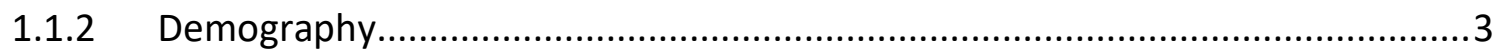

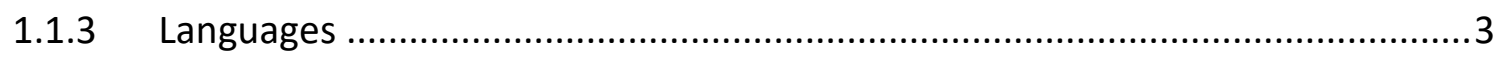

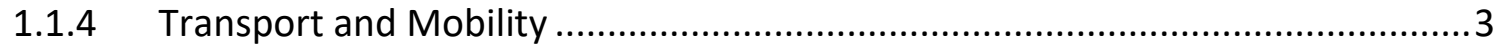

1.1.5 Vanuatu Society and Custom ..................................................................... 4

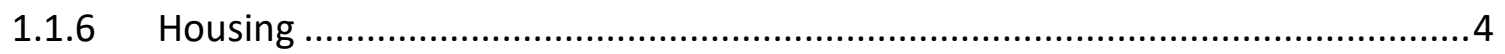

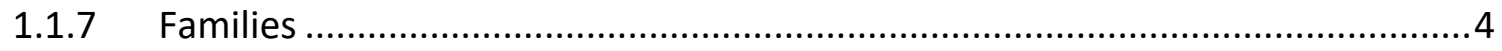

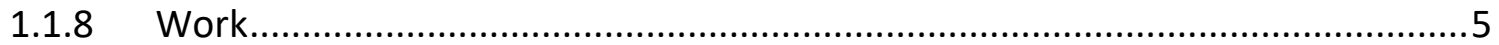

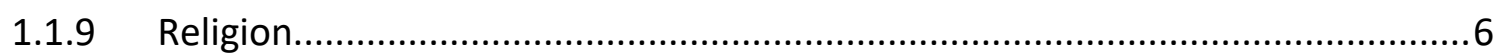

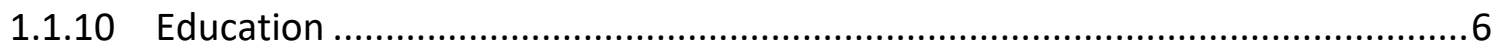

1.1.11 Status of People with Disabilities..............................................................

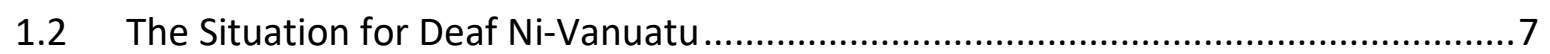

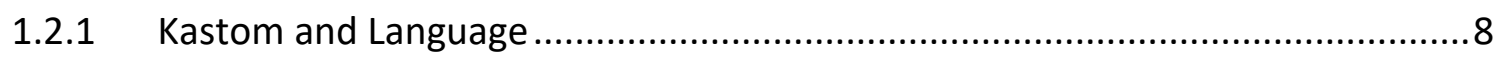

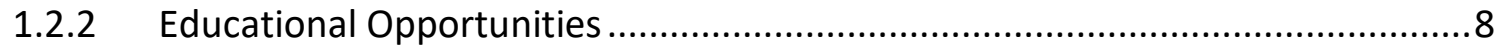

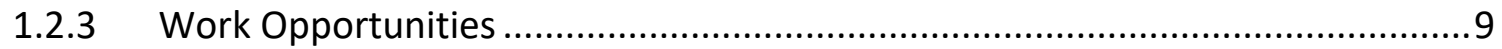

1.2.4 Social Contact Between Deaf People...........................................................

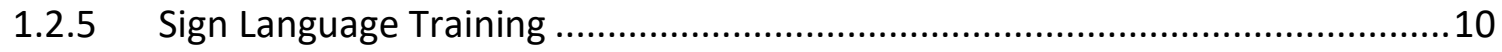

2 From Gesture to Sign: The Development of Sign Languages and Signing Communities 12

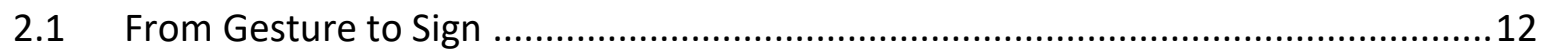

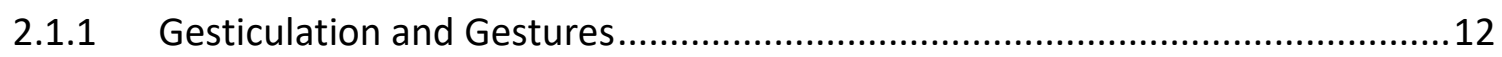

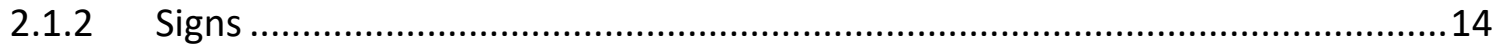

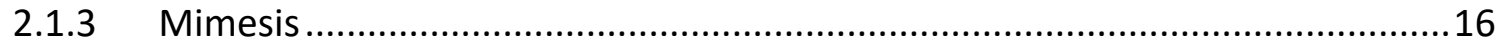

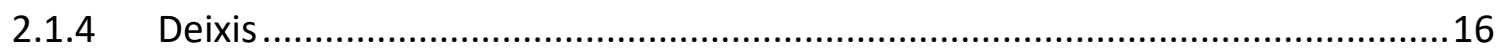

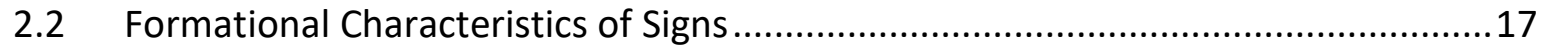




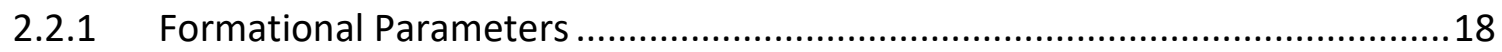

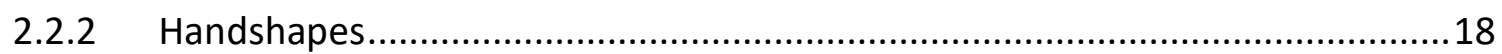

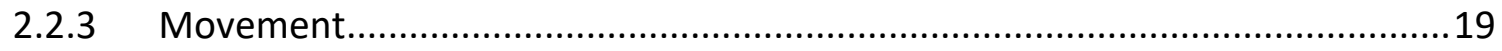

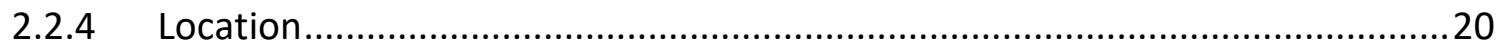

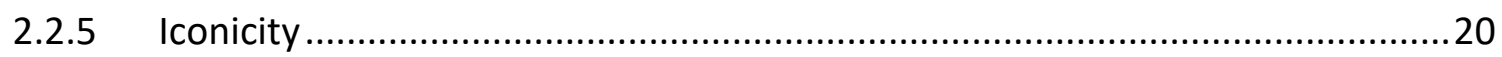

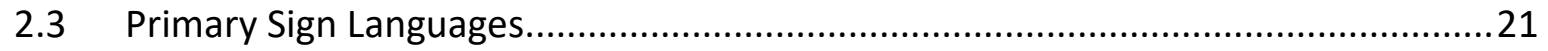

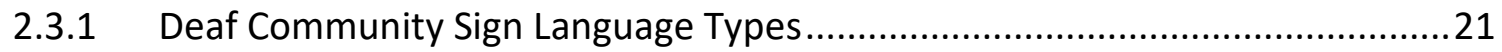

2.3.2 Urban Deaf Community Sign Languages.........................................................21

2.3.3 Emerging Deaf Community Sign Languages ..................................................22

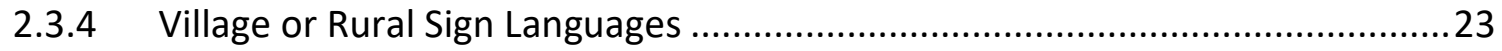

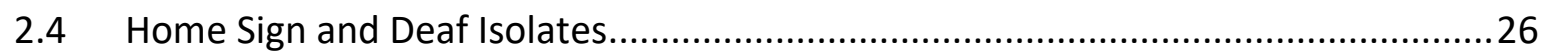

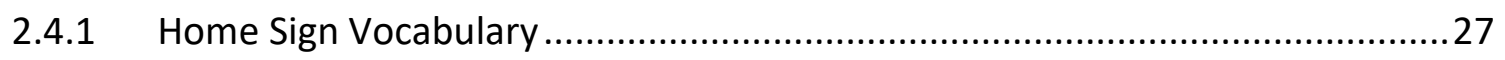

2.4.2 Formation and Production of Home Signs..................................................28

2.4.3 Types of Gestures Used by Home Signers .....................................................29

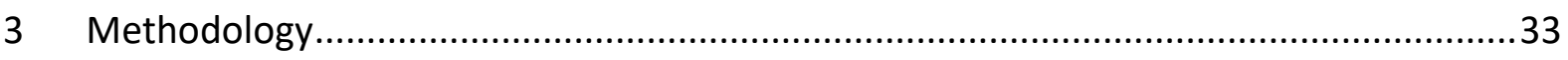

3.1 Data Collection and Fieldwork Challenges..........................................................33

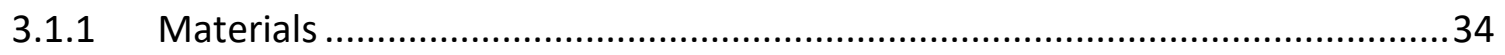

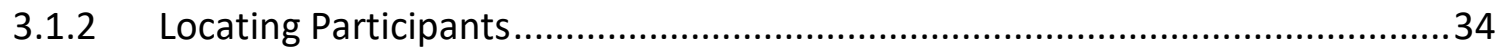

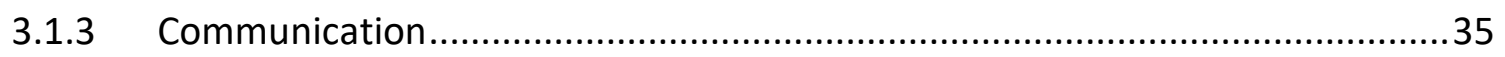

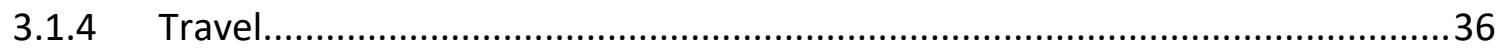

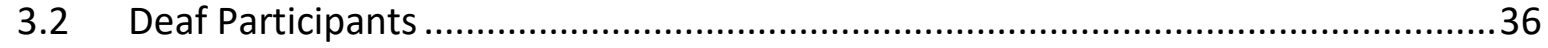

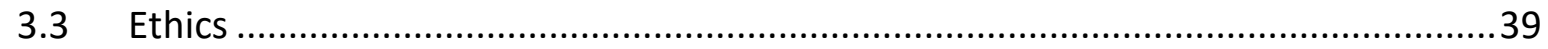

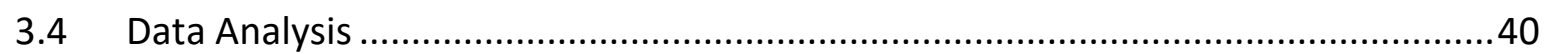

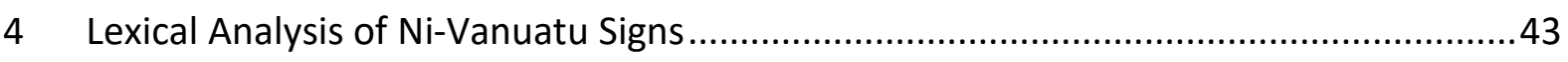

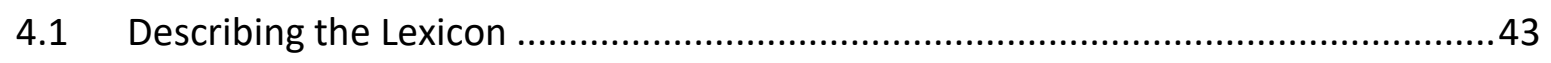

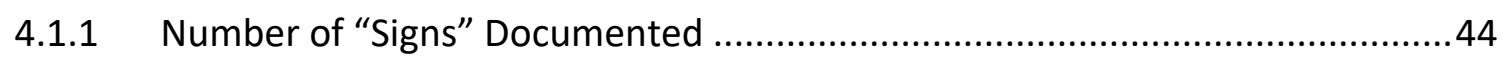

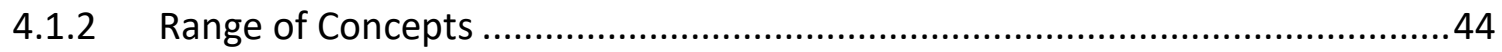

4.2 Degree of Similarity or Variation Across Participants and Concepts ........................52

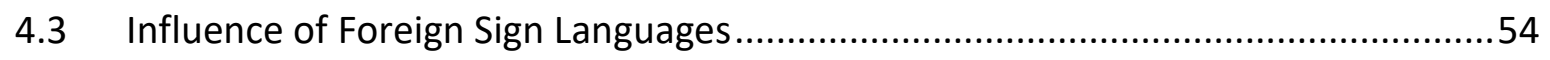

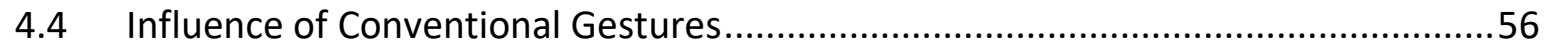

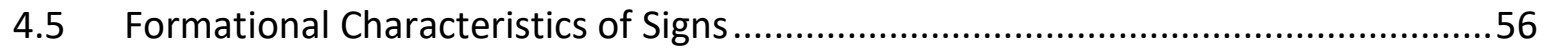

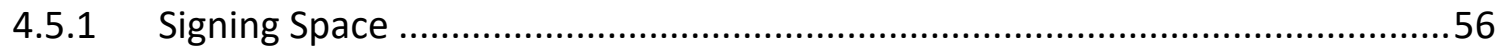

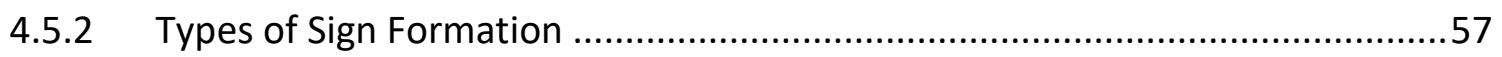




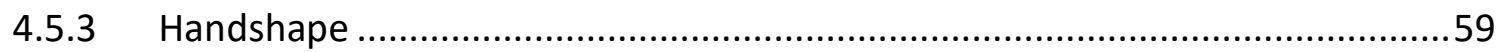

4.5.4 Handshape Variation Between Individuals................................................62

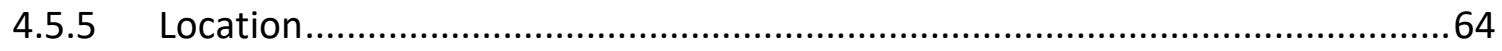

4.5.6 Location Variation Between Individuals .......................................................69

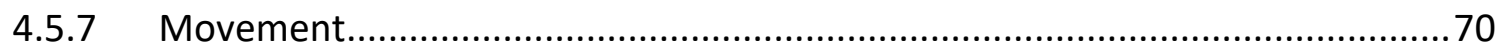

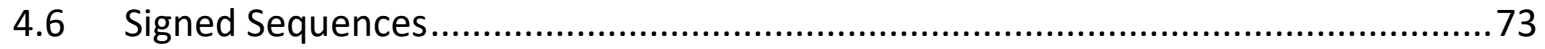

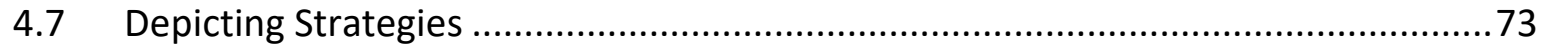

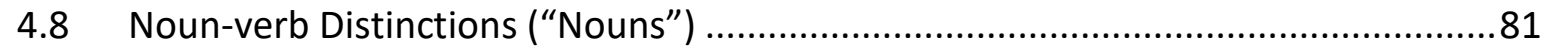

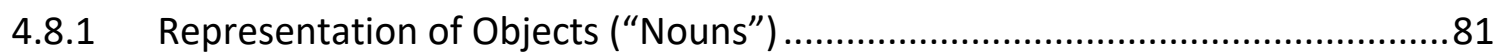

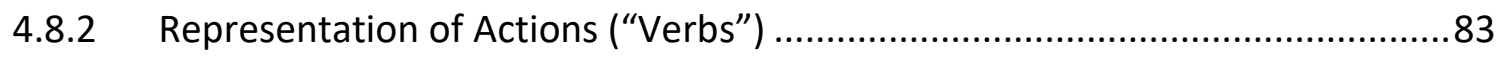

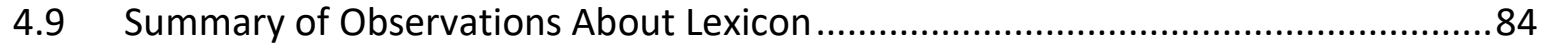

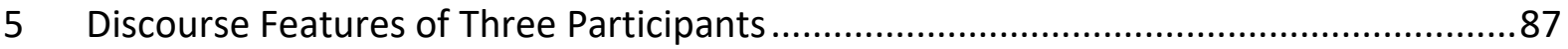

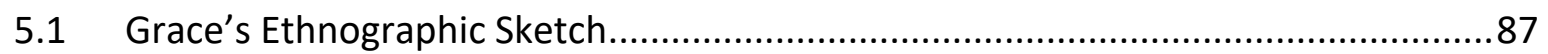

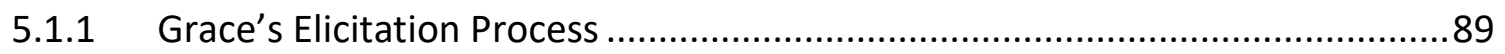

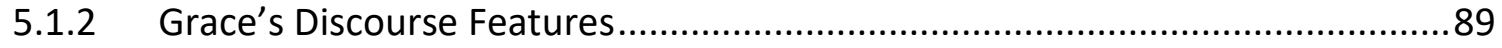

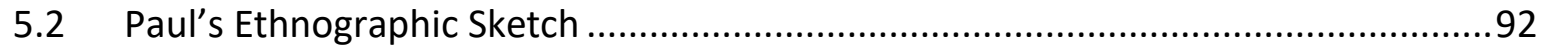

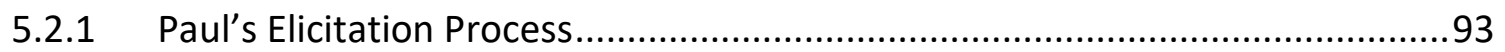

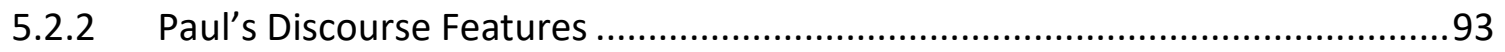

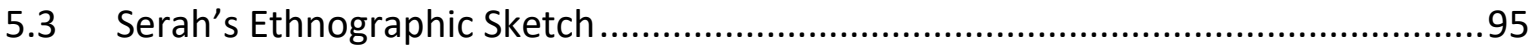

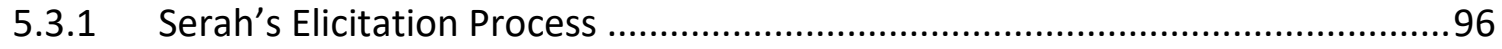

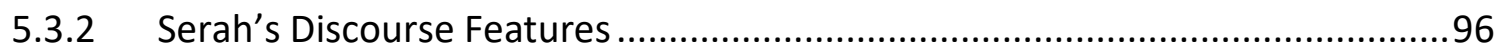

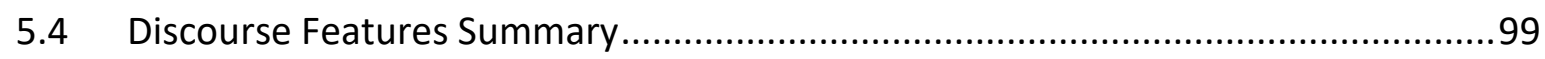

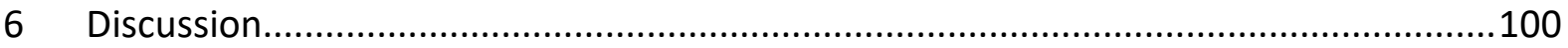

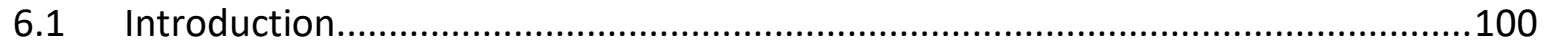

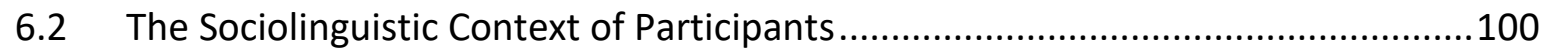

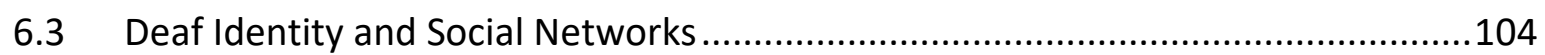

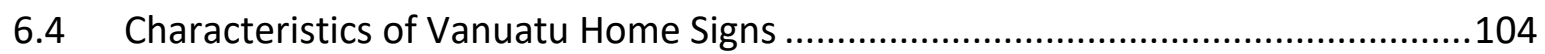

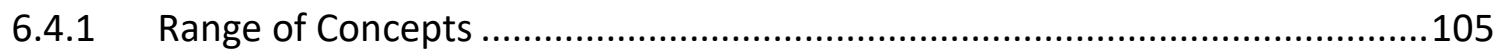

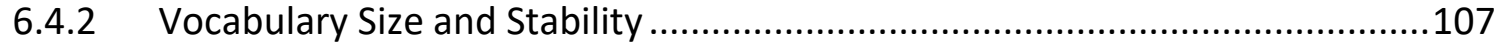

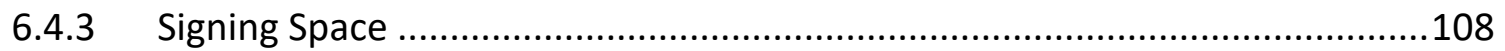

6.4.4 Formational Characteristics of Signs.......................................................... 108

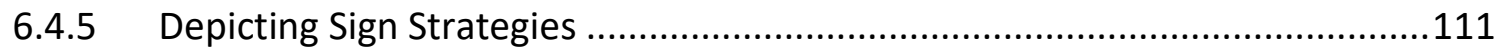

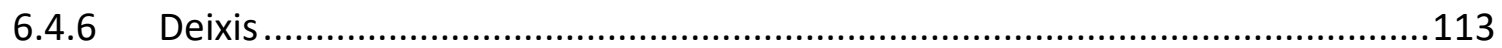


7.1 The Sociolinguistic Context for Deaf Ni-Vanuatu ...............................................116

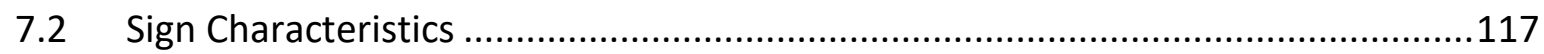

7.3 Conditions for a Shared Sign Language ............................................................118

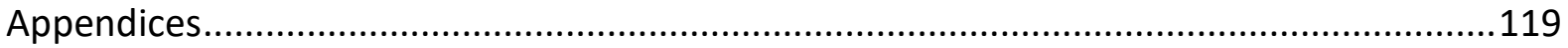

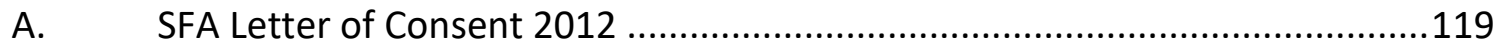

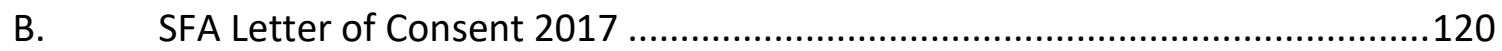

C. Participants' Location, Gender and Approximate Age .................................121

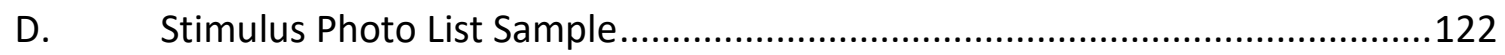

E. Dictionary Page 83 Seascape Sample ..........................................................123

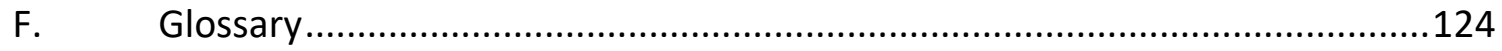

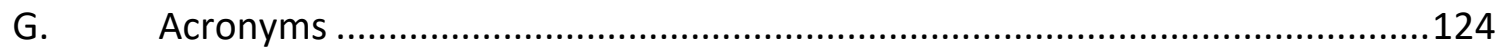

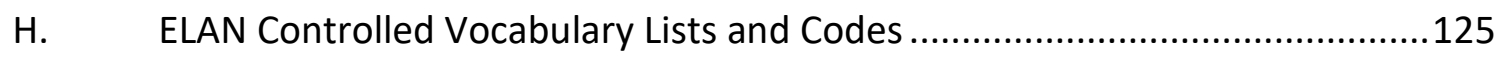

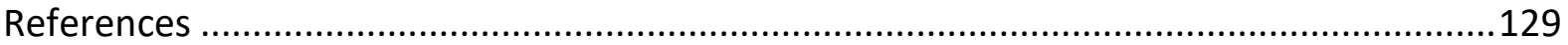

List of Figures

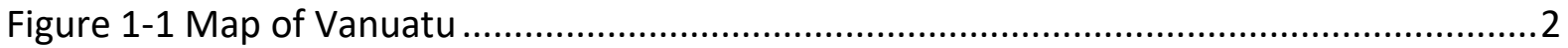

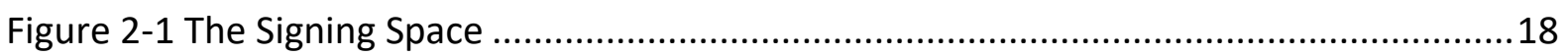

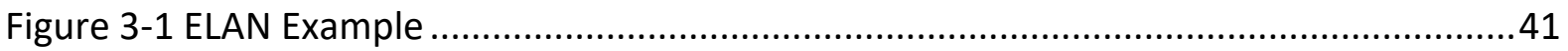

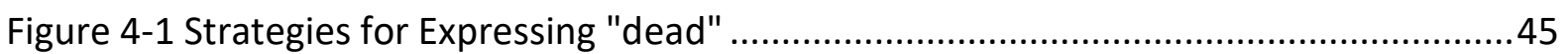

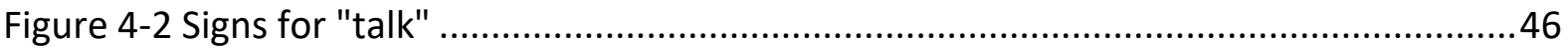

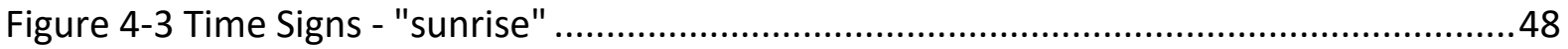

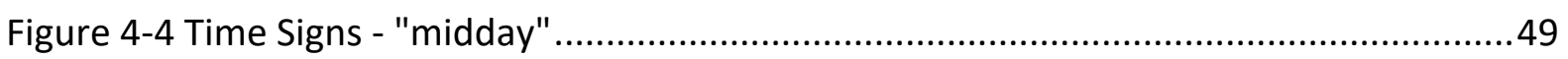

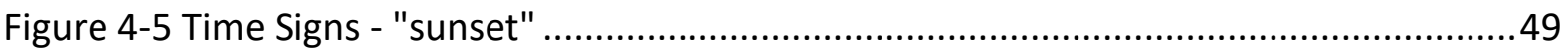

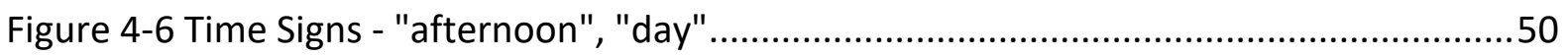

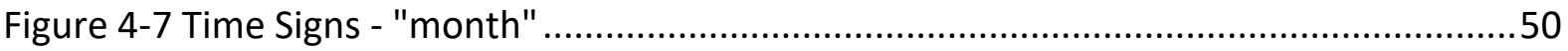

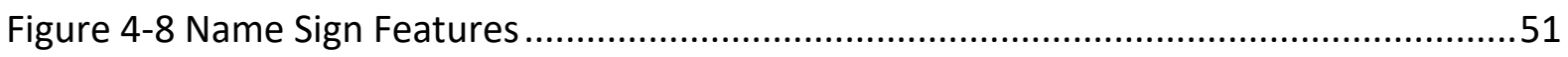

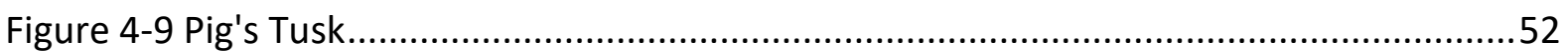

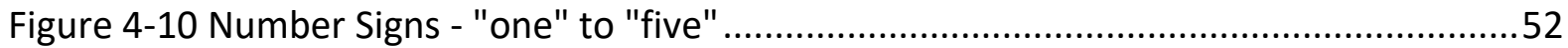

Figure 4-11 Malakula Variants for "married" or "partner"..................................................53

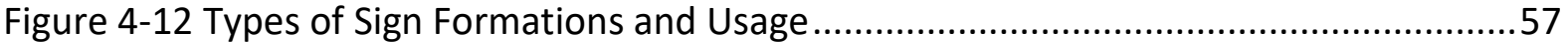

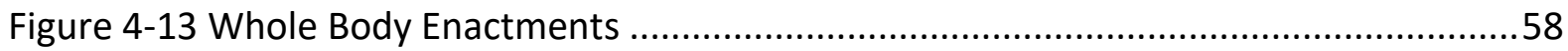

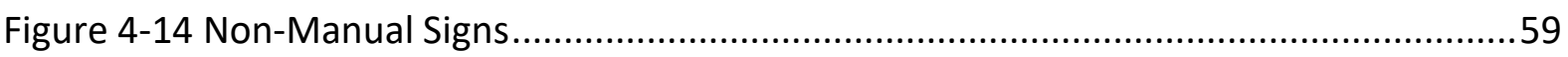

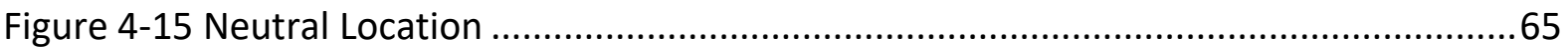

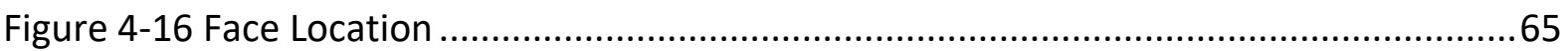

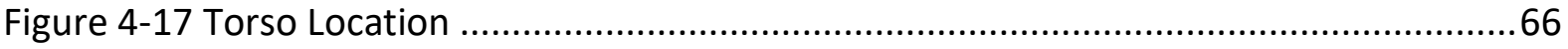

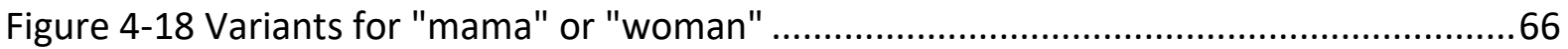


Figure 4-19 Above Location

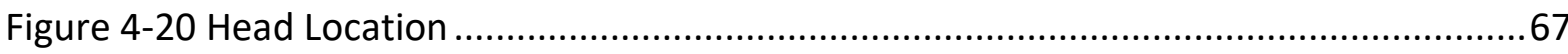

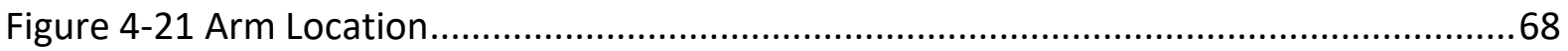

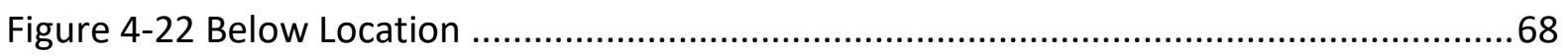

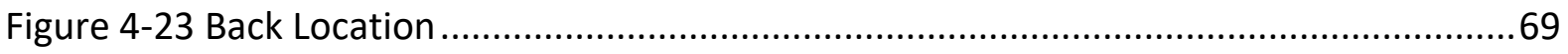

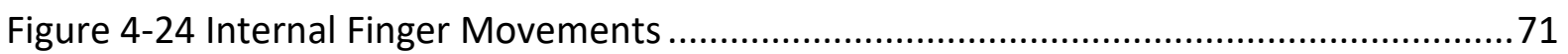

Figure 4-25 Combined Internal and Path Movements .................................................... 71

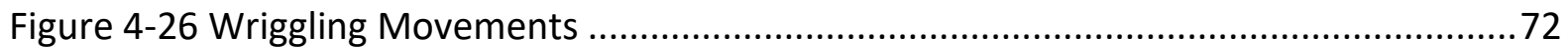

Figure 4-27 Differing Simultaneous Hand Movements ......................................................72

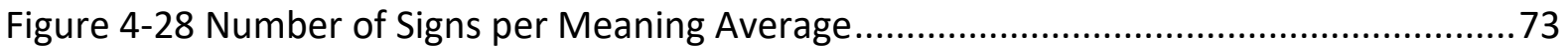

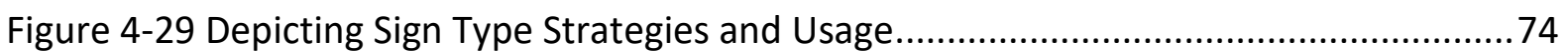

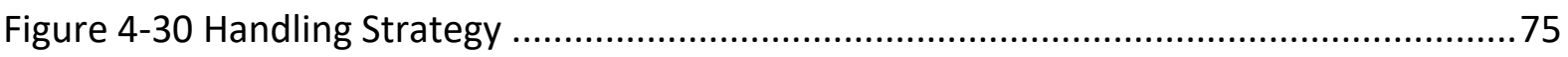

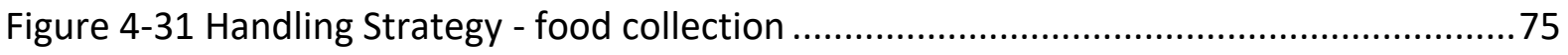

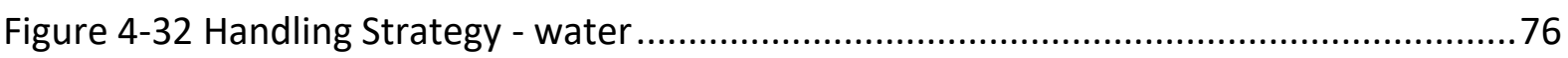

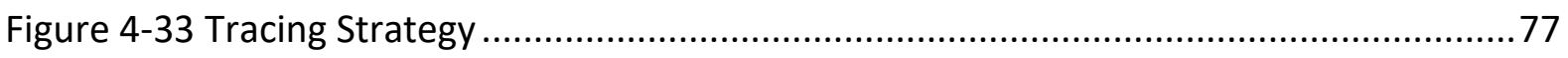

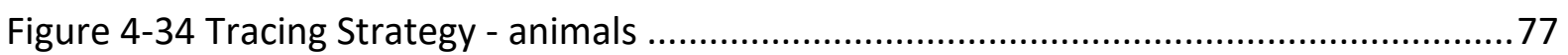

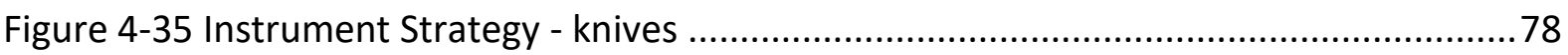

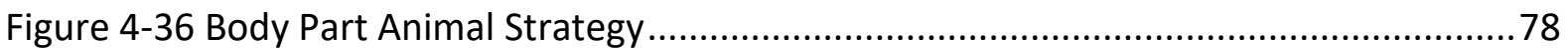

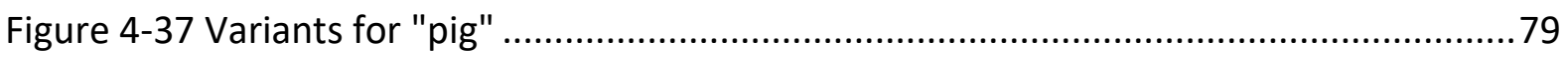

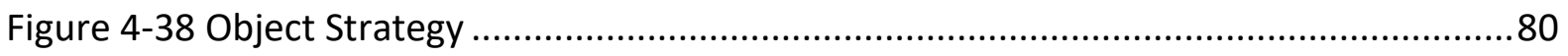

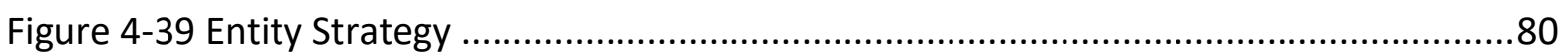

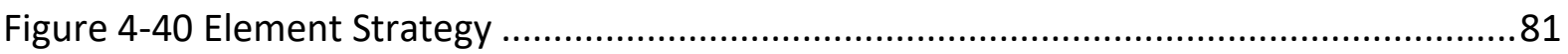

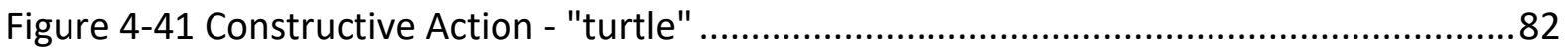

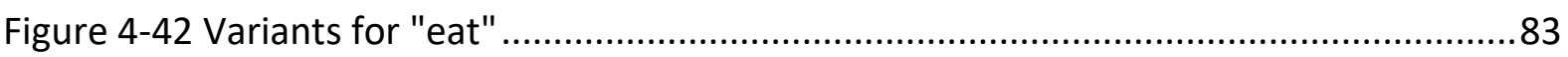

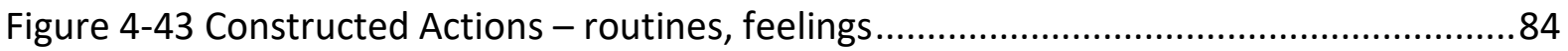

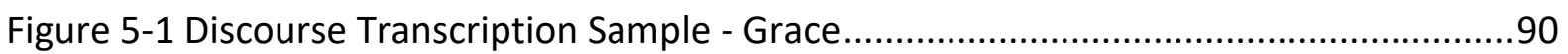

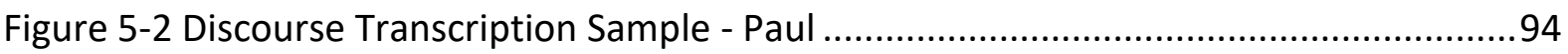

Figure 5-3 Discourse Transcription Sample - Serah ..........................................................97

\section{List of Tables}

Table 4-2 Handshape Types and Frequency for Right-Hand and Left-Hand .........................60

Table 4-3 Individual Lowest and Highest Handshape Inventory ........................................63

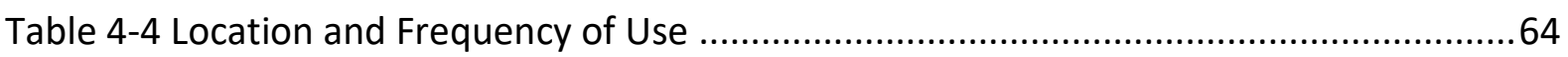

Table 4-5 Individual Lowest and Highest Location Distribution .......................................... 70 


\section{Introduction}

I went to the Republic of Vanuatu (Vanuatu) in September 2010 for two years, when my husband was appointed through New Zealand's Volunteer Service Abroad program as the Tourism Advisor to the Malampa Tourism Officer. We were based in Lakatoro, on the island of Malakula, the third largest centre in Vanuatu, which had approximately 750 town residents and more who commuted daily from outlying villages.

My experience as a sign language interpreter in New Zealand (NZ) led to my interest in the sociolinguistic situation of local deaf people; as I had not located a description of communication used by deaf people in Vanuatu, I hoped to meet them, and anticipated possibly encountering a Vanuatu sign language. I was not experienced as a linguistic researcher and had no formal methodology planned, and I expected the travel logistics, social introductions, and communication would likely be challenging and unpredictable. As Tourism Adviser, my husband and his local counterpart travelled occasionally to outlying areas and to other islands in the Malampa Province, so I accompanied them, paying my own expenses, to seek out deaf people in remoter locations.

In an initial effort to locate deaf people, I met with two organisations for children and adults with disabilities that were based in the capital, Port Vila on Efate Island, and the other main town, Luganville on Espiritu Santo Island. As a result of these contacts, I was invited by Mrs Doriane Naliupis of the SANMA Frangipani Association (SFA), a disability advocacy nongovernmental organisation (NGO) to teach a NZ Sign Language (NZSL) workshop to a mixture of deaf and hearing people, which eventuated in Luganville during June 2011. From this encounter and after discussions with Mrs Naliupis, I developed the idea of documenting the local signs of deaf people, whether shared or individual, in a first "dictionary" that would contain photographs of the signers, with picture referents for meaning. The process of eliciting signs is described in Chapter 3.1. After returning to NZ, my supervisor encouraged me to explore this data further in a Master's thesis to document a first description of sign communication by deaf Ni-Vanuatu (people local to Vanuatu).

This study has both applied and theoretical aims. Firstly, the study aims to increase an understanding of the social conditions and constraints for deaf individuals living in the 
context of a linguistically complex village society. Hence, this thesis will provide the first description of the sociolinguistic context for deaf people in Vanuatu, based on my fieldwork.

Secondly, documentation of deaf Ni-Vanuatu signs and analysis of their formational, semantic and certain grammatical properties will result in a description of their means of signed communication. Comparison with previous accounts of homesigns and emerging sign languages in other locations, such as Kuschel (1973), Haviland (2013), Polich (2005) and Sandler (2012), will contribute to understanding conditions affecting the characteristics of sign languages used by deaf individuals and groups in rural or dispersed populations.

\subsection{Geography, Demographics and Languages of Vanuatu}

Figure 1-1 Map of Vanuatu (Gaba, n.d.)

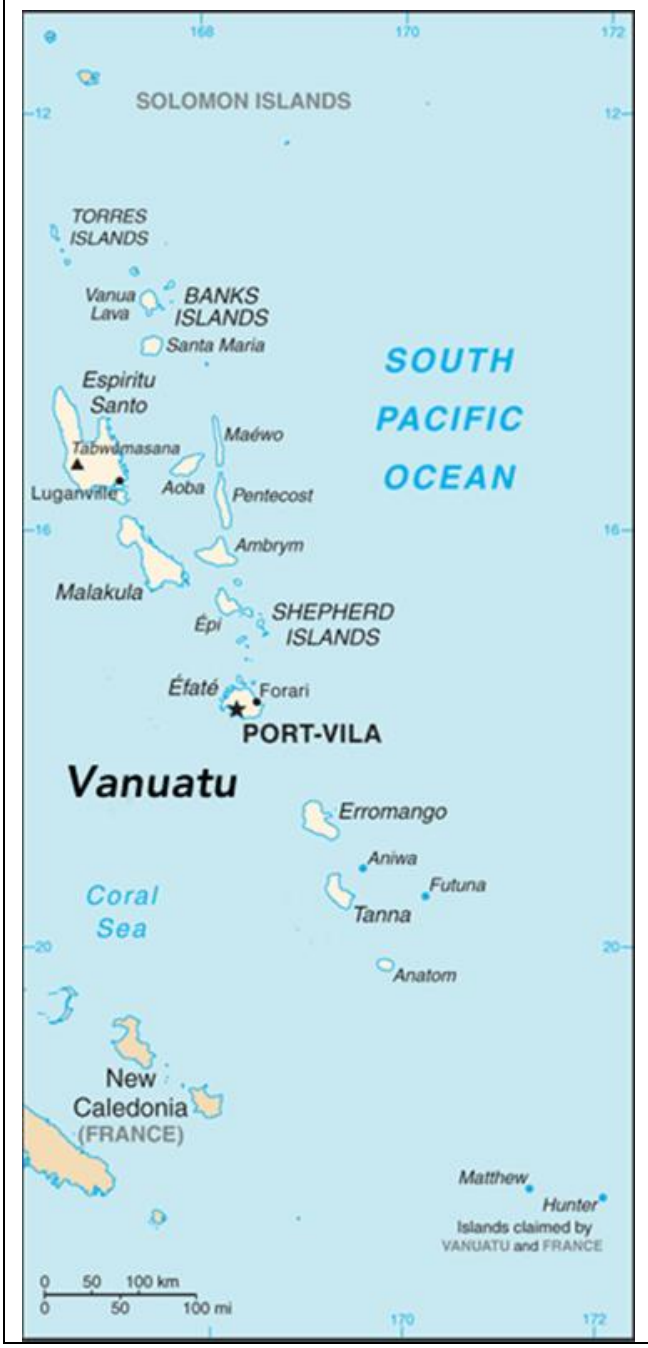

This section briefly sketches a backdrop for the lives of deaf people in Vanuatu by outlining some key facts about the physical and social context.

\subsubsection{Geography}

Situated in the South Pacific Ocean, Vanuatu comprises approximately 83 islands, of which 65 are inhabited, stretched over 1,300 (810 miles) kilometres from north to south (Nunn, Kumar, Eliot, \& Mclean, 2016) (see Figure 1-1). The closest neighbouring countries are the Solomon Islands, Fiji, New Caledonia (Noumea), Australia, and Papua New Guinea (PNG) (Nunn et al., 2016). The terrain is actively volcanic and rugged, largely covered by tropical rain forest with a small proportion of arable land (Nunn et al., 2016). Approximately $97 \%$ of "Vanuatu's total land area is covered by customary ownership title" (Clarke, Leach, \& Scambary, 2013, p. 718). Of the Pacific nations, it is one of the most vulnerable to natural disasters, such as cyclones and volcanic activity (Regenvanu, 2005). The largest

towns are the capital Port Vila, on Efate Island, Luganville on Espiritu Santo Island, and Lakatoro on Malakula Island. 


\subsubsection{Demography}

Vanuatu's 2009 census reports the population was 243,304, of whom 98.5\% are Melanesian, and the remainder Asian, European and Pacific Islanders (UNICEF \& Republic of Vanuatu, 2014). Although Port Vila and Luganville have populations in the tens of thousands, the majority lives rurally and is engaged in small-scale agriculture and fishing. From 1906, Vanuatu was a condominium, jointly administered by colonial powers France and Britain, until becoming an independent republic in 1980 (Geismar, Herle, \& Longga, 2007).

Vanuatu is classified as one of the world's least developed countries by the United Nations (UNICEF \& Republic of Vanuatu, 2014). The Vanuatu 2009 census reported only $13 \%$ of the population have a disability, of whom 7,323 people have "hearing complications", with minimal difference in gender distribution of these (UNICEF \& Republic of Vanuatu, 2014). These figures seem very low compared to NZ's population having $20 \%$ with a disability and 9\% with hearing loss in the 2013 Disability Survey (Statistics NZ, 2013).

\subsubsection{Languages}

Vanuatu is an extreme case of a Melanesian tendency towards social differentiation through linguistic diversity, with 105 indigenous Austronesian languages and three official languages - Bislama (a creole), French and English (François, 2012). Multilingualism within villages and even within households is typical, due to exogamous marriage between language groups, although many indigenous languages are now losing ground to the increasing dominance of the lingua franca, Bislama (François, 2012).

\subsubsection{Transport and Mobility}

Although Vanuatu is an archipelago of islands, there are no public transport options and therefore arranging travel within and between the islands can be unpredictable (Jayaraman \& Ward, 2006). All transport is subject to breakdowns and weather dependency (Jayaraman \& Ward, 2006). Subsequently, travel is rarely straightforward, which reduces the likelihood of deaf children having contact with services, schools, or other deaf individuals beyond their immediate locality. 


\subsubsection{Vanuatu Society and Custom}

Vanuatu has a strong heritage of "kastom" (custom) which is multi-faceted and incorporates: "extended-kin-based communities on their ancestral land"; growing their own food and producing items such as clothing and housing from the natural materials grown; "social order is maintained by community leaders appointed and governing according to customary principles; "speak(ing) their indigenous language"; and participation in "customary rituals" and celebrations (Regenvanu, 2005, p. 41), which all reinforce both familial and community connections. Additionally the social structure of society is similar to that of other Melanesian societies, with a patriarchal National Council of Chiefs, who are elected from the Island Council of Chiefs and the Urban Council of Chiefs; their responsibilities as a "governing body" are to oversee these two organisations and advise the government on customary issues, including land disputes (Regenvanu, 2005; Republic of Vanuatu, 2006). The Vanuatu National Council of Women and Vanuatu Women's Centre continue to advocate for change in women's unequal status on most islands (Douglas, 2002; Shah, 2013). Ni-Vanuatu kastom life is regarded as highly important for continued unity amongst clans (Clarke, et al., 2013).

Social interaction patterns are strongly differentiated by gender. It is not considered culturally acceptable for males and females to socialise as individuals in public unless perhaps in groups. In public, it is common to see females walking with females, and close friends of the same sex holding hands.

\subsubsection{Housing}

Outside of the two main centres, frequently the only indication of a village's presence are small foot tracks weaving through the grass. Housing is mostly made of local materials such as woven bamboo walls and natanggura (sago palm) leafed rooves, with either dirt or concrete floors. Separate small buildings or shelters are allocated for either cooking (by open fire), sleeping, or socialising, whilst further away there is likely a bush toilet. The water supply outside of the main centres is likely to be either rain water, a well, a stream or infrequently a tap supply. Occasionally, a generator may supply intermittent electricity.

\subsubsection{Families}

Historically there are "Systems of exchange relationships within these family networks" which take priority over other relationships resulting in "strong social capital" (Clarke et al., 
2013, p. 718). Today, many marriages result from inter-island school connections, but traditionally, intermarriage of relatives was common between nearby villages or islands, and marriages cemented long term links (Geismar \& Herle, 2010). Families raise their children in a community with little distinction between the father and the father's siblings, demonstrating the concept of the village raising the child with strong familial connections. Historically and recently, marriage involved a bride price payment and the wife moved to her new husband's village which often resulted in little contact with the wife's family.

\subsubsection{The Status of Girls and Women Within the Family}

Males hold authority in the family structure, and when females challenge this authority there are often physical repercussions, contributing to Vanuatu's high domestic violence statistics (Douglas, 2002). A survey in 2009 by the Vanuatu Women's Centre found approximately two out three women in rural areas experienced physical and sexual violence; a high incidence of incest and unwanted pregnancy appears to be common among young unmarried women, as well as infanticide (Vanuatu Women's Centre, 2011). Furthermore, "Almost one in three women were sexually abused before the age of 15 years, most perpetrators being male family members and boyfriends." (Royson, 2014, p. 1). Apparently, education on these social matters and judicial options are yet to be improved sufficiently to affect outcomes (Shah, 2013), and females with any type of disability in most societies are more vulnerable to abuse (Anderson, Leigh, \& Samar, 2011).

\subsubsection{Work}

Vanuatu is mainly a subsistence economy with very little paid employment available, subsequently world financial crashes have little impact (Regenvanu, 2005) unlike natural disasters, such as cyclones and volcanic unrest. Government organisations have a significantly higher proportion of males employed (Douglas, 2002) whilst NGO's appear to redress this imbalance. Often village groups migrate to NZ and Australia for seasonal work for months at a time. Women are the mainstay of domestic work; firstly, responsible for housework, childcare, weaving and the gardens, although men assist in the gardens with "the intermittent and seasonal heavy work" (Douglas, 2002, p. 12). Secondly, many women use microcredit finance, to start small home-based businesses to sell produce at the roadside or market, thereby earning school fees. Children also share work responsibilities 
for supervising younger children, housework and gardening, and socialise around these activities, until they attend school.

\subsubsection{Religion}

Church is generally an important part of community life. Vanuatu was Christianised in the late 19th and early 20th centuries. Presbyterian, Catholic, Anglican and Seventh Day Adventist are the main dominations, and affiliation varies by island and/or locality.

\subsubsection{Education}

Historically Vanuatu's education was neither compulsory nor free and consequently many adults and children have not attended school, either because of cost or parental disinterest. Both NZ and Australia's Agencies for International Development (i.e., NZAID, AusAID) addressed this barrier, by providing funding to the Vanuatu Government for free primary education (New Zealand Government, 2003). However, in 2012 schooling was still neither compulsory nor free, so many did not attend.

The 2009 Census Report indicates for the population over 15 years old: $17.2 \%$ never attended school, $51.5 \%$ received a primary education, $26.4 \%$ attended secondary school and 3.8\% achieved a tertiary education (VNSO, 2009). The Education Department's system is beleaguered with multiple systemic complications which has hindered generations; subsequently, a substantial number of teachers themselves are inadequately educated (Crowley, 2000; ICDE, 2010).

Language is a complex issue in the school system. Prescriptive policy requires children to start pre-school using the village vernacular, continuing into primary school, while introducing Bislama, then shifting to either English or French instruction; a legacy of Vanuatu's condominium. Shifts in language use at school are likely to be especially problematic for children who are deaf or hearing impaired.

The provision of special education for children with disabilities is a relatively recent consideration, and although current policy aspires to an inclusive model, in practice, resources and expertise are limited, and many parents of disabled children do not enrol their child in school. 


\subsubsection{Status of People with Disabilities}

Traditionally, Vanuatu society did not give equal value to people with disabilities, and in post-colonial times many tended to believe that the disability of a child is a punishment by God for parental wrongdoing. Consequently, children with disabilities tend to be hidden away through shame, often unwanted by parents; therefore, grandmothers frequently raise these children. For example, a 25 year-old disabled individual told me that their grandmother had rescued them from being left to die. These attitudes suggest that the prevalence of disability is likely under-reported in statistics.

In an effort to advance social equality, inclusively of those with disabilities, the Vanuatu Government's Priorities and Action Agenda for 2006 to 2015 adopted the United Nations Millennium Development Goals for completion in 2015 - two of these were universal primary education, and the promotion of gender equality and to empower women (CRIN, 2017; DESP, 2006; UNICEF \& Republic of Vanuatu, 2014). Currently, the Ministry of Justice and Social Welfare holds the Disability Portfolio, which may be due to people with disabilities experiencing criminal injustice. Although various formal international documents have been signed by the Vanuatu Government, implementing these policies and achieving change in public attitudes and understanding of the issues is a challenge still to be addressed.

\subsection{The Situation for Deaf Ni-Vanuatu}

The incidence of deafness amongst the Vanuatu population is generally higher than in more developed countries, for a variety of reasons. Medical access (affecting maternal and child health) is restricted for the population outside the main centres due to challenges in negotiating the island terrain and seas. Also, the prevalence of mosquitoes carrying malaria and dengue fever contributes to a higher incidence of disease often resulting in prelingual or post-lingual deafness. Prelingual hearing loss occurs in children up to 3-years-old and prior to language acquisition, whereas post-lingual deafness occurs after spoken language has been acquired (Goldin-Meadow, 2003). The 2009 Vanuatu Census figure for hearing loss included 504 profoundly deaf people, 284 males to 220 females which contrasts with the census' overall disability distribution by gender where $4.7 \%$ of males and $5.5 \%$ of females have a disability (VNSO, 2009). All factors previously mentioned potentially increase the real number of deaf people requiring signed communication. Generally, people with a less 
severe hearing loss are unable to access hearing aids, partly due to insufficient audiologists (if any) for diagnosis, prohibitive costs, and their maintenance impractical in tropical conditions; therefore, they also require signed communication.

\subsubsection{Kastom and Language}

Regenvanu's (2005) definition of Vanuatu kastom includes "indigenous language", and language is key to inclusion in a society (p. 41). However, for deaf Ni-Vanuatu (as for prelingually deaf people in most societies) spoken language is usually inaccessible, which excludes them from knowing their oral history and understanding the reasons for their family and clan's cultural practices. Nevertheless, when permitted, they may participate in the visible components of custom such as food production, weaving and some aspects of ceremonial dances. However, the deeper levels of custom grading that organise the social stratification of men and women are inaccessible without access to the spoken discourse of the community.

Vanuatu's multilingual families create a lip-reading challenge for post-lingually deaf people who attempt to comprehend their family members' speech; it requires enormous concentration to distinguish the word possibilities among Bislama's interchangeable voiced and unvoiced phonemes - /b/ and /p/, /d/ and /t/, and /g/ and / k/ (Crowley, 2003). In general, lip-reading is a highly skilled activity, with frequent guesswork, that relies on prior language, context and topic knowledge (Lane, Hoffmeister, \& Bahan, 1996). For pre-lingually deaf children, lip-reading is not an option and sign language is vital. Consequently, for deaf people without a shared visual language, participation in family, community and public life is limited.

\subsubsection{Educational Opportunities}

The general education system gives context to the limited formal learning opportunities available to deaf people. There is no specific deaf school and few deaf children receive an education. According to the UNICEF and Vanuatu National Statistics Office 2014 report 225 boys and 194 girls with a "hearing impairment" attended school in 2012. However, individual levels of hearing impairment, or the number of students with severe hearing loss are not reported, and these figures are unlikely to include children with severe or profound hearing loss who remain at home, unable to participate in formal education. Also, there is a lack of specialist teacher training or support for them to acquire an education due to 
complex factors. One factor is the lack of awareness by parents and educators of the value of sign language for deaf children, and more fundamentally, the lack of availability of a common sign lexicon, which results in insufficient language acquisition. This was the applied motivation for my project to create a first dictionary as a form of support to parents' with deaf babies or children (Iseli, 2012). Nonetheless, this lack of deaf awareness and/or targeted funding for specialist education and services for deaf people (UNICEF \& Republic of Vanuatu, 2014) constrains their opportunities.

\subsubsection{Work Opportunities}

Options for paid employment opportunities are limited for both deaf and hearing $\mathrm{Ni}-$ Vanuatu. In the rural areas most people are involved in subsistence farming, and if living near a plantation then copra and/or cacao processing is available, which are the main occupations of rural participants. However, deaf men are freer to move to where work is available, often with a degree of independence rarely found among deaf women.

Occasionally I encountered a deaf person working in a different occupation, such as crewman on the Big Sista interisland ferry. A few participants were self-employed or worked in other businesses (see section 3.2). Generally, deaf women's work was keeping house for extended family and providing sex in some instances. Although no opportunity presented to ascertain whether this was willing or by coercion, research suggests coercion is more likely (Vanuatu Women's Centre, 2011). For example, according to an SFA Fieldworker, a deaf young woman who was unable to move or communicate, became pregnant, which strongly suggests sexual violence.

\subsubsection{Social Contact Between Deaf People}

Contact between deaf people was rare for a variety of reasons. Firstly, deaf individuals are widely dispersed across islands, and there is no educational or social institution to bring deaf children or adults regularly into contact. Secondly, a pejorative societal attitude to deafness appeared likely, which did not facilitate deaf individuals meeting with other deaf people, or recognition that they may have a common social identity. Thirdly, familial allegiance is at the core of social relations and takes priority over any notion of potential affinity with others who are deaf from outside the kinship network. Fourthly, the deaf people I met were reluctant to sign in public, which limits the likelihood of them being visibly identified as deaf or meeting another deaf person. Fifthly, there are few social spaces 
open to deaf people, such as SFA's infrequent events. Therefore, for many deaf Ni-Vanuatu, local and national socialisation opportunities with other deaf people are limited or nonexistent.

Due to the brevity of encounters I had with various deaf people their basic personal information was incomplete. I am aware of only four who were married (two to each other), although five deaf women had children, of whom at least some, had been abandoned by their hearing partners. However, I suspect that most deaf people were single due to societies' low status of people with disabilities and perhaps inadequate language to develop a relationship and understand the responsibilities of being married and a parent. I surmised that some deaf young women had become parents as a result of sexual violence.

Generally, the deaf people I encountered in Vanuatu lived as social isolates within a hearing family and village community. Young, unmarried deaf women lived with their families or with their employer if it was too far to walk daily. I met few deaf male youths and it was socially inappropriate for me as an unrelated woman to seek them out, although information was provided on the general area I might locate them. However, the few young deaf men I did encounter seemed cooperative and relied on their interlocutors to communicate with me.

\subsubsection{Sign Language Training}

No known history of sign language being formally used in schools or other contexts exists in Vanuatu. However, in 2006 under the auspice of Vanuatu Society for Disabled People (VSDP), a deaf-blind individual from New Zealand, Chris Farrelly, set up a NZSL and Braille training programme, which continued for several years. I encountered two postlingually deaf people who had learnt signs from Farrelly.

The Luganville NGO Disability Promotion and Advocacy (DPA) ran sign language training on Ambae, the year before I visited. However, the DPA appeared to neither comprehend the complexity of the issues for profoundly deaf people nor have the expertise to teach sign language to either hearing or deaf people (see section 4.3).

In 2012, some SFA Fieldworkers volunteered to support a few deaf children in school but this was unsustainable, in part due to their limited sign vocabularies. 
Within Vanuatu's sociolinguistic context, and given these structural and interpersonal challenges, it is evident documentation and dissemination of a local sign language is essential to enable deaf $\mathrm{Ni}$-Vanuatu to connect with people around them, to learn, and thus to increase their social equity. This thesis therefore goes on to address the following research questions:

1. What is the nature and extent of the signs used by deaf people in Vanuatu?

2. To what extent are signs shared between participants within and across localities?

3. How do similarities and differences in their respective signs reflect sociolinguistic facts, such as individuals' social networks and opportunities for a shared language and identity to develop in Vanuatu?

4. How do the lexical and grammatical features that are identified in the signs they use relate to the documented characteristics of homesigns and emerging sign languages?

Chapter two reviews literature that exemplifies differences between gesticulation, gesture, and signs, and examines characteristics and contexts for the development of home sign, village sign languages and Deaf Community sign languages. 


\section{From Gesture to Sign: The Development of Sign Languages and}

\section{Signing Communities}

This chapter will provide context in which to understand the social circumstances and the characteristics of signs used by deaf Ni-Vanuatu, by firstly introducing terms for categorising non-verbal modes of communication on a spectrum of gesture, signs, mimesis, and deixis. Secondly, the chapter will review studies that exemplify different social and historical contexts that have given rise to different types and scales of signed languages that exhibit differing degrees of conventionalisation. Lastly, the formational parameters of signs as described by linguists in relation to conventional sign languages will be briefly covered, since these terms will be used to describe some properties of deaf $\mathrm{Ni}$-Vanuatu signs.

\subsection{From Gesture to Sign}

This section covers the various gestural forms that have either contributed to or are contributing to sign development and subsequently to the signs of deaf people. Gestures are a part of every language and its culture and for many years sign language was regarded as gesture until Stokoe's research into American Sign Language (ASL) refuted this misconception (as cited in Johnston \& Schembri, 2007). Later, Kendon's gestural research identified five main types of manual communication and McNeill categorised these according to linguistic complexity creating "Kendon's Continuum" (as cited in McNeill, 2005) as: "Gesticulation $\rightarrow$ Mime $\rightarrow$ Pointing $\rightarrow$ Emblems $\rightarrow$ Signs" (Johnston \& Schembri, 2007, p. 23). Although Kendon's Continuum suggests a linear progression between these forms, commonalities exist across some of the linguistic divisions (Johnston \& Schembri, 2007) whilst also exhibiting distinctive features that clearly separate them. Nonetheless, these writers suggest there is evidence of a pathway from gestures to signs.

\subsubsection{Gesticulation and Gestures}

Gesticulation and gesture are terms that are often used interchangeably (Johnston \& Schembri, 2007). Therefore, this section aims to clarify differences between gesticulations, gestures and conventional gestures and the basic shared gesticulation/gesture types (Goldin-Meadow, 2003). 


\subsubsection{Gesticulation}

"Gesticulation" with the hands "occurs only when someone is actively engaged in an utterance" (Kendon, 1975, p. 353). Between 80 to 90 percent of gesticulations are speech connected, either before or simultaneously but not after speech, and it is the predominant gestural form, universal across spoken languages studied to date (McNeill, 2005).

Additionally, gesticulations are spontaneous, the hands rarely produce two different handshapes or perform differing actions simultaneously; that is, two-handed gesticulations are rarely asymmetrical (McNeill, 2005). Gesticulations "Lack hierarchical, combinatorial principles" (Singleton, Goldin-Meadow, \& McNeill, 1995, p. 288), therefore they have no equivalency to an idea and subsequently cannot be combined to make sentential meaning.

Gesticulation has four gestural types:

(i) Beat gestures, which occur when the hand is replicating musical beats or "signalling the temporal locus ..." (McNeill, 2005, p. 60);

(ii) Deixis, or pointing at "the location or existence of an object" (Singleton et al., 1995, p. 295) (see section 2.1.4);

(iii) Iconic gestures are a visual representation of an object's feature or action (GoldinMeadow, 2003) (see section 2.2.5);

(iv) Metaphoric gestures have two forms: those "containing smooth, continuous motions ... that represent change over a single non-partitioned event" or "gestures containing discrete movements" which "represents an abstract idea rather than a concrete object" (GoldinMeadow, 2003, p. 7). The latter is illustrated by a person saying, "Going forward" and bouncing their hand outwards with small arcs.

Thus, gesticulations may take various forms and are usually co-speech gestures.

\subsubsection{Non-Verbal Gestures}

Non-verbal gestures are recognised as having "qualitative differences" from gesticulation; they have the beginnings of "linguistic properties and thus resemble(s) signs" (GoldinMeadow \& Brentari, 2017, p. 9). These non-verbal gestures or "gesture units", account for the other 10 to 20 percent of actions that are not speech generated, but importantly are connected to only one idea (McNeill, 2005). Similarly to gesticulation, non-verbal gestures 
include some deictic gestures and lexical gestures, which may contain iconic or metaphoric gestural elements, of which the latter are solely "global and imagistic in form" (GoldinMeadow, 2003, p. 194). Van der Kooij and Crasborn (2016) suggest gestures may be wellformed but without necessarily consistent meaning in the same way as signs. Apart from metaphoric gestures which are language-related, these gestures are probably the foundation of deaf children's signs when they are without an accessible language input (Goldin-Meadow, 2003).

\subsubsection{Conventional Gestures or Emblems}

A community's conventional gestures, known as "emblems", have stable meanings, with iconic or metaphorical origins; they become connected to a particular concept and their meanings differ between cultures (McNeill, 2005). Conventional gestures may become "speech-framed gestures", taking the place of speech in discourse (McNeill, 2005, p. 59) and similarly this occurs in sign language (Goldin-Meadow, 2003).

In summary, gesticulations are co-speech gestures without a fixed meaning, whilst nonverbal and conventional gestures have meaning and form, are not speech dependent and may have language-like properties. The four gestural types are beats, deixis, iconic and metaphoric, which occur in gesticulation and only the latter three occur in gestures.

\subsubsection{Signs}

The signs of established sign languages are the "most linguistic" type on Kendon's Continuum (Johnston \& Schembri, 2007, p. 23; McNeill, 2005). However, signs may originate elsewhere in Kendon's Continuum, such as "non-verbal" or "conventional gestures", moving toward "sign" on the continuum as linguistic properties increase. Signs cover a broad spectrum of topics relevant to the cultural context of the deaf people who use the language (Johnston \& Schembri, 2007). Many signs are fully lexicalised, that is, with a conventional form-meaning relationship that is stable across users and across contexts and therefore usually found within a sign language dictionary (Johnston \& Schembri, 2007). According to Johnston and Schembri (2007) lexicalisation is a slow diachronic process whereby individual meaningful parts of a sign become reduced and increasingly arbitrary in form. Schermer and Pfau (2016) illustrate this with the sign $\mathrm{MEET}^{1}$ (used in several sign languages) in which two

\footnotetext{
${ }^{1}$ Gloss: capitalisations represent a sign in written form
} 
upright index fingers represent two people approaching each other to meet face to face, however the conventional sign meaning can now refer to more than two people, who may not meet physically, but online, for example. Signs may contain iconic elements in their form that transparently represent the referent, such as a handshape, location or movement, that reflects an object's feature (Johnston \& Schembri, 2007). For example, in the following NZSL examples: the extended thumb and pinky fingers in the sign AEROPLANE suggest the plane's wingshape; similarly location may be iconic, as in many signs for DEAF touch the ear; and/or movement may be the iconic element, such as the hand mimics the foot action of pressing the brake pedal for BRAKE (Kennedy, 2002). Other signs are arbitrary (or become arbitrary over time), so their form does not convey the sign's meaning; in these signs, the association between form and meaning require learning (Johnston \& Schembri, 2007).

Furthermore, sign language discourse also includes many sign formations that are not fully lexicalised, but are created spontaneously using handshapes and movement to describe specific referents in a context, thus having highly localised meaning (Johnston \& Schembri, 2007). These are known variously by the terms productive signs, depicting signs, and classifiers. This thesis will, in general, use the term "depicting signs" to refer to this non- or semi-lexicalised category of signs. Consistent patterns exist within sign languages in how depicting forms are used, such as selecting a particular handshape to represent a semantic category of objects (e.g., person, vehicle, animal), to describe the visual properties of objects (e.g., sparkly, flat), or to trace size and shape features (e.g., square, thick, tubular, spherical), or to represent the handling or use of objects (e.g., turning a dial, grasping a tool) (Johnston \& Schembri, 2007).

The productive capacity of depicting signs enables the creation of signs to refer to new ideas, objects or events within a sign language, which may undergo a rapid path to lexicalisation. For example, in NZSL a construction depicting a person "jumping/falling off any flat surface" became lexicalised through regular use as the sign for "bungy jump" (McKee \& Vale, 2017, p. 3). A range of productive depicting strategies exist, and Padden, et al. (2013) make an important distinction between handling and instrument strategies which focus on either the use of the object or on properties of the object, and different sign languages show preferences for either handling or instrument strategies for "tools". Padden et al. (2013) suggest an instrument strategy preference may be stronger in an 
emerging sign language, due to limited strategies for "marking nouns", in contrast to an established sign language which has developed more strategies for this purpose (p. 304). They broke these categories down even further based upon the absence of actions, as in object, tracing, touch and body part forms (see Appendix $\mathrm{H}$ ).

Therefore, over historical time, the signs of established sign languages usually evolve within the acceptable parameters of a sign language into fully or partly-lexicalised forms, resulting in a relatively stable vocabulary which continues to grow as new concepts require expression.

\subsubsection{Mimesis}

Mimesis can be defined as "an expression in which the hands, face and body signify those of the same person in the event being conveyed", which means none of the body is being utilised for language purposes (Sandler, 2012, p. 281). Importantly, shared contextual knowledge of life and the environment is key to comprehension of mimesis (GoldinMeadow \& Feldman, 1977; Kegl, Senghas, \& Coppola, 1999). In a context where deaf individuals do not have access to a conventional sign language, they have been observed to make frequent use of mimesis as a discourse strategy (R. Senghas, 1995).

\subsubsection{Deixis}

Deixis, or pointing, "encode(s) only the location or existence of an object, rather than encoding the object itself or a feature of the object" (Singleton et al., 1995, p. 295).

However, added information, such as in speech or sign, is required to understand the deictic referent when it is not visible, unless a space has prior shared information (Meir \& LilloMartin, 2013). Deixis is often performed with the index finger extended, however, it is not limited to this handshape or form, as in societies, such as Thailand, people point with their lips to indicate direction (Blok, 2013; Johnston \& Schembri, 2007).

Pointing for real-world or absolute-direction is the basic form of deixis used by deaf signers (de Vos, 2012). In the context of a small-scale sign language, de Vos (2012) acknowledges that a pointing "sign" and a pointing "gesture" are fundamentally the same, although she suggests pointing ceases to be gestural when used for abstract reference; however, to be able to allocate a part of speech to a specific pointing sign, it is necessary to know the 
context to identify the actual referent. De Vos also notes that when eye gaze aligns with the direction of a pointing sign it is being more "sign"-like (ibid).

Nonetheless, linguists continue to debate the question of when a pointing gesture becomes a sign with allocated grammatical status (Coppola \& Senghas, 2010; de Vos, 2012; Meir \& Lillo-Martin, 2013).

In sum, gesticulations may take various gestural forms but are co-speech based which informs the listener of the gesticulation's meaning, whereas non-verbal gestures are bipolar (with meaning and form). Conventional gestures have also become bipolar through systematic use in a culture and may substitute speech, and be incorporated into sign lexicons. Mimesis is a full-body enactment of a previous event that may require shared knowledge for comprehension of the context. Signs in established sign languages generally originate in non-verbal gestures becoming lexicalised to varying degrees, over time, and are learned as part of a shared code. Deixis takes a spectrum of forms from basic gesticulation with pointing, usually using the index finger, through to more lexicalised forms used for grammatical purposes in established sign languages.

The following section outlines the formational characteristics of conventional signs, as described in studies of established sign languages of deaf communities. These parameters are relevant to the later description of signs documented in Vanuatu.

\subsection{Formational Characteristics of Signs}

This section covers the various formational characteristics of signs. A sign originates in gesture (see section 2.1.2), and becomes systematised through repetitive use, evolving into a word that has a conventional meaning (Goldin-Meadow, 2003). Linguists identify three basic types of "sign": (i) manual signs, which are articulated with the hands, are the predominant type in sign languages; (ii) non-manual signs, which are articulated solely on the head or body (e.g., headshake for "no"); and (iii) non-manual features (also called nonmanual signals), that occur on the face, head and upper body simultaneously with a sign to provide additional morphological, syntactic and prosodic information (Johnston \& Schembri, 2007; Sutton-Spence \& Woll, 1999). These signs are performed in an area called the "signing space" which is in front of the body from about waist to top-of-head height, where the arms can move with the elbows bent in a relaxed manner. This signing space is consistently 
adhered to in an established sign language with few exceptions (Johnston \& Schembri, 2007). In contrast, descriptions of young or less conventionalised sign languages, such as "village sign languages" (as described in section 2.3.4), report a less constrained signing space (see Figure 2-1).

Figure 2-1 The Signing Space

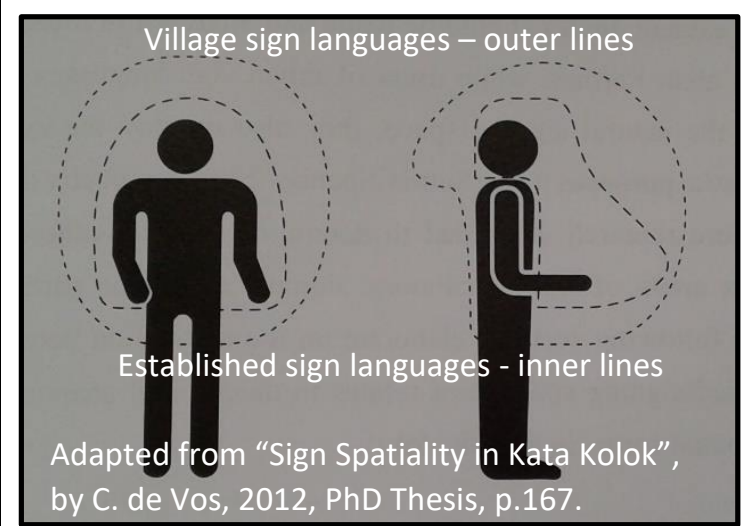

Manual signs can be sub-divided into onehanded or two-handed symmetrical, or asymmetrical formations. In the production of signs, one hand (normally the writing hand) is considered dominant, and the other hand is non-dominant. One-handed signs, which may be static or moving, are made by the dominant hand. However, two-handed signs are formed according to Symmetry and Dominance Conditions, identified in ASL by

Battison (1978), whereby if the dominant and non-dominant hands have different handshapes, the dominant hand tends to have a more complex (marked) handshape and movement, whilst the non-dominant hand has a less complex (unmarked) form and a more passive role in the sign configuration (as cited in Johnston \& Schembri, 2007).

\subsubsection{Formational Parameters}

Manual signs consist of four formational parameters: handshape, movement, location, and palm orientation; sometimes an additional non-manual parameter occurs (Sutton-Spence \& Woll, 1999). Stokoe identified the first three main parameters (as cited in Sutton-Spence \& Woll, 1999), and proposed that these parameters have phonemic status in the formation of a sign. Non-manual features (NMF) are used in discourse to modify the meaning of signs and clauses - such as intensification, negation, or focus. NMF tend to increase in complexity and grammatical function as a sign language matures (Johnston \& Schembri, 2007; Sandler, 2012).

\subsubsection{Handshapes}

Handshapes are the primary formational parameter and often reflect iconicity (van der Kooij \& Crasborn, 2016) (see section 2.2.5). Handshapes are easily perceived, and have the 
greatest scope for notable differences between languages, although there are limited repertoires observed across sign languages (Channon \& van der Hulst, 2011; GoldinMeadow, 2015).

Handshape inventories of deaf signers, with or without a conventional sign language, reflect a general preference for simpler, unmarked handshapes. They occur in $50 \%$ of BSL and $60 \%$ of ASL signs, and are the first to be acquired by deaf children (Goldin-Meadow, 2003; Johnston \& Schembri, 2007). The seven unmarked handshapes that occur commonly across signed languages are easily distinguished from each other, can be used in a variety of locations, and may occur in two-handed symmetrical signs (Johnston \& Schembri, 2007). By contrast, marked handshapes vary between signed languages, are less frequent, have more complex finger selection configurations, and occur on the dominant hand in one-handed or two-handed asymmetrical signs. Unusually marked handshapes are normally motivated by a referential meaning, such as handshapes that represent either the shape of a specific entity (such as an aeroplane), a fingerspelled letter, or express a number by extended digits (van der Kooij \& Crasborn, 2016). Such complex handshapes occur in less than one percent of signs in conventional lexicons, whilst the balance consists of moderately complex handshapes; including groups of handshapes with variants (Brentari \& Eccarius, 2011; van der Kooij \& Crasborn, 2016).

\subsubsection{Movement}

The movement parameter can apply to the whole sign configuration, or to internal movement of the fingers (open to closed or vice versa) (van der Kooij \& Crasborn, 2016). Movement may be arbitrary, or may have metaphorical or iconic semantic properties; for example, signs with negative meaning tend to use downward movement (such as "sad" in NZSL), whilst those with positive meaning move upwards (van der Kooij \& Crasborn, 2016). In addition to being a phonological parameter, movement may carry morphological meaning, such as marking noun-verb differences - nouns displaying short movements, sometimes partially repeated, whilst verbs tend towards larger movements with more repetitions (Tkachman \& Sandler, 2013). Also, how the hand moves in relation to the body, or in the signing space, may convey manner and path of an object (which are often combined), express agreement information in transfer verbs, or add adverbial and aspectual meaning (Sutton-Spence \& Woll, 1999). Therefore, movement is a basic formational 
parameter, and may convey additional linguistic information that requires the recipient to have grammatical competence for production and comprehension.

\subsubsection{Location}

Location of a sign is the third parameter. Signs are formed within the signing space or at a contact point on the body. Across languages, a high proportion of signs are located on the head or face, for reasons of visual salience, and in the neutral space in front of the signer's body where the hands are naturally located (van der Kooij \& Crasborn, 2016). In general, conventional sign languages rarely allow the formation of signs at locations behind the head or body, or below the hips.

\subsubsection{Iconicity}

Iconicity is a significant resource in the development of sign language lexicons, and subsequently grammars, and often exists within the three main parameters (Handshape, Movement and Location) either separately, collectively or in combination within a sign (Channon \& van der Hulst, 2011). Iconicity is considered an inherent part "at all levels of the phonological organisation in sign languages", although not a part of every sign (Pfau, 2016, p272; Goldin-Meadow, 2003). The morphological use of movement and non-manual features to modify the meaning of verbs, adverbs, and adjectives also has a strong element of iconicity, for example representing qualities such as direction, duration, or intensity (Johnston \& Schembri, 2007).

In summary, a sign can originate in gesture, and through systematic use over time, develop linguistic complexity and become conventionalised and increasingly arbitrary. Signs may occur in manual or non-manual form. Manual signs are either one or two-handed and contain three basic parameters. Firstly, signs draw on a large inventory of unmarked or marked handshapes. Secondly, movement in a sign may be either static, iconic, or arbitrary, and modifies the sign with various types of morphological information. Thirdly, signs have a conventional location parameter, which may have semantic meaning. In signs these three parameters may contain iconic elements separately, collectively or in combination, whilst the simultaneous addition of non-manual features can add linguistic information to manual signs and clauses, or modify word class. Deaf people from diverse contexts have developed similar sign complexity within different types of sign languages which will be considered in the next section. 


\subsection{Primary Sign Languages}

The focus of this section is the various types of "primary sign languages" developed by deaf people (Johnston \& Schembri, 2007). Primary sign languages are distinct from "alternate sign languages" which are systems of manual communication developed by hearing communities for specific practical or cultural purposes, such as for communication by monks in silent orders or for interchange between Native American language groups (Davis, 2011). A primary sign language has various developmental factors that can influence its emergence, such as, the incidence of deafness, and urban or non-urban locations, including linguistic or geographic isolation (de Vos \& Zeshan, 2012). These and other relevant terms will be defined, to show contextual and linguistic differences and similarities in language outcomes across the range of established and emerging sign language types.

\subsubsection{Deaf Community Sign Language Types}

There are essentially two types of deaf sign languages: (i) established (urban), and (ii) village or rural sign languages, also known as "macro" and "micro" sign languages (Woll \& Ladd, 2003). Principally, established sign languages are those used inter-generationally with sufficient numbers of deaf people to have evolved grammatical and social features parallel to spoken languages (Brentari \& Coppola, 2013; Goldin-Meadow, 2003; Johnston \& Schembri, 2007). In contrast, village sign languages tend to occur in isolated populations with a high incidence of genetic deafness; recent research suggests that language complexity evolves within a few generations in such contexts (Padden, 2011; Sandler, 2012). This typology is based mainly on documentation of Western sign languages, as opposed to established sign languages that exist in Asia and Africa.

\subsubsection{Urban Deaf Community Sign Languages}

Urban sign languages share the main contextual feature for sign language emergence which is a critical mass of people (importantly, children) with significant hearing loss, resulting from either genetics or disease, coming together regularly and over historical time, with a desire to communicate and be known (Woll \& Ladd, 2003). Residential educational institutions for deaf children are the usual location in which this development of a language community occurs. In the Western world, the standard incidence of congenital deafness in the population is 1:1000 births, however, it is higher in developing countries (Johnston \& 
Schembri, 2007). Sign language communities also include individuals who are postlingually deaf but exposed early in life to social interaction with deaf sign language users.

Sign languages such as ASL and NZSL, have developed in urban, national deaf populations which are described as "oppositional communities" due to their existence within a dominant hearing community which tends to exclude deaf people, thus creating a differentiated identity of solidarity among sign language users (Woll \& Ladd, 2003, p. 152). Historically, and even up into the present, hearing society has generally labelled deaf people disabled, using the medical model with associated negative connotations, which impacts on their identity (Lane, et al., 1996; Woll \& Ladd, 2003). Woll and Ladd (2003) argue that a "multidimensional sense of self-esteem is generally considered impossible for a Deaf person to develop if their life takes place solely within majority societies" (p. 153). Identity in any culture is powerfully integrated with language, thus for $95 \%$ of deaf people without familial language, a sense of belonging is developed through contact with Deaf peers (McKee, 2001). "Deaf" is "a label of cultural identity, a way of being and communicating shared by people who feel most akin to other Deaf, regardless of gender, ethnicity, age, education, or nationality" (McKee, 2001, p. 11). The connection strength of Deaf Communities is attributed to an intensely shared experience in residential deaf school environments (Lane et al., 1996; Woll \& Ladd, 2003), where their own signs may have been put aside and/or merged through multiple interactions in the playground which is key to language development (McKee, 2001; Sandler, 2012; Trudgill, 2012; Woll \& Ladd, 2003).

Consequently, Deaf communities and their sign languages tend to evolve over generations, forming a language that encompasses everything required to exchange information, including creative expression and cultural transmission. Sign language users promulgate their collective language identity through Deaf community organisations, deaf school settings, and social networks.

\subsubsection{Emerging Deaf Community Sign Languages}

In recent times linguists have documented new sign languages that are still emerging in circumstances where deaf people have a short history of coming together, significantly through deaf schools, and Nicaragua and Israel have examples of this. 
Firstly, Nicaragua's deaf population increased significantly through several maternal rubella epidemics between 1962 and 1977 which resulted in infantile congenital deafness, and no intergenerational deaf familes were known (Polich, 2005). The most influential factor that contributed to the birth of Nicaraguan sign language (ISN- Idioma de Señas Nicaragūense), was the establishment of both deaf-focussed primary and vocational schools (Polich, 2005). The age of exposure to sign and language acquisition is significant to the form of an emergent language, as Ann Senghas (2003) explains: "Young children have the ability to develop new, more specific form-function mappings out of generally applied forms from the environment", that is "sculpt grammar", whilst "social capacity" provided by the adolescents' interactions (at the vocational school), was equally important (pp. 529, 530). This brought deaf children into the realm of inclusion, people who had previously had very limited communication at home were brought together in a new deaf school and vocational training environment in the 1980s (Polich, 2005). Accompanying this Nicaraguan school development was a move away from parental shame and the "Eternal Child model", which is the belief that a deaf child will remain childlike as an adult and incapable of responsibility and adult participation in society (Polich, 2005; R. Senghas, 1995). Unfortunately, deaf children in the rural areas remained isolated, unable to access this change of status and Nicaragua's emerging ISN.

Secondly, Israel's Deaf Community began with a collective of Deaf adult signers in the 1930s, who brought knowledge of various sign languages from European and Middle Eastern countries, and also present were some deaf isolates with their own form of signs (Lanesman \& Meir, 2012, p. 154). Sustained interaction through clubs, assorted social activities, and later among children in schools for the deaf, has resulted in Israeli Sign Language emerging in a period of approximately 70 years (Sandler, 2012). These relatively recent cases of emergent Deaf Community sign languages differ from smaller-scale village or rural sign languages, as discussed in the next section.

\subsubsection{Village or Rural Sign Languages}

This section reviews the differing contexts for "village" or "rural" sign languages which tend to occur in small and geographically isolated populations, in which linguistic and religious isolation can also be present, such as AI-Sayyid Bedouin Sign Language (ABSL) which evolved in a Muslim village within Jewish Israel (Sandler, Meir, Padden, \& Aronoff, 2005). A common 
pre-cursor to the development of village sign languages is a higher than average incidence of deafness in the population (Padden, 2011; Sandler, 2012), ranging between 1:100 to 11:100, for which the etiology is often assumed to be genetic (David, Edoo, Mustaffah, \& Hinchcliffe, 2009; Kusters, 2012; Sandler, 2012; Sandler et al., 2005).

In several village sign languages that have been described, ostensibly absent is the division between deaf and hearing identity and socialisation patterns that develop in urban sign language communities. This may be partly due to the youth of village sign languages - in existence between two to seven generations at the time of documentation - as opposed to the usually older Deaf Community groups (de Vos \& Zeshan, 2012). Village sign languages usually share contextual factors that lead to a less differentiated social status between deaf and hearing villagers: agricultural employment, with a high manual component inclusive of deaf people; children's participation in formal education is equally low; endogamous marriage, which concentrated the gene pool, such as Kata Kolok in Bali (de Vos, 2012; Lanesman \& Meir, 2012; Nonaka, 2014; Panda, 2012; Sandler et al., 2005). All these contextual factors contribute to a limited but highly integrative context for shared reference in communication between deaf and hearing individuals, which is ideal for sign language development (Padden, 2011; Trudgill, 2012) and engenders a high level of sign bilingualism among hearing people (de Vos, 2012; Lanesman \& Meir, 2012; Nonaka, 2014; Panda, 2012). Consequently, these are often referred to as "integrated communities" with shared sign languages, as illustrated next in a description of emerging ABSL.

\subsubsection{The Development of Al-Sayyid Bedouin Village Sign Language}

A Muslim Bedouin tribe settled in Israel's Al-Sayyid village and in the 1920s four deaf children were born to this family who then developed their own form of communication using gestures (Kisch, 2012). Over time these gestures were increasingly used by both deaf and hearing family members becoming a village sign language (Kisch, 2012). This language has been studied in terms of its evolution across generations. For instance, Sandler (2012) identified evidence of a sequence in the introduction of various linguistic NMF, which she posits may be an indicator of the developmental stage in other village sign languages. A few of these differences are now described.

The signing space of village sign languages, is described as: "Signing with fully outstretched arms, bending down for signing in a lower space, and a wider range of places of articulation 
on the body such as on the lower extremities have been documented (de Vos \& Zeshan, 2012, p. 15) which is a less defined area than in established sign languages (see Figure 2-1). Initially, Sandler divided ABSL deaf signers into four age categories to analyse differences in each cohort's grammatical content. Rather than using the term "signs", Sandler (2012) describes the use of "dedicated gestures" in each age cohort, defined as "visible actions of any part of the body that perform a linguistic/grammatical function", as distinct from the ordinary gesticulations which accompany speech (p. 268) (see section 2.1.1). Sandler observed that the formation of dedicated gestures developed across subsequent age cohorts, to involve (in this order) the hands, head, facial expression, torso and finally the non-dominant hand. Sandler observed that dedicated features were intermittent in a cohort, whereas the following cohort adopted the dedicated features consistently with increasing complexity throughout the cohorts, such as clauses marked with prosody, by head movement. Additionally, Sandler noted their broad topics of discussion, despite language restrictions, which included some non-concrete concepts.

Sandler's (2012) work suggests that dedicated gestures are the precursor to NMF found in sign languages, which develop through multiple deaf signer interactions, intergenerationally, thus suggesting a developmental trajectory towards an integrated, consistent system of manual and non-manual features of a signed language.

In sum, Deaf Community sign languages are formed when a collective of deaf individuals meet regularly. In contrast, shared village sign languages tend to evolve from communities with a high incidence of genetic deafness, where deaf people are socially and economically integrated with their hearing counterparts. All types of evolving sign languages require sufficient interactions between young children and older youth, which is essential for the full development of linguistic features in a conventional sign language over generations. Rural or village sign languages display some of the features of established sign languages, including non-manual features that contribute to the linguistic content of communication. When deaf individuals are isolated, without exposure to either a signing Deaf Community or a shared village sign language, there are important language and social implications which are discussed next. 


\subsection{Home Sign and Deaf Isolates}

This section will introduce definitions of home sign and deaf isolates, with reference to social implications, vocabulary, and gestural origins of such signs. A deaf isolate is a profoundly deaf person born into a hearing family, isolated from both spoken language and other deaf people who may use a conventional sign language (Goldin-Meadow, 2003). In this case, the child creates their own visual-gestural communication called "home sign" (Goldin-Meadow, 2003).

A natural signed language is completely accessible for those who rely on vision to acquire language and knowledge; however, since $95 \%$ of pre-lingually deaf children have hearing parents there is likely to be no sign language, or an impoverished form, in the immediate environment, meaning a deaf child cannot develop full communication with their family and community (Goldin-Meadow, 2003; Johnston \& Schembri, 2007). Therefore, unless language intervention occurs, usually through an education system, such individuals will experience little, or no, development of a conventional language. They are widely observed to create "gestural communication" systems, referred to as "home sign", which "typically develops within a family or limited social sphere where one member is deaf, and no pre-existing sign language is available" (Kegl et al., 1999, p. 183). Furthermore, these gestural signs are described as "...unique, idiosyncratic, variable even within the individual and lacking most characteristics, particularly syntactic," in a comprehensive language (Kegl et al., 1999, pp. $179,180)$.

Research demonstrates that home signs have strong linguistic similarities irrespective of context, although linguists' debate whether these can all be defined as "home sign" (GoldinMeadow, 2015; Goldin-Meadow \& Feldman, 1977; Green, 2014; Nyst, Sylla, \& Magassouba, 2012; Kegl et al., 1999).

A home sign system used within a family group may be inadequate for members to fully comprehend each other at a basic level, therefore interlocutors require "shared knowledge" (Goldin-Meadow \& Feldman, 1977, p. 402; Kegl et al., 1999). Additionally, the family and community are often not cognizant of the effects of deafness upon a child's development and comprehension of family events (Polich, 2005). These misperceptions are epitomised in a quote from Nicaraguan Elena Gonzáles who described her experience of communication with her deaf sister Camila, both as a child and an adult as: 
“...It was easier with Camila when we were younger. It was easier to understand her, but now it is more difficult. I don't remember having such a hard time understanding her then as I do now. But, we never knew her as a person. We never knew what she was thinking or feeling" (Polich, 2005, p. 13).

When deaf children have insufficient shared language to convey identity they will likely find their emotional and intellectual developmental needs neglected (Lane et al., 1996; Woll \& Ladd, 2003), which places them in a position vulnerable to physical and emotional abuse. Moreover, some community members may doubt that a deaf isolate is actually profoundly deaf, such as in the Solomon Islands and in Guatemala, where a few people expressed a belief that deaf people can hear but choose to speak with their hands (Horton, in-press; Kuschel, 1973). Hence, a deaf isolate who lacks linguistic access to cultural socialisation may transgress the community's social customs leading to further stigmatisation.

\subsubsection{Home Sign Vocabulary}

Home sign vocabularies tend to be small and alter little in a person's lifetime due to both limited experiences and opportunities to communicate (Kuschel 1973: Polich, 2005). Kuschel (1973) documented 215 home signs of a Solomon Islands' Rennellese solitary deaf man. This adult home sign repertoire is limited compared to a typical three-year old's vocabulary (Bates et al., 1994), albeit topics differ. In the context of deaf sibling home signers, such as the three deaf members in the "Z Family" near Tzotzil of Mexico, the vocabulary of the youngest, who will likely acquire signs and communication capacity earlier than the older siblings, is likely to be more extensive, with increased complexity (Haviland, 2013; Safar, 2017).

Some American deaf child home signers have developed gestures that indicate the past and future (Goldin-Meadow \& Feldman, 1977); in contrast there was no evidence of the ability to discuss the past, the future or intangible ideas in Nicaraguan home signers (Polich, 2005).

Until a deaf isolate is approximately eight years-old there is insufficent cognitive development to mime a series of complete actions, therefore at some later point they are likely to use mimesis or constructed actions (Goldin-Meadow, 2003). Additionally, mimesis 
will reduce as more manual signs are utilised, such as occurred in Nicaragua (R. Senghas, 1995).

Further analysis of Goldin-Meadow and Feldman's (1977) home sign data revealed that utterances were marked prosodically, and contained structural information absent from the wording (Applebaum, Coppola, \& Goldin-Meadow, 2014). Prosody in home sign is achieved by raising the hands, signing, and either eventually lowering the hands at utterance final, the hands becoming still, or repeating the sign (Haviland, 2013; Sandler, 2012). However, the skill to narrate stories must be modelled and developed over time (Bamberg, 1987), whereas for many home signers there is little interactional opportunity to develop this ability. Further research on adult home sign may give greater understanding of the "impact that cognitive and social maturity has on linguistic function" (Goldin-Meadow, 2011, p. 309).

\subsubsection{Formation and Production of Home Signs}

Home signers develop their own rules for signing space, sign creation and manipulation of the formational parameters (see section 2.2.1). Firstly, the signing space is less restricted than that of conventional signed languages, and similarly to village sign languages, mainly occurs in front of the upper body and occasionally touching the lower limbs, or the back of the body (Sandler, 2012). Secondly, many home sign handshape inventories utilise approximately 12 handshapes (Morford \& Goldin-Meadow, 1997), which is restricted compared to established sign languages; however, both home sign and sign language inventories contain similar handshapes types and iconicity (Johnston \& Schembri, 2007).

Thirdly, in the first few years a home signers' hand gestures may become "language-like", their status as "signs" being determined by consistency of use and meaning (GoldinMeadow, 2003, p. 202). This is illustrated by an American deaf child home signer who formed gestures with word equivalency (nouns or verbs), which contained a single meaning or idea, and he used these gestures sequentially to form utterances, thus demonstrating his gestures are combinatorial, that is, able to be combined to give sentential meaning (GoldinMeadow \& Feldman, 1977). These signs tend to be "large, often symmetrical, and continuous, with few distinctive boundaries between lexemes"; and fourthly, they tend to lack fluency in comparison to users of sign languages (Kegl et al., 1999, p. 183). 
Fifthly, compounding is described as a "type of productive word formation process that develops earliest in the life of a language" and can take various forms or combinations of word classes (Meir, Aronoff, Sandler \& Padden, in-print, p.13). Goldin-Meadow (2003) describes how deaf children utilise pointing in the same way hearing children do, plus using them combinatorically with an iconic sign, to point to a non-present item, that is a noun. Meir et al. (in-print) state that compounding is used to convey an idea, or an object not covered in their lexicon. They describe compounds as having a reduction in repetitions, a smooth transition between signs, and when pointing or size and shape specifiers (SASS) are combined they are always in final position. However, in contrast, Coppola and Senghas (2010) found that Nicaraguan home signers' had no preferential order for deixis in their compounds. Haviland (2013) found SASS constructions were first, with an iconic representation second, which suggests compounding patterns vary between home signers.

\subsubsection{Types of Gestures Used by Home Signers}

Home signs are typically on the hands, although head movements are acquired as conventional gestures may become signs, which was demonsrated by the Z Family of Mexico (Haviland, 2013). Home sign gestures/signs may firstly be categorised into four types of gestures which may then be sub-divided further (Hunsicker \& Goldin-Meadow, 2013).

a) "Conventional gestures" are present in the home signer's family and/or community to differing levels, and can account for $11 \%$ of utterances by deaf home signers in the highly gestural community of Nebaj in Guatemala (Horton, in-press).

b) "Marker gestures" which "function to modulate the meaning" of an utterance; for example, negation by headshaking, or marking questions with the generic gesture of "flipping the hands from down to up" (Hunsicker \& Goldin-Meadow, 2013, p. 358). While these seem likely copied from the family's conventional gesture repertoire, these are incorporated into the lexicon according to the home signer's understanding, and ostensibly, become linguistic features unconnected to the family gesticulations (Goldin-Meadow \& Mylander, 1983).

c) "Deictic (pointing) gestures", which emerge before language, tend to comprise a high proportion of home sign utterances and these are used in place of nouns and pronouns similarly to any young child's pointing (Goldin-Meadow, 2003). Research into deaf 
Nicaraguans' deictic use, compared home signers (aged 20 to 30 years) with various agebased cohorts of sign language users, showed the home signers "pointed to objects in the environment to refer to entities or attributes more frequently", as in the use of "Real World Direction", than those with a developing or developed sign language (Coppola \& Senghas, 2010, p. 19).

d) "Iconic home signs" strongly resemble the action associated with the object, accounting for 30\% of signs (Haviland, 2013; Sandler, 2012). Furthermore, Horton (in-press) reported Nebaj home signers averaged $46 \%$ of all signs being enactments or mimesis, which indicates differences in how home signers draw on their linguistic resources.

To illustrate some characteristics of deaf isolates' communication which may offer some parallels for the Vanuatu situation, the following section reviews three separate studies of the signs of two deaf people in Melanesia (Kendon and Kuschel) and several in South America (Le Guen and Safar).

\subsubsection{The Solomon Islands' Rennellese Deaf Isolate's Home Sign}

Initially, Kuschel (1973) documented the ethnographic background of a Polynesian people on Rennell Island, in the Solomon Islands, situated within Melanesia in the Pacific Ocean. However, when Kuschel met a deaf isolate, named Kagobai, an opportunity arose to document his home signs. A local person who was familiar with Kagobai's communication mediated. Kuschel observed Kagobai as being highly integrated into society, however, I think this unlikely; rather Kagobai's social status may have been influenced by his chiefly clan class and/or perhaps the influence of Kuschel's presence. Although marriage was likely the cultural norm Kagobai was not married.

In reviewing Kagobia's lexicon, a number are likely gestures, or mimesis - such as actions performed lying on the ground, which is outside the boundaries of what is described as either gesture or sign - which would considerably reduce the reported lexicon size. Nonetheless, Kuschel tested for the iconicity and arbitrariness of Kagobai's gestures/signs and classified these into three categories of comprehensibility: outside of the Solomon Islands; within his local networks; and those known only to "a few selected members" of his intimate circle (p.10). The latter is illustrated by his father's sign name, motivated by a 
tattoo. Kagobai's signs for objects tended to represent the canonical action associated with its use or handling (Kuschel, 1974).

\subsubsection{Papua New Guinea's Enga Rural Or Valley Sign Language}

Kendon's $(1980,1980 b, 1980 c)$ study of the signed communications of a deaf woman and her hearing associates in the Enga Province of PNG does not establish if this is an individual "home sign" system. Factors, such as evidence of its existence prior to government officials or outsiders arriving in the area, its dispersal over a large area of the province, other deaf people living in the valley, and the linguistic complexity that has evolved (Kendon, 1980) suggests this is either an "alternate sign language" created by the hearing valley community, a young "rural sign language", or a combination.

In regard to the Enga sign forms, Kendon (1980b) suggests that iconic elements in a sign do not necessarily mean the signer has chosen this feature to enable comprehension, as this "is usually irrelevant" for the deaf person (p. 81). However, Goldin-Meadow's (2003) theory that children's signs employ iconic features for the purpose of enabling others to comprehend contradicts Kendon's theory. Kendon (1980) analysed the distribution of sign types compared with ASL, which generally showed a $10 \%$ variation in the frequency of one and two-handed formations, sign types, and locations (p. 26). Interestingly, Kendon (1980) did not find signs expressing emotions, as these were conveyed as facial expressions - for example, accompanied by pointing to a sore body part.

\subsubsection{Mexico's Yucatec Mayan Rural Or Home Sign Language}

Four separate Yucatec Mayan villages in Mexico, that have an unusually high incidence of deafness, have emerging sign languages used among families with deaf members (Le Guen, 2012). They have a smaller population and time scale than the emerging sign languages previously described (see section 2.4.3.3). In this cultural context, the wider community regards deafness as just another individual trait, and communication through shared conventional gestures/signs is commonplace (Safar, 2017). Significantly, some of these Yucatec Mayan sign languages could be technically categorised as home signs due to being limited to single families and "have not (yet) been subject to deaf-to-deaf intergenerational transmission" (Safar, 2017, p. 5). Safar (2017) found through shared similarities of environment, lifestyle and sign iconicity, these deaf individuals were enabled to negotiate understanding between themselves and family members using a variety of strategies. 
Subsequently, within one generation these micro-communities have created "complex sign languages with stable lexical and grammatical conventions" (Safar, 2017, p. 5). Therefore, these deaf individuals are not isolated in the true sense as communication with their families and other community members is quite rich (Safar, 2017). This reinforces Polich's (2005) assertion that the degree of deaf people's inclusion into everyday life corresponds to the growth of a sign language, and although there is no collective of deaf children being brought together as in the Nicaraguan school, Yucatec Mayan signing may demonstrate an early stage in a home sign system becoming a shared sign language.

In sum, there exists a deaf isolate spectrum from almost complete language isolation to being one of several in a community with irregular access to other deaf people. A home signer's identity and social status may be marginalised within the hearing society they live in, due to their limitations in receptive and productive language skills; this impedes learning and socialisation into the family and community, and their integration into society. Also, home signers rarely have the option of socialisation within a community of deaf signers. For deaf isolates in cultural contexts where conventional gestures are a prevalent part of the community's communication repertoire, this can facilitate acceptance of a deaf individual's gestural mode of communication and contribute to their social integration. Nonetheless, home sign has been described as containing a limited experiential vocabulary, and there are significant differences between individuals' capacity to develop an idiosyncratic vocabulary with which to successfully communicate. A comparison of the Vanuatu data with previous descriptions of adult deaf home signers can contribute to an understanding of this phenomenon, and to the broader question of how natural sign languages emerge, particularly in social contexts where geographical separation is a factor. The next chapter will describe the methodology used to collect and document data from deaf Ni-Vanuatu. 


\section{Methodology}

\subsection{Data Collection and Fieldwork Challenges}

The initial aim and outcome of my fieldwork was to make the dictionary, ("Storian wetem han olgeta' - "Telling stories with your hands"), so I filmed signs used by deaf Ni-Vanuatu in a variety of environments (Iseli, 2012). Technically this was not a dictionary, but more of a lexicon. Although I was not experienced as a linguistic researcher, I was trained as a sign language interpreter and familiar with modes of communication with deaf people and observing sign language analytically. I collected data between July 2011 and September 2012.

Video recorded signs were elicited in three ways:

(i) The deaf participant responded to looking at and identifying a familiar object in the actual context or a photo of a familiar object or activity (see Appendix D). Initially, I listed everyday items a child needs to learn in their first few years, gradually including various cultural items, and activities unique to Vanuatu village life. Also, if a deaf person offered a sign for something new I would endeavour to add an appropriate photo to the collection. (For example, Renjo ${ }^{2}$ produced a sign for "whale", which was not in my photos). I categorized the objects into sections that were logical to visual concepts. For example, the subsistence lifestyle where children assist in most work required signs related to food production and tools, so I collected photographs in either the market, the local store, or home. Work and leisure activities were relevant to signs developed by deaf individuals who had experienced those specific activities, such as cricket. The collection was inconsistently presented to participants, as it evolved over time.

(ii) The deaf participant responded to a question from the mediator, after I conveyed the question to the mediator. The mediator was whomever was available and willing to mediate communication through sign and/or gesture between myself and the deaf person. Generally, this process was not straightforward and revealed the nature and extent of communication between deaf people and their interlocutors. Even when the deaf participant seemed to understand with head nodding, the signed answer was sometimes rejected by the mediator as being irrelevant or inadequate. Upon reflection this may have

\footnotetext{
${ }^{2}$ Pseudonyms are used for all deaf participants
} 
been beyond the mediator and deaf participant's experience of communication in everyday life. Nonetheless, I was multi-tasking: communicating in Bislama, filming, trying to comprehend the signing whilst planning the next question and signs I would like to elicit, whilst all around us people were noisily enjoying the novelty of the occasion.

(iii) The deaf participant was invited to sign freely on camera. Obtaining this data was complicated because free expression in sign was likely outside the experience of both the mediator and the deaf participant. Insufficient interlocutors in the participant's lifetime results in little opportunity for extended communication and unfamiliarity with the kind of discourse I ideally hoped to record. My first impression was that the deaf individuals may not have had enough vocabulary to maintain an extended text (e.g., a description of their daily routine, or their family), and secondly that no-one had ever requested that they do this before. The situation was also very challenging for participants, in some cases intimidating, as many villagers came to watch, shouting suggestions and gesturing at the deaf participant. Although they were deaf, some could hear the onlookers' noise to some extent but not make out words, which caused additional distractions. Nonetheless, after the mediator explained my request a few did tell a story about their basic activities.

\subsubsection{Materials}

In preparation for recording signed communication whilst in Vanuatu, I took a Flip videocamera, a Fujifilm Finepix S camera, a Toshiba notebook laptop and disks for essential backups. The Flip video-camera proved conveniently small and unobtrusive to use, travelled with me always, in a dry bag with a notebook and pen inside a locally woven basket, prepared to meet a deaf person anywhere. I used either the camera or the video-camera to capture everyday objects and village activities. However, the camera and laptop were often left behind due to equipment risks inherent to the environment.

\subsubsection{Locating Participants}

In the absence of deaf organisations or identified leaders as a starting point for locating deaf people, I met with two organisations VSDP (Port Vila), and SFA (Luganville), who assisted me in locating several deaf participants. However, generally everywhere I went, I constantly asked if anyone had "nambut" (deaf and mute) family or friends; I always signed whilst speaking hoping a deaf person might approach me. I became officially linked to SFA, which gave me credibility to move about under both VSA and SFA's organisational umbrellas, 
whilst seeking permission to make contacts for this work. Cultural protocol in villages, particularly where I was unknown, required contacting the village chief first, then meeting with family members, as a deaf person is subordinate in these social structures.

Additionally, my time, sometimes only half an hour, was limited to when the Tourism Department's hired truck or boat was moving on.

The layout of villages, with hidden homes, leaves little opportunity for deaf people to meet each other, and in the larger towns a deaf person might be unaware of deaf people living or working nearby. The timing of walking around the village may be critical as to whether a deaf person might be met or not, as I found in Lakatoro (see section 5.1).

\subsubsection{Communication}

Communication complications occurred on several levels. I started learning Bislama immediately upon arriving in Vanuatu, as part of VSA's Orientation Program, and this developed over time. Consequently, there was opportunity for confusion, between me and the Ni-Vanuatu mediator, as we tried to communicate in Bislama, English and a little gesture. Ascertaining basic facts about the deaf person could not always be asked and/or verified as their families either did not know the answers, were absent during my visit, or occasionally it was inappropriate to ask, either due to cultural gender customs or because I was an outsider. I kept with me a small book of personal photographs of my family members to identify myself as part of a family, in keeping with local custom, and a map of Vanuatu and the world to locate me and my husband, for use when I met a deaf person. This assisted me in developing rapport, along with using my hands to communicate, however, ideally it required regular time over many days for comprehension of each other's signs/gestures which was not feasible. Apart from a few exceptions where the child of a deaf parent was fluent in their signs, there was often confusion between the hearing and deaf Ni-Vanuatu, with a variety of communication strategies being used, including speaking, shouting, gestures, pointing, homesigns, and occasionally drawing in the sand/dirt.

My early observations of communication between deaf and hearing people suggested that hearing family and friends would probably not be a source of reliable information about their signs. Therefore, due to these communication challenges I started creating a photograph collection portraying various aspects of life in Vanuatu (see Appendix D); then later the photographs helped to create links between signs and potential meanings. 


\subsubsection{Travel}

Signs were collected from one or more deaf people at locations on seven islands, in four of the six provinces (see Appendix C), according to opportunity. For example, I flew from Norsup (Malakula Island) to Liro (Paama Island), then a banana boat trip to Ambrym, followed by a truck ride to Ulei, where I met a deaf man.

\subsection{Deaf Participants}

This section will cover the participants' personal information, if known: the age of onset of deafness, the reported cause of their deafness, deaf isolate or not, family situation, schooling opportunities, and employment. Firstly, ages were approximate for the majority, as birth dates may be unknown, with little to mark the date or year in families' daily lives. Secondly, I was mainly seeking signs and was unaware of the importance of collecting personal data at the time; it was not possible to collect it retrospectively, although for some individuals I could later clarify and confirm through SFA in Luganville. Further descriptions of the participants follow, with a summary in Appendix C (Participants' Location, Gender and Approximate Age).

My first participant was Paul who I met in July 2011, living near Atchin on Malakula (see section 5.2). Paul was probably around forty years old, and profoundly deaf because of malaria. Paul agreed to sign a story which I recorded on this first visit. Subsequently, Paul gave further signs for the photo library on two later visits. In one instance Paul's youngest son Daniel, who was ten years old, mediated using his father's signs.

I had the impression that Susan, Paul's wife, had a hearing impairment rather than being profoundly deaf and she was similarly aged to Paul. We had little communication, apart from one session of Susan signing about her work at home, and she spoke the word "wire". Later, when I was teaching sign language and deaf awareness workshops for SFA at a local pre-school in Luganville, Janet told me of her deaf son. Subsequently, we arranged to meet and film Yonathon who was a 17 year-old. Janet conveyed that Yonathon became deaf at two years old, after a coconut tree fell onto him during a cyclone. Janet borrowed copies of PNG's “Melanesian Sign” (MS) (Papua New Guinea Department of Education, 1994), an ASE book, and an NZSL booklet to teach Yonathon sign language. Yonathon worked with his father repairing vehicles. 
VSDP arranged for me to meet four deaf people near Port Vila. Firstly, Jane, a young 19 year-old woman, who was born with hearing loss, spoke with a deaf voice, and had attended school. Jane participated in Farrelly's NZSL training, although she preferred to use speech. Jane worked with a group of people with disabilities who were contracted to prepare food for Air Vanuatu.

Secondly, I located Serah, an approximately 35 year-old hospital shift worker (see section 5.3). Serah reportedly became deaf when a 3 year-old from malaria and was educated in Fiji. Serah's 14 year-old daughter mediated our communication.

Thirdly, I met Édouard a 20 year-old deaf man, in Port Vila. Édouard's coach said his deafness resulted from malaria, although Édouard believed it happened when he banged his head at school. Édouard played for the Vanuatu Cricket team, and coached children with disabilities to play cricket.

Fourthly, I visited Ifira Island, where I met Isabella a 19 year-old deaf woman. No one was available to mediate communication, but she showed me a few signs for her daily chores. Isabella was probably unfamiliar with meeting Europeans, and this perhaps explains part of her hesitation to sign with me.

The following four deaf participants had previously attended the workshop I facilitated in Luganville in June 2011. Firstly, Lisa is a deaf 20 year-old woman, who with her hearing sister, had developed many home signs. Lisa's parents withdrew her from school after one year, after deciding it was neither cost effective nor beneficial. Lisa worked as a "haosgel" (maid) independently from her family in another village.

Secondly, Hillary is a deaf 21 year-old woman, who attended school until Year 10. Hillary was developing a small sewing business and lived with her educated professional parents.

Thirdly, Edna is a 20 year-old deaf woman. Mrs Naliupis, of SFA, told me Edna's family had an ASE dictionary, and Edna told me she had attended some basic computer and sewing courses at the Youth Centre.

Fourthly, Maryann is a 17 year-old deaf woman, like her mother. Both likely became deaf through illness in infancy. Maryann kept house for her family. I met Maryann's mother once, she was employed as a seamstress, however, she did not participate in the project. 
In accompanying my husband and his counterpart on Tourism business to Ambrym, I encountered Renjo through his hearing acquaintance Peter, who mediated for me. Renjo is a 20 year-old deaf man, who signed a few stories about his everyday life, and lived on his parents' property.

I encountered Grace near Lakatoro (see section 5.1). Grace was prelingually deaf, approximately 40 years-old, and a mother of one. Her brother, who lived at their village, mediated communication with her. Grace cared for her child, family members and worked around their village and garden.

One day, late in our time on Malakula, I met a plantation manager visiting Lakatoro, who informed me that his wife's deaf cousin had many signs. Subsequently, I hired a truck and driver to locate her village, and upon arriving the manager's wife, arrived and mediated communication with Daisy.

Daisy is a 54 year-old deaf woman who has two grown children, they resided elsewhere. Daisy had lived alone since her husband deserted her years before. Ascertaining that most Fridays she visited Lakatoro market to sell tuluk, we arranged to meet, and later walked around the market identifying produce and items. I visited Daisy once more in her village for clarifications, and she was quite isolated this time. During my first visit to Daisy, I also met John a 17 year-old deaf man, who refused to look at the photo library but was persuaded by villagers to sign about his life.

On an island off Malakula I met a woman who introduced me to her deaf daughter, Jeanine who is approximately 25 year-old, and had several children. Jeanine's mother offered to mediate, however they were distracted by the large audience that congregated to watch, so few signs were recorded.

In August 2012, I was invited by Haka Huri Frens (Friends) Disabled Association to deliver a sign language workshop on Ambae, where I met three more deaf people from different villages. Fred and Rosemary were both deaf isolates and in the older age group, with very few signs that I witnessed. Rosemary walked several hours to the workshop, returning home nightly to her family. In contrast, according to the local pastor who mediated for me, JeanMarie is a 34 year-old deaf man, who signed about several topics, including his football interests. 


\subsection{Ethics}

Formal research data collection protocols exist for deaf people, such as those advised by the University of Bristol and the American Anthropological Association's Code of Ethics (Kusters 2012). However, Kusters notes that such guidelines assume literacy levels that deaf participants and their families in her fieldwork experience lacked. Similarly, my data collection protocol was rather haphazard and a formal "consent to participate" process was not feasible to implement at the time. However, my experience as a trained interpreter, adhering to a professional Code of Ethics, gave me a sense of professional boundaries and an appreciation of the ethical implications of working with vulnerable deaf people.

Permission to video is also considered a form of consent to participate, and this is what I ultimately relied on. Although one deaf participant's brother expressed consent on his behalf on camera to me, I was conscious that some of the consents given may have been influenced by the situational factors. For example, the imbalance of power in being a white person with technology arriving in a truck, and limited communication with some family, friends and particularly the deaf people themselves. In terms of filling out a consent form, literacy was a significant unknown, and if someone did not understand I suspect they would not have been confident to admit this in front of the congregating villagers and to me as a foreigner. Also, an imbalance of power existed between the hearing and deaf people, who were often to be heard laughing at the deaf person, whilst I filmed them.

Consequently, whenever I encountered a deaf participants' family members or friends I explained that this project could not help participants directly, but that family members of deaf children born in the future could use the dictionary for early language acquisition. Additionally, I kept Paul's brief signed story on the Flip video, so I could show participants, and/or play back the new participant's video clip to them and their mediators to view. When I had all my equipment with me I downloaded the data to the computer, to firstly lower the risks of data loss due to equipment failures, and secondly so they could view this directly on my larger computer screen. Also, I always attempted to communicate to the participant that the person pictured or videoed, was deaf and signed like them. Their responses were invariably big smiles.

At the end of my fieldwork, it was not feasible to re-contact the deaf participants, who had limited language in which to understand the concept of formal consent. Travel logistics were 
also complex and costly. Thus, a letter of permission from my SFA advisor, Mrs Doriane Naliupis was obtained before leaving Vanuatu in 2012 and renewed in 2017 (see Appendices $A \& B)$. This letter permitted me to use the filmed data for further professional education and research. This approach was approved by the Victoria University Human Ethics Committee in consideration of the specific circumstances. Pseudonyms were considered appropriate to protect participants' identity because deaf individuals (especially females) may have a higher level of vulnerability when their deafness is exposed in a society with a high incidence of sexual violence.

\subsection{Data Analysis}

Living in Vanuatu for two years developed my familiarity with the physical and social details of village life, which provided essential context for collecting and analysing data, particularly in the instances when their gestures/signs represented experiences and objects in ways that were visually motivated by objects and activities of everyday life.

Digital videos were downloaded to my PC, from which I examined the data including mediators' commentary to me, and my voicing of sign meaning, to identify as many signs as possible. Analysis of these signs raised some of the issues which Zwitserlood (2010) identified when performed without either formal methodology or sufficient depth of linguistic knowledge, such as some incorrect conclusions on sign meanings. There were no sign language specialists available in Vanuatu. Analysis was checked with my supervisor who is a NZSL specialist, and some data with a Deaf linguist and a Deaf NZSL tutor.

ELAN annotation software (ELAN, 2018) from the Max Planck Institute of Psycholinguistics was used to transcribe and analyse data (see section 5). Transcription of sign language via written language meanings is commonly referred to as glossing, although practical limitations in converting three-dimensional languages into two-dimensional formats exist (Van Herreweghe \& Vermeerbergen, 2012). A sign's formational parameters, which can vary to alter meaning, are not encompassed in gloss, and therefore the meaning is only an approximation of the sign itself. Additionally, non-linguistic information, such as gestures and/or body language, that interlocutors glean from face-to-face interactions is not glossed. However, glossing in a conventional sign language allows sign forms and meanings to be consistently paired, with contextual meaning usually explained by the linguistic context, translation, subscripts, or descriptive information hyphenated in the sign gloss (Van 
Herreweghe \& Vermeerbergen, 2012). Gloss transcriptions are usually accompanied by a written translation in the relevant spoken language.

Figure 3-1 ELAN Example

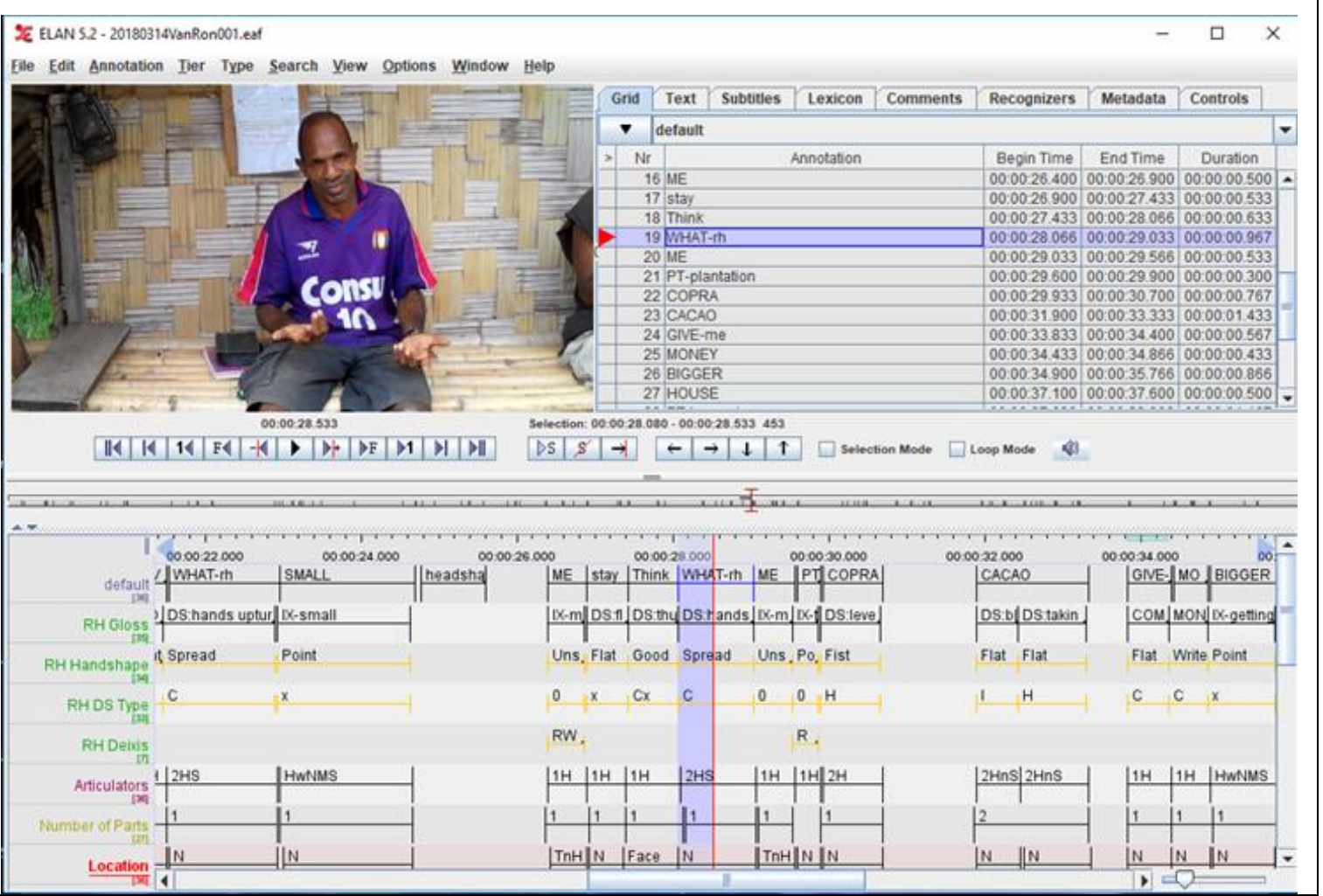

Glossing this data was an inherently difficult process as deaf participants used idiosyncratic signs, and utterances also contained significant amounts of gesture, mimesis, and sometimes foreign signs. Often utterances appeared to lack grammatical cohesion and the mediator (and I) could comprehend only the gist. Clarification to identify meaning was not technically possible for every sign or action; often signs were repeated without a reason being evident. Additionally, each deaf person's idiosyncratic gestures/signs were not always consistently produced thus creating variants, which could not be allocated lexical status.

Generally, in the glossing process I could allocate meaning to a sign, but these were usually unconfirmed by the mediator. Therefore, when meaning could not be identified to use as a gloss for a sign, the form was described, however, mixing form and meaning in this way is not ideal glossing practice (Van Herreweghe \& Vermeerbergen, 2012). Nonetheless, I glossed the meaning of signs with variants numbered sequentially as they occurred in a clip. In many cases, a sign had a general meaning that was specified by contextual knowledge, 
such as an indicator for "height" at variable levels to refer to persons of different size or age, which I glossed as HEIGHT-short (for a child), HEIGHT-tall (for an adult or senior person), and a rising level, HEIGHT-grow-up. When translating such forms, I included information that I could infer from the context into the translation in brackets. Therefore, glossing idiosyncratic signs and gestural information is complex and difficult to apply a "system" to; subsequently, I aimed for consistency, but the data's variability created blurred lines.

Further coding tiers were: Handshapes, where both hand formations were identified although some were loosely formed, with 23 codes; Depicting Sign Type was identified by the hand displaying dominant formational characteristics, the same code allocated to both hands, with 12 codes; Deixis was coded to the relevant hand, with four codes; Articulators, were identified by whether a formation was one or two-handed ( four types), non-manual formations, combined, or whole-body enactments (eight codes); Sign location, was identified by where the sign was located (11 codes); Number of parts, was how many signs per meaning (three codes); Head movements, such as tilting and turning, were considered for linguistic significance; Eye gaze, was considered for lexicalising of deixis; and NMF were identified for affect or modifiers (two codes) (see Appendix H). 


\section{Lexical Analysis of Ni-Vanuatu Signs}

This chapter is an analysis of the signs produced by deaf participants in response to picture stimuli and spontaneous communication, with the original aim of producing the lexicon "Storian wetem han olgeta - A Dictionary of Deaf Ni-Vanuatu Family Signs" (Iseli, 2012). I have generally included participants' names (pseudonyms) with sign descriptions to emphasise that these signs are generally their own idiosyncratic forms and not shared across participants. Firstly, the data was analysed in terms of the range of concepts found, and then for evidence of: (i) a shared language; (ii) foreign sign language and conventional gesture influences. Secondly, the formational characteristics of signs are described in terms of signing space size, types of sign formation, handshapes, and locations. This chapter also addresses visually motivated depicting strategies in the lexicon, and the possibility of nounverb distinctions.

\subsection{Describing the Lexicon}

In this description I refer to signs in terms of "the lexicon", although I reiterate that their status as "signs" (rather than gestures or mimesis), remains unclear, in terms of their stability and conventionalisation, as explored further in this chapter.

Overall, I recorded free expression from 12 participants, and eight participants responded to the set of photo stimuli, in various stages of its development. The concept of producing decontextualized "language", as elicitation requires, is likely to be completely outside the communicative experience of the deaf participants. Thus, it is unclear whether the deaf participants were either: (a) spontaneously depicting the object shown in the photo; (b) describing the whole picture; (c) expressing their knowledge of how the object is used - such as how food is prepared for eating; or (d) whether they produced a sign form that they use regularly to communicate with their family or other villagers. In fact, it is likely that many of the participants would have few opportunities in daily life to have "conversations" that required reference to many of the concepts recorded - that is, reference that is displaced from an immediate and visible context. Five participants had children, and one participant had a sibling, and I believe they were therefore more likely to have a regular interlocutor with whom daily life would be discussed or referred to, using shared signs. 


\subsubsection{Number of "Signs" Documented}

Approximately 1,385 signs with 1,117 meanings, were identified in the data collected from 19 participants, who individually provided between three to 227 signs each. Firstly, the disparity between signs and meanings results from individual variants for meanings, such as six variants of "pig", or some participants responding with sequences rather than a single sign, to describe an item or a process that item was subjected to. For example, Lisa's response to "spider" was described in three parts: (i) a spider crawling; (ii) outlining a body; and (iii) outlining a web. Whereas, Paul's response to "bamboo laplap" (a root mixture) comprised of ten signs to describe preparations from cutting the bamboo, through to its consumption. Only 13 participants' data were used for analysis of formational characteristics due to the small number of signs collected from six participants.

\subsubsection{Range of Concepts}

A limited range of concepts was found. Generally, these were concrete terms, either present or photographed, whereas abstract concepts were difficult to portray in stimulus materials. Abstract concepts, such as time (see Figure 4-3 to 4-7), were expressed by few participants. Concepts recorded, in varying numbers, are described next.

Social identity terms were restricted to male and female, married, parent, child, deaf, boss and European foreigner. Only one participant referred to a boss which may reflect Vanuatu's low employment levels and their relatively limited experience of employment situations. Some participants had accessed foreign sign language dictionaries, which was reflected in their range of signs for social identity, although it is unknown whether they used these signs regularly.

Family signs identifying family roles or relationships were few. Eight participants used signs that referred to father/male, and to mother/female, for each category, one sign form expressed both meanings; of these, seven participants gave signs for both genders. Kinship terminology in Ni-Vanuatu culture is often defined differently to English, and two participants presented these in foreign signs (NZSL; MS). The height SASS was varied in actual height to refer to "child", "children", "siblings", "smol papa" and "big papa". In some cases, the height marker referred to physical size, and in others it metaphorically referenced relative seniority (age or status difference). For example: (i) Renjo used graduated heights for siblings; and (ii) Lisa used contrasting heights relative to her own; that is - "smol papa" 
was shorter, whilst "big papa" was taller. Only two participants used the collective concept of "family"; one referred only to their family and the other sign was NZSL. Other participants are unlikely to communicate this concept, since their daily interactions are mainly with family members.

Personal appearance concepts were limited and found in four participants' data; three were stimulus responses, and one described a family member. These signs indicated a person's body size - fat (possibly a conventional gesture), or thin.

States of being signs were rarely used by participants in discourse or in stimuli responses. These were: (i) "pregnant" ( $n=4)$; (ii) "sick" or "fever" ( $n=5)$; (iii) "dead" (person) ( $n=3)$; and (iv) "hot" ( $n=1)$. For Ni-Vanuatu death is part of daily life (people and animals), and expressions of "dead" ranged from sign to mimesis (see Figure 4-1). For example: (i) Serah's two-handed symmetrical sign showed the spirit metaphorically leaving the body - 1; (ii) Lisa dropped her head to one side, expressionless with arms held limp by her sides - 2; whereas (iii) Grace threw herself backwards in death - 3.

Figure 4-1 Strategies for Expressing "dead"
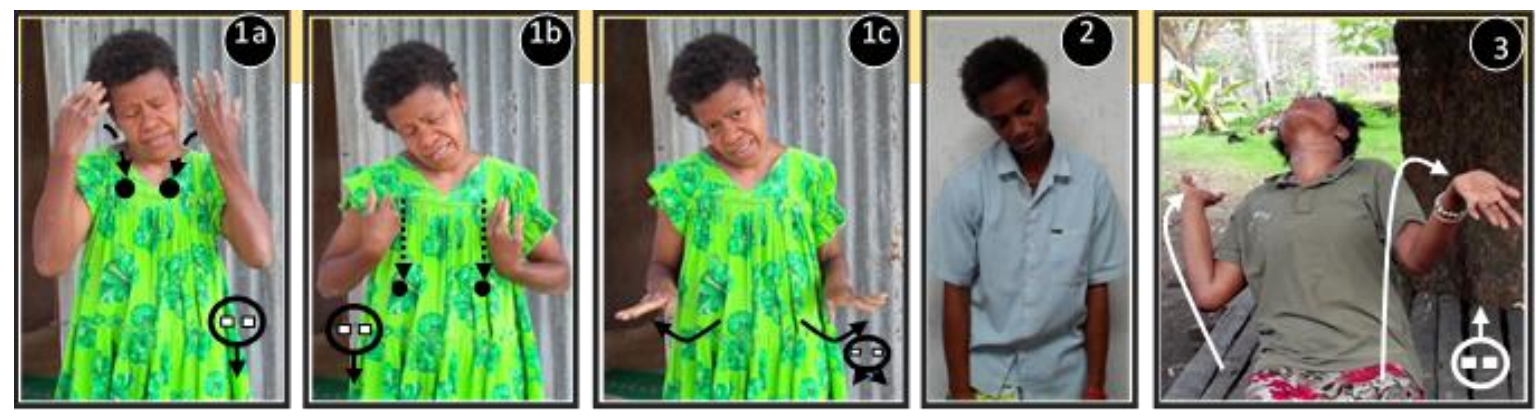

Emotion signs were difficult to locate. Generally, deaf people are unlikely to either be asked to communicate their feelings or have the language to do so. In response to staged stimulus photos, that demonstrated various feelings by facial and body language, participants produced mostly mimetic actions.

Modifiers were used by only two participants. Paul used the same form for both "big", and "small" (indicating "extent" with two hands, palms facing), with movement to indicate becoming smaller or bigger, to express money quantity and insect size. Grace described 
both humans and an animal using the same "small" sign. Colour references were absent, although I only asked one participant.

Action signs expressed specific activities, such as swimming. In signed languages generally, actions that involve the handling or movement of a physical object, such as "put", will include iconic elements that indicate the size/shape/placement/handling of the object. For example, "put" was elicited with photo stimulus of a book being inserted into a basket; the sign produced in response was iconic in both handshape (the book's shape and thickness) and movement (path direction). In contrast, one participant in discourse, conveyed putting a baby down with a flat handshape (palm faced downwards), which is visually motivated only in terms of path movement, but not by the baby's handling. Nonetheless, action stimuli tended to elicit specific mimetic depictions or conventional gestures. For example, two responses by one participant, Edna, to a homemade ladder photo, with a boy climbing up it, elicited two forms: (i) a constructed action using the hands, as if alternately grasping ladder rungs, with an upward glance; and (ii) the body-enactment which was the same but with alternated foot actions. Interestingly, two participants responded differently to stimulus for "talk" (verbally): the likely prelingually deaf person used a one-handed sign with internal movements of the fingers representing the lips/mouth opening and shutting, as if the speaker was facing towards her (see Figure 4-2).

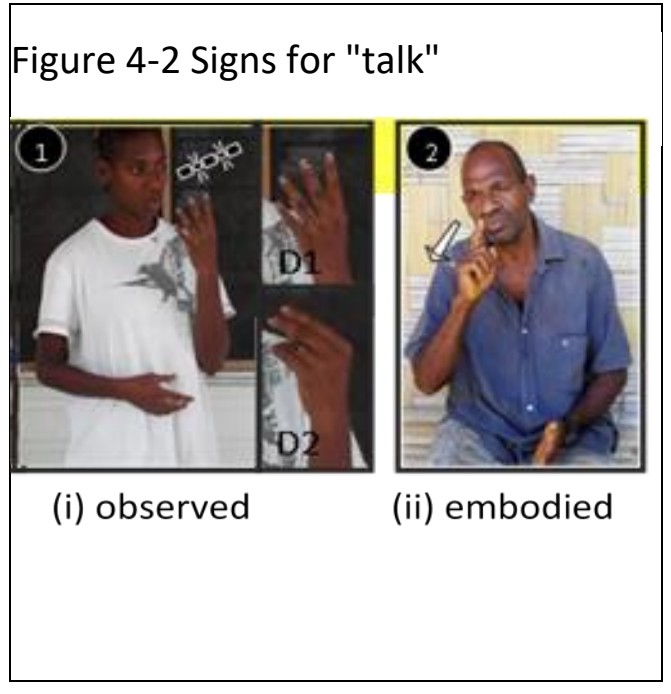

In contrast, the likely postlingually deaf person used a pointing handshape moved outwards, indicating speech coming from his mouth. These two depictions of talk may reflect observed (passive), versus embodied (active), perspectives on the act of speaking. 
Objects (real items, or photos) often prompted sign sequences. Some of the original stimulus items proved to be either culturally or materially irrelevant (e.g., table, chair, kitchen implements). Whereas bush knives (and smaller knives), as important tools for daily chores, food collection and preparation, were owned by most adults, and subsequently occurred frequently in data.

Food items were the largest category of signs elicited, with 118 signs, including some sequences. For example, Lisa and Paul responded to approximately 17 food items each, depicting the item being picked, processed and eaten. In contrast, Daisy's predominantly single signs (45 items), depicted one distinctive part of the process, such as using sticks to prod the octopus out from between the rocks (see Figure 4-22 i). Daily life strongly focuses on activities related to gardening and food preparation, yet its consumption seemed rarely discussed, which may be why few food signs occurred in free expression.

Animals are a common part of daily life and 81 animal signs were identified in 11 participants' data. Edible animals were mentioned more frequently than inedible animals. Seven participants produced a sign for pig, one in response to a Nakamal (meeting house) picture, the place of ceremonial pig killings. Overall, animal signs were more likely to be used to refer to animals of either cultural or dietary salience, or those that were dangerous (or perceived to be) to health, such as mosquitoes, centipedes and sharks.

Negation was used by only four participants. Three were observed to give a headshake (a Ni-Vanuatu conventional gesture) - firstly, as a negative response to direct questioning; secondly, to describe earnings that were particularly low compared to expectations (i.e., "not much"); and thirdly, combined with pointing.

Affirmation was seen occasionally, as a head nod and in one instance raised eyebrows. Generally, it was unclear whether this was an affirmation or an encouragement to continue communication with the person.

Quantifiers were used by seven participants, but rarely occurred in discourse. Number signs $(n=35)$ ranged from one to 10 using extended finger/s or thumb signs. Generally, a similar pattern for numbers one to five is evident (see Figure 4-10). A few participants produced inconsistent number forms. For example: (i) Grace used four different handshapes to express number one, and two different handshapes to express number two; (ii) Daisy used 
the same handshape for 30 vatu (currency) and number three, when describing selling tuluk (cassava pudding). Two participants counted by pointing to their fingers in turn. For example: (i) Paul, counted the five months he lived in NZ; and (ii) Grace counted by pointing to her fingers and then her toes to quantify her siblings and their children. Grace's "counting" was uncertain and unclear which suggested this was an infrequent activity. As quantifiers were not systematically elicited, few conclusions can be drawn from this.

Time signs were difficult to elicit and rarely used in free communication. Only two people, indicated the past with a sign in discourse: (i) Serah used BEFORE (NZSL) and a variant of YEAR (NZSL); and (ii) Édouard used his thumb to point back over his shoulder for a past time reference. Yonathon knew some foreign time signs (see section 4.3). In response to stimulus photos showing the sun in positions of sunrise, noon, and sunset, Paul and Daisy used deictic signs that pointed to the sun's real-world direction and movement (see Figure 4-3 to 4-5). Also, Paul, the only participant who wore a watch, having previously worked in NZ where clock time structured daily routines, related the sun's position to clock times by pointing to three positions on the sun's trajectory, and indicating numbers (five (am); two (12pm); five (pm) (see Figure 4-3 to 4-5). It seems that his number "two" indicates twelve, in the same way that Daisy extended 3 fingers to mean 3 and 30.

Figure 4-3 Time Signs - "sunrise"

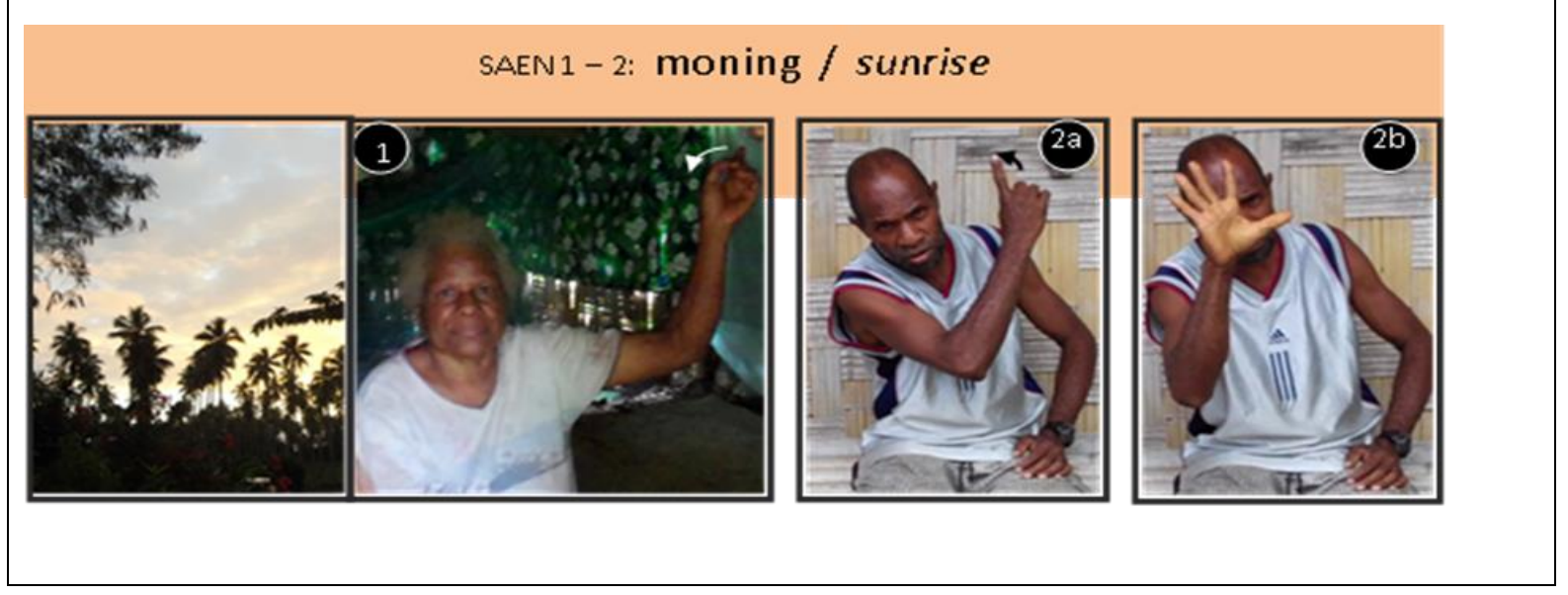


Figure 4-4 Time Signs - "midday"
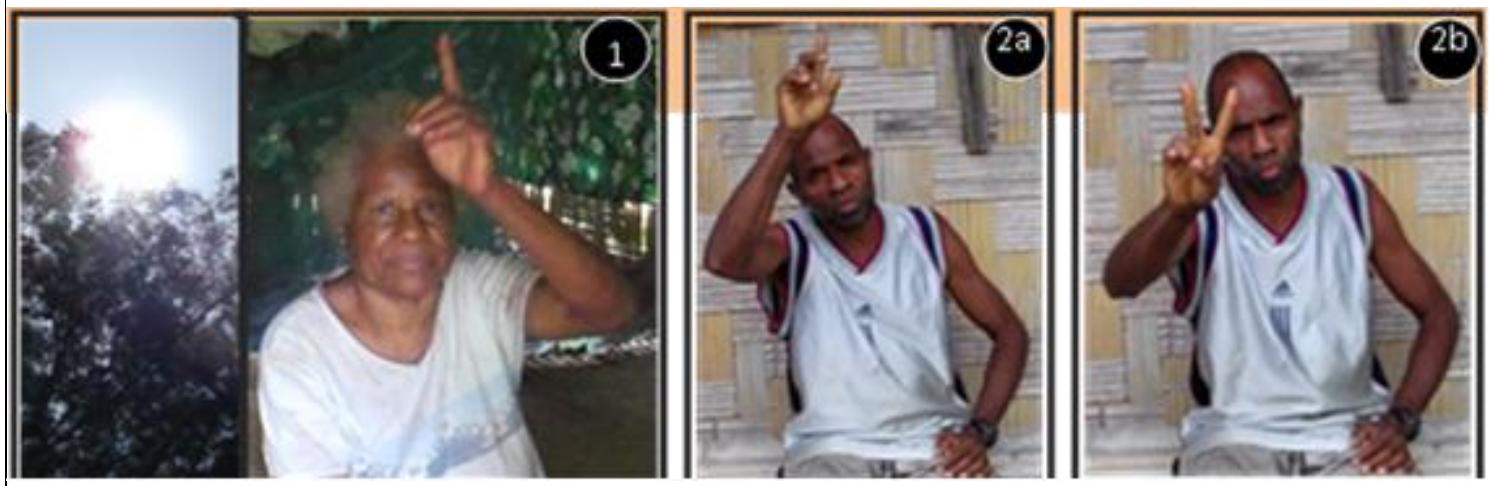

Figure 4-5 Time Signs - "sunset"

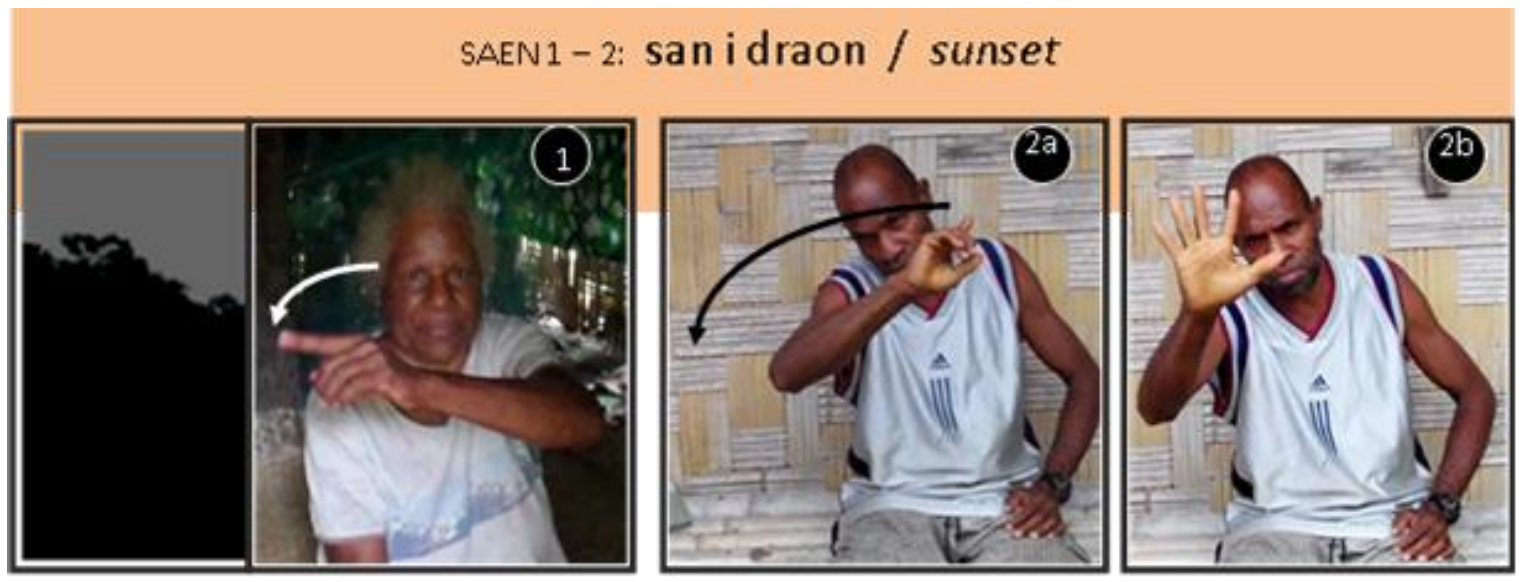

Daisy and Paul both indicated midday by pointing to the sun's position directly above. Lisa was the only participant who used "afternoon", tracing the sun moving in a lateral arc rather than a literal depiction of the sun's path from noon until sunset (see Figure 4-6 i). In contrast, Jean-Marie used deixis for "day" with a flat hand to indicate the sun rising in front of him and setting behind his shoulder (see Figure 4-6 ii). 
Figure 4-6 Time Signs - "afternoon", "day"

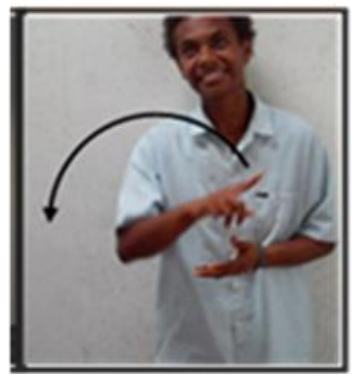

(i) afternoon
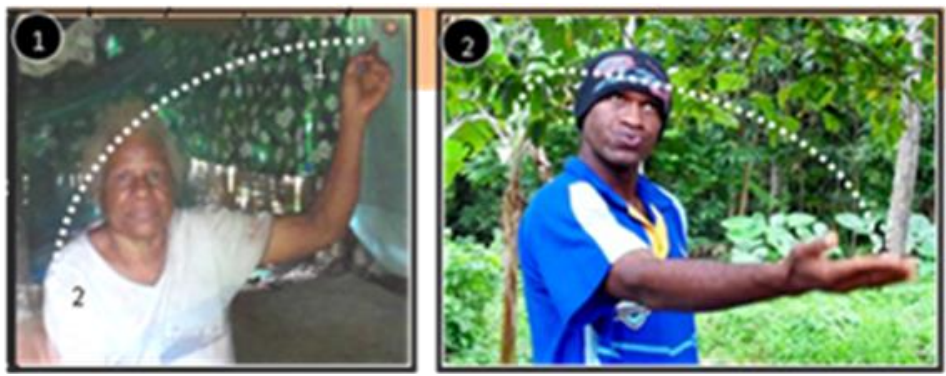

(ii) day

Although, two instances of "month" occurred, Paul's was in discourse, whereas Daisy's was a photo stimulus response. Both participants used deixis for the moon's path, traced twice (see Figure 4-7). However, Paul's path movements were truncated and noun-like. In one instance, Lisa used the reference of "sleep" to denote the day's end before describing the next day's ("tomorrow") events.

Figure 4-7 Time Signs - "month"
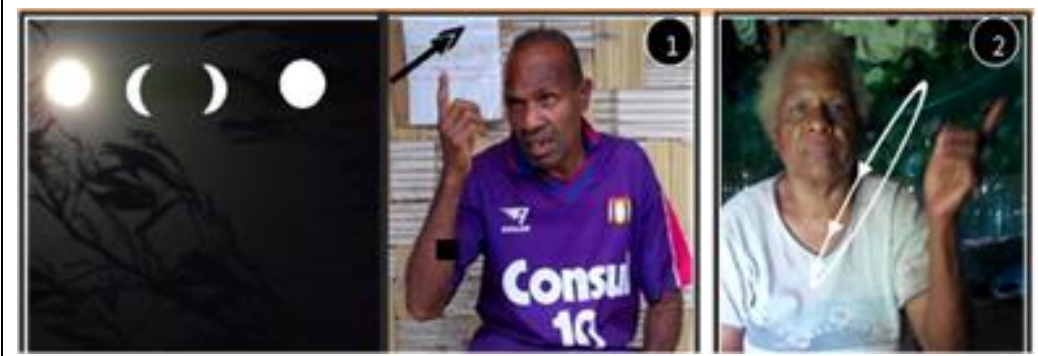

Evaluation signs for concepts good or bad, right or wrong, were limited to the conventional gesture GOOD, which was used by five people $(n=7)$. However, occasionally facial expressions indicated evaluation, such as Paul's surprise at his NZ work payment.

Proper nouns were rarely expressed as a single sign when referenced, such as a company, two places, and name signs (see Name signs below), although deixis was used to locate more places. Firstly, for "Air Vanuatu" Jane fingerspelled A-I-R and signed Vanuatu, which she identified as a Fijian sign (however this sign was unknown to Manasa, a Fijian Deaf man, 
visiting Vanuatu). Secondly, Serah pointed away and mouthed "Fiji" as the place of her education, and Hillary fingerspelled P-E-N-T-E-C-O-S-T Island. Thirdly, several participants referred to "hospital" depicted as an arm injection, then pointed to the hospital's real-world location. One participant tapped the back of her left hand, where an intravenous drip may have been inserted, then pointed in the hospital's direction, multiple times. These examples were likely rudimentary compound forms (see section 4.8.1). Overall, participants pointed in the actual direction of places that were out of sight, and few could fingerspell proper nouns.

Name signs for family members were used by two participants. Firstly, Grace used four name signs for her siblings which described personal features or adornment. For example, her sister's flat hair style and large body size, and three brothers were individually identified by a thumb scarred or missing ("cut"), a cross-shaped stomach scar, and a watch strap, (see Figure 4-8).

\section{Figure 4-8 Name Sign Features}

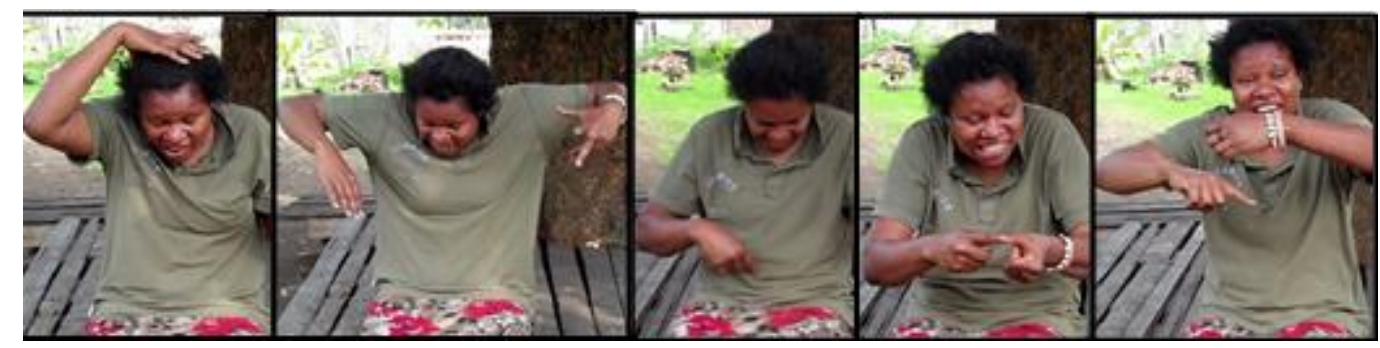

(i) hair

(ii) fatness

(iii) scar

(iv) thumb

(v) watch

The fourth brother's name sign was not elicited as Grace saw no pragmatic reason to refer to him by a sign, despite requests, since he was present at the time of filming. Remarkably, Grace and her brother had different signs for their mother (breasts patted; breast outlined). Secondly, Lisa and her sister shared their sign for "mama", a zig-zag gesture across their chests (see Figure 4-18 ii), although this may be generic for female (relatives). Few participants referred to people not present.

Religious concepts were rarely referenced, by only three participants. Two participants used the foreign signs of CHURCH, JESUS and HOLY SPIRIT (see section 4.3). 


\subsection{Degree of Similarity or Variation Across Participants and Concepts}

Due to complex and opportunistic circumstances for data collection, there was little opportunity to systematically cross-check for similarity of signs between participants.

However, data analysis suggests signs are generally idiosyncratic with little overlap in the forms produced by different individuals in response to the same stimulus items (photos) or free expression. Across participants, some signs appear analogous, however, this similarity is visually motivated by the referent. For example, slightly varying handshapes and movements are used for "eat" (based on the action of the hand bringing food to the mouth, with or without a plate), "pig" (based on tusk depictions, which are both visually and culturally salient - a traditional form of currency) (see Figure 4-9; Figure 4-37), "sick" (hand

Figure 4-9 Pig's Tusk

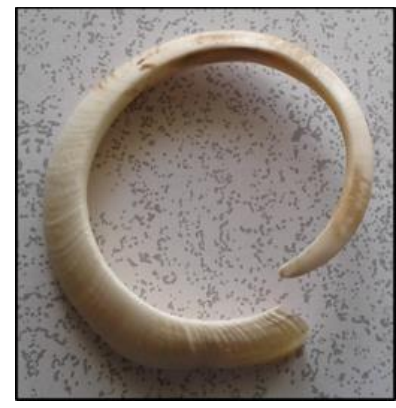

on forehead indicating fever), and "wash-clothes" (scrubbing clothes either on the opposite hand or thigh). Also, whilst four participants gave similar signs for "dead", (with a hand or finger drawn across throat), this was likely influenced by a conventional gesture. Furthermore, some quantifiers were similar which suggests an overlap with conventional gestures for numbers one to five in Vanuatu, and this was confirmed (Personal Communication, Kolika Markie, June 10, 2018) (see Figure 4-10).

Figure 4-10 Number Signs - "one" to "five"

Vanuatu's possible conventional gestures for number s 1-5
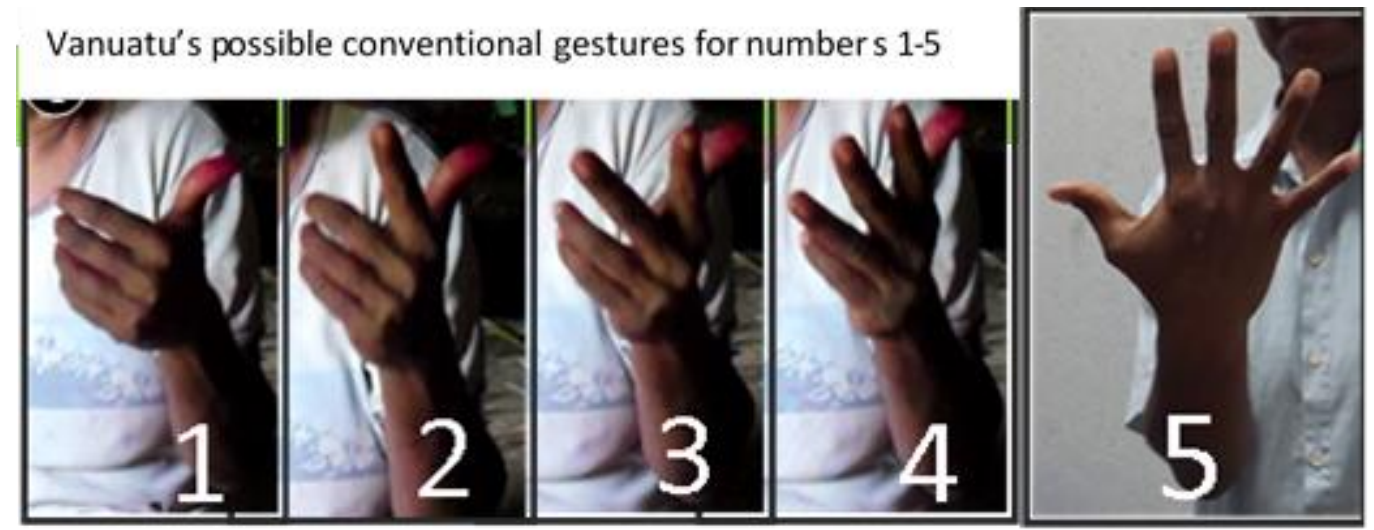
On Espiritu Santo, Lisa and Hillary (friends who live an hour apart) would not respond directly to photo stimulus during data collection but persistently looked to Daphny (Lisa's hearing sister) to supply signs. Lisa and Daphny shared their childhood and signs, so I accepted this process for her, but stopped recording Hillary. Nonetheless, Hillary and Lisa's signs for "turtle" (see Figure 4-41), and "intravenous line" (in a hospital context) were similar, possibly due to their iconicity rather than shared use.

On Malakula there were four participants. Daisy and John lived in the same village. Only Daisy responded to stimulus materials, but John described his life in basic terms.

Afterwards, comparisons showed they shared a few signs, such as "tie-up-with-rope" (the bullock), "bullock", and "copra"; the latter two signs were similar to Paul's who lived two hours' drive away; and Paul and Daisy had similar signs for "cacao" and "time" references. Paul and Daisy's "married” variants were similar to Grace's, who lived an hour away (see Figure 4-11), and are likely Melanesian conventional gestures (Personal Communication, Kolika Markie, June 10, 2018).

Figure 4-11 Malakula Variants for "married" or "partner"
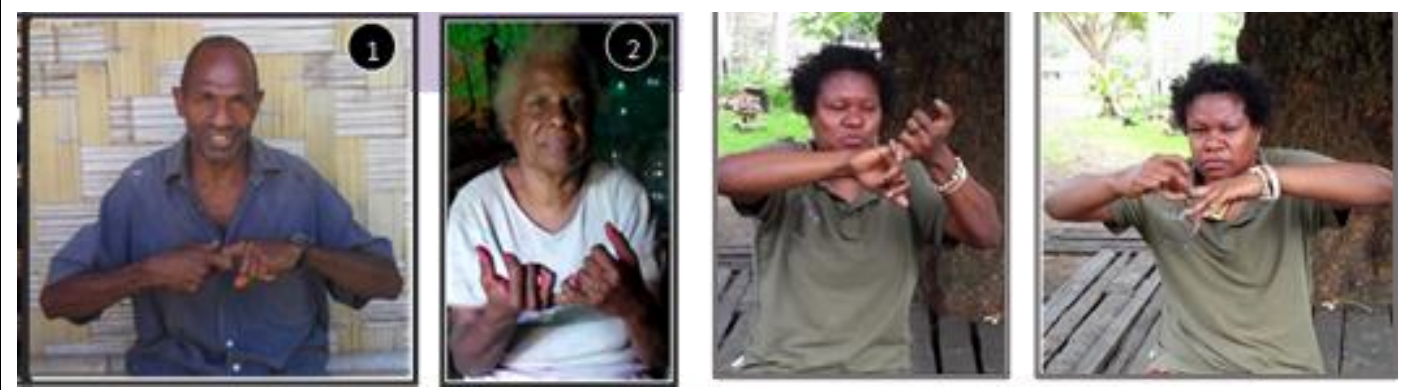

On Efate two participants, Serah and Édouard, lived in different villages. Although their generic "grow up", "child" (height specifier), and "bullock", were similar these are unlikely to be shared signs but rather iconic forms.

Two participants on adjacent islands, Renjo (on Ambrym) and Paul (on Malakula), shared the "fish-caught" sign where the forearm is seized by the other hand (see Appendix E), and is likely a Vanuatu conventional gesture for "catch" (Personal Communication, Kolika Markie, June 10, 2018). 
In sum, three possible reasons were identified for similarities between participants' signs. Firstly, when participants live in the same locality there is opportunity for shared signs, but there was little direct evidence of this. Secondly, deaf individuals create similarly iconic signs motivated by common visual referents. And thirdly, signs with strong similarities (e.g., counting gestures) between participants may overlap with Ni-Vanuatu conventional gestures.

\subsection{Influence of Foreign Sign Languages}

Some participants' signs showed outside influences, including from NZSL, MS, Fijian Sign Language (FJSL), ASE and Auslan. The overall presence of foreign signs in the dataset was $6.92 \%(n=59)$, of which $3.52 \%(n=30)$ are recognisably NZSL, $1.17 \%(n=10)$ are MS, and the balance appear to be modified foreign sign forms. Four participants used no recognisable foreign signs, whereas nine participants had foreign signs in their lexicon, ranging from $1.37 \%$ ( $n=1$; Édouard) up to $24.59 \%$ ( $n=15$; Yonathon).

Firstly, FJSL is likely the earliest foreign sign influence to occur. According to the "Fiji Sign Language (FJSL) Dictionary" (2007) FJSL is a hybrid of Auslan, NZSL and local Fijian signs, and some ASL signs. One participant, Serah, had 12 years of schooling in Fiji, albeit details are unknown. Also, prior to 2010, a Ni-Vanuatu man (hearing), who visited Fiji, had learnt FJSL whilst working in a Fijian Deaf School's male dormitory. Afterwards, organisations attempting to be inclusive, requested he "interpret" for deaf people around Port Vila. However, he reported that deaf people found his signing incomprehensible, therefore transmission of FJSL by this individual is unlikely.

Secondly, in 2006, NZSL was introduced by Farrelly through VSDP training using NZSL resources, and in 2011, by my workshop in Luganville. In total, nine participants confirmed contact with NZSL at some time. One participant, Jane, had attended VSDP's training, while another three participants, and a few others I met, had secondary contact with attendees of that program. A few people had accessed NZSL dictionaries in various forms. Four of the deaf participants attended the NZSL Workshop I facilitated, but influence on their lexicon was likely small. For example, of Lisa's signs $6.29 \%$ were of NZSL origin, and she was the only one with a hearing family member who had attended the workshop. Additionally, teacher aides or SFA field workers who attended this workshop continued to refer to the NZSL dictionary to supplement Vanuatu signs in their work with deaf children. 
Thirdly, signs from PNG's "Melanesian Sign" (1994) were present; this lexicon is based on ASE, which the PNG Government introduced in the early 1990s. During my time in Vanuatu, the Ministry of Education was discussing introducing MS to Vanuatu. One participant, Yonathon, who used $16.39 \%$ ( $n=10)$ MS signs, displayed the most influence of foreign signs but his mother prompted him during data collection, so whether he used these signs in spontaneous communication is unknown.

Fourthly, Edna had accessed an ASE dictionary, and attended the workshop, and there were a few ASE/NZSL signs in her data.

Fifthly, for several years, Auslan signs were used in pre-school sessions for children with disabilities, which a few deaf children attended.

I encountered evidence that foreign signs were sometimes introduced without appropriate knowledge; two incidents illustrate this. Firstly, on Ambae in August 2012, I arranged to video Jean-Marie, and the local pastor volunteered to mediate. I established Jean-Marie had attended a local DPA run NZSL workshop the previous year, and I recognised his papers as Farrelly's handouts. Jean-Marie recited these sign lists, including the manual alphabet, without any communicative intent or apparent comprehension. Also, his articulation of the signs was very inaccurate; a Deaf NZSL consultant who viewed the recording confirmed the signs were incomprehensible. I also recognised that Jean-Marie's sign for GOOD mirrored Farrelly's idiosyncratic articulation of this sign, which I had noticed in previous interaction with Farrelly; this confirmed to me that Jean-Marie's previous sign tutor had attended Farrelly's training.

Secondly, Serah had an NZSL dictionary, and her use of some of these signs was modified. For example, she signed FATHER (NZSL), in which the letter " $F$ " is formed twice, while mouthing the local translation, "papa".

In summary, whilst NZSL and MS had some influence on the vocabulary of a small number of participants, the overall presence of foreign signs was minimal. The general lack of contact between deaf people suggests very limited opportunities for transmission of either local or foreign signs in this context. 


\subsection{Influence of Conventional Gestures}

Conventional gestures are gestures that have been incorporated into the signer's lexicon, usually with similar meanings, such as "good" with the thumbs-up, or "married" with interlinked fingers from each hand (see Figure 4-11). Although conventional gestures were overall the second most frequent type (14.65\%, $n=121$, of signs from 11 participants), individual use was sometimes minimal.

\subsection{Formational Characteristics of Signs}

Signs in established sign languages are usually described in terms of phonological parameters (Handshape, Location, Movement, Orientation). In an established sign language these parameters are specified and conventional for any given sign. In the context of idiosyncratic or emerging signs, these features are difficult to specify in the sense that their formation varies, and not all parameters may be equally important to convey meaning in the context. This section will cover signing space, types of sign formation, handshapes and sign locations, and movements, and poly-componential (manual and non-manual signs combined) and sign sequences, as identified in the data.

\subsubsection{Signing Space}

The signing space used by participants was a loose oval shape from hip level to about head height, sometimes using fully extended arms, therefore laterally wider than established sign languages (see Figure 2-1). Also, a few participants, by either bending over (forwards or backwards), or reaching behind themselves for some signs, enlarged the signing space. This resonates with "signing space" observations in village sign languages (de Vos, 2012).

Occasionally, whole-body enactments were outside the signing space. For example, Grace, to indicate "dead" (person) fell backwards, almost prone, on the platform she was seated on (see Figure 4-1 iii), although in subsequent repetitions she truncated the action to throwing her head back and hands above her shoulders, then returned to the first whole-body enactment. In discourse, Serah located two "injections" on her buttocks, which would be similarly located in established sign languages to indicate a specifically located event such as this. 


\subsubsection{Types of Sign Formation}

The types of signs documented were one or two-handed manual signs, non-manual signs, or whole-body enactments. The two-handed category was further divided into four categories based upon whether the handshapes and/or movements were symmetrical or not. These formation types are presented in order of prevalence in Figure 4-12 and explained further below.

Figure 4-12 Types of Sign Formations and Usage

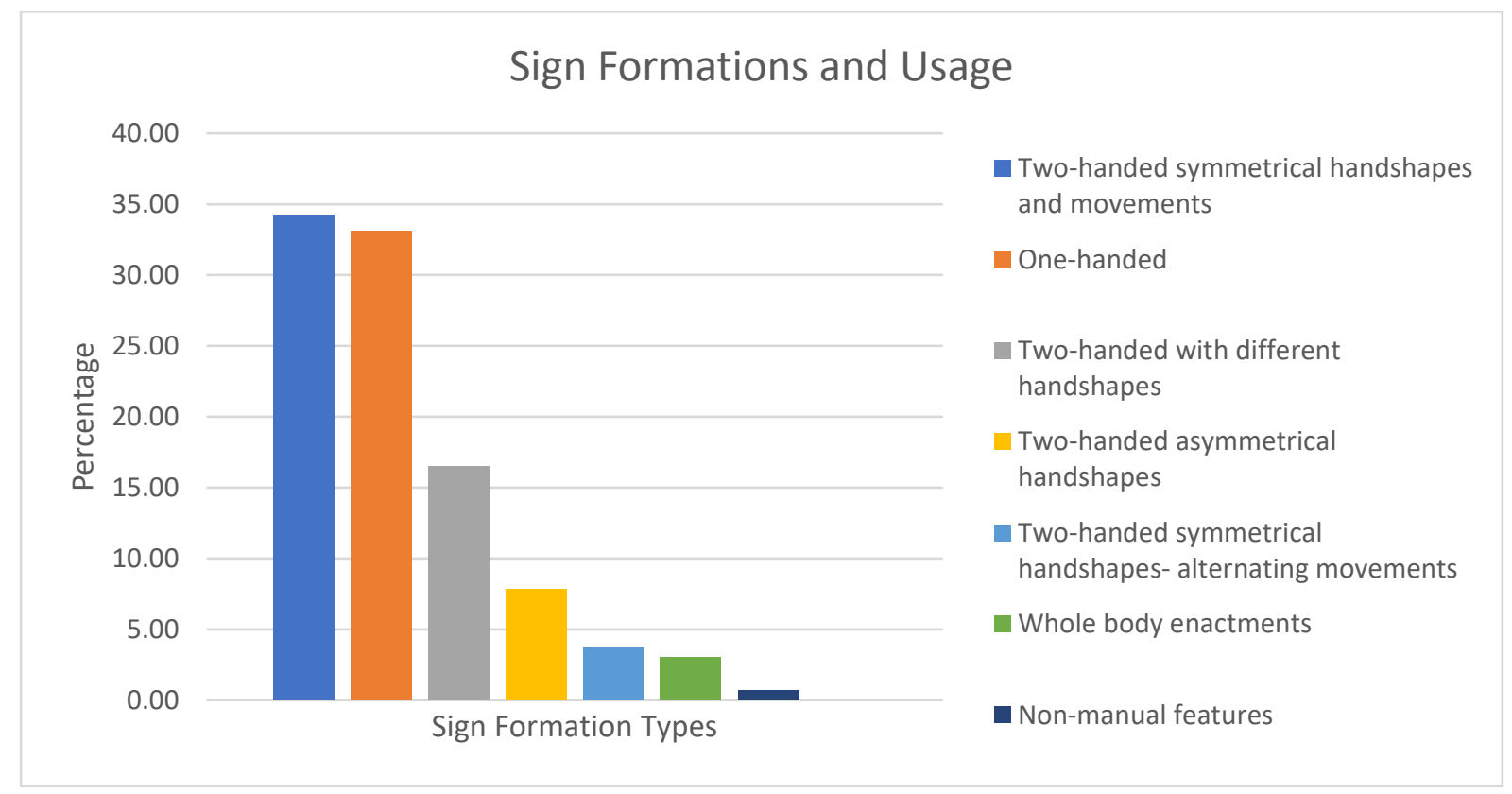

Two-handed symmetrical signs (2HS), with symmetrical handshapes and symmetrical movements were the most frequent type in $34.27 \%(n=292)$ of signs used by all participants. Individual use of $2 \mathrm{HS}$ ranged from $18.18 \%(n=2)$ to $46.15 \%(n=22)$ of signs. These were particularly frequent in signs for animals, accounting for $43.69 \%(n=45)$ of these.

One-handed signs $(1 \mathrm{H})$ were the second most frequent type, in $33.74 \%$ ( $n=282)$ of signs used by all participants. Pointing signs were generally excluded from this count, but deictic uses are occasionally and necessarily present in the lexicon, such as those indicating celestial time. One-handed signs were produced, in descending frequency, in the following three locations (see section 0): Neutral 43.97\% ( $n=124)$; Face 20.57\% ( $n=58)$; and Above $10.99 \%$ $(n=31)$. Eleven participants were clearly right-handed, although only five were consistent in right-hand (dominant) production of $1 \mathrm{H}$ signs and one participant suggested dominance on their left-hand. One participant had ambiguous hand dominance. 
Two-handed signs $(2 \mathrm{H})$, with different handshapes, were the third most frequent type in $16.43 \%(n=140)$ of signs used by all participants. Six participants used $2 \mathrm{H}$ sign types minimally, whereas they comprised up to $18 \%$ of seven participants' lexicon.

Two-handed non-symmetrical signs ( $2 \mathrm{HnS})$, with symmetrical handshapes but different movements, were found in $7.85 \%(n=67)$ of signs used by 10 participants. In these constructions, the non-dominant hand frequently represented an object being acted upon by the dominant hand (depicting an action).

Two-handed symmetrical handshapes with alternating movement signs (2Halt), were few, in $3.75 \%$ ( $n=32$ ) of signs used by 10 participants. For five participants, this sign type occurred in one instance of a constructed action, such as walking or drumming. Some notable constructed actions were: (i) two hands representing "flippers" on the feet; (ii) "sinking ship" with the hands rolling downward; (iii) "flying-fox" hanging upside down by its feet (replicating the animal's position in a stimulus photo); (iv) "bullock" hooves walking; (v) "bird walk" using flat hands to depict the bird's feet; and (vi) "texting" using two thumbs. Whole-body enactments (WB) were least frequent, in 3.05\% $(n=26)$ of signs, used by six participants. Five participants used whole-body enactments rarely in contrast to one participant responsible for $65 \%(n=17)$ of WB. These enactments were mostly related to either: (i) sports, such as putting on protective equipment; (ii) animal actions; or (iii) human actions (see Figure 4-13).

Figure 4-13 Whole Body Enactments

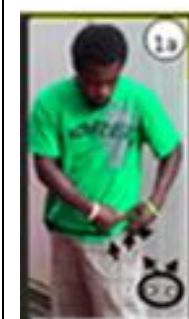

(i) sport equipment

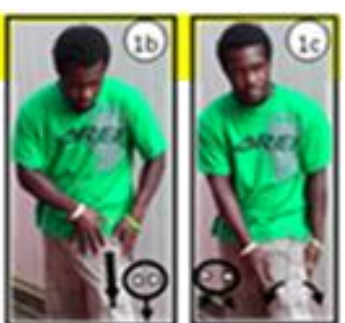

(ii) bird (large)
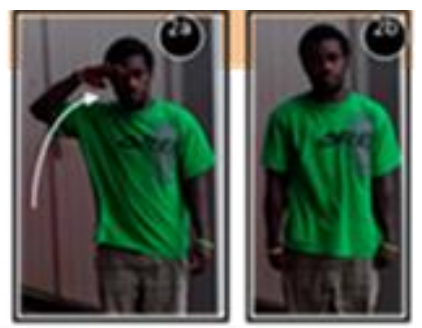

(iii) Police

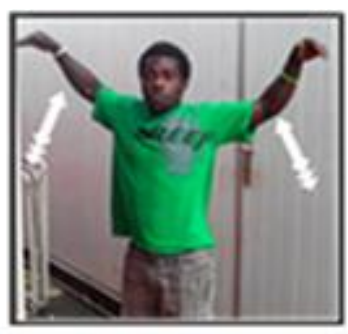

Non-manual signs $(\mathrm{OH})$, where the head and/or face express meaning exclusive of hands, were rare: $0.70 \%(n=6)$ of signs used by three participants. The two forms of these were: (i) 
mimicking animals, such as the head actions of a dog (head tilt with barking) and a pig (rooting action); and (ii) conventional facial gestures - brow-raise for yes, and headshake for no (see Figure 4-14).

Figure 4-14 Non-Manual Signs

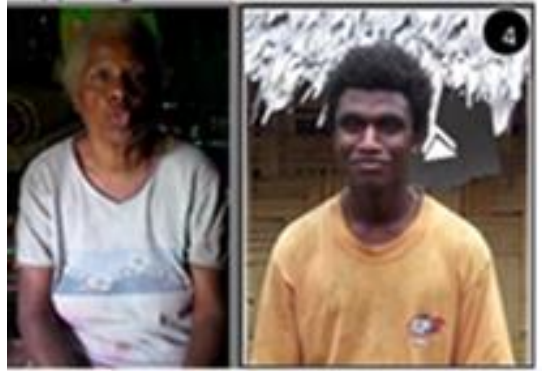

(i) dog pig

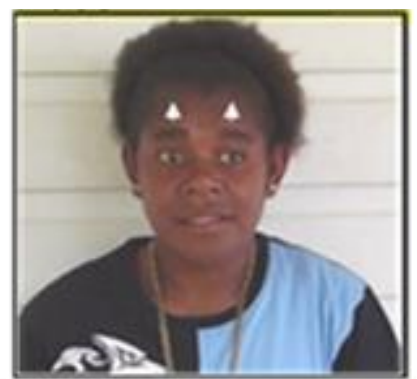

(ii) yes

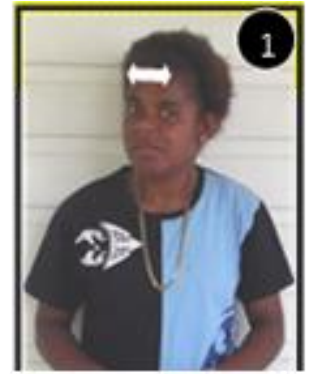

(iii) no

\subsubsection{Signs Modified by Non-Manual Actions}

Manual signs modified by non-manual actions were rare, and only occurred in discourse.

Two participants produced the following three examples: (i) HERE negated by headshake; (ii) HIGH on the dominant hand, with lips pursed and eye gaze up, and simultaneously signing NO on the non-dominant hand while shaking the head, followed by lowered eye gaze as the dominant hand signed LOW; and (iii) pursed lips to indicate smallness. Possibly there were more but these were the most salient and purposeful combinations observed.

In sum, $62.37 \%$ ( $n=532)$ of signs analysed were two-handed, of various types, and $33.74 \%$ ( $n=282)$ were one-handed, with the balance comprising whole-body enactments and nonmanual signs. There were a few instances of manual and non-manual combinations.

\subsubsection{Handshape}

Handshapes were coded separately for Right-Hand and Left-Hand, rather than dominant or non-dominant, because participants' hand dominance was unconfirmed when coding commenced. A total of 1390 tokens of handshapes were coded, resulting in 22 handshape types, plus 25 variants ("phonetic" variants of these). I used an "indeterminate" coding for either obscured handshapes or those unlisted in the Auslan handshape index. Handshapes are identified in Table 4-1, in order of most to least frequent, according to the number of 
right-hand (nine participants were apparently right-handed) over left-hand tokens, and the percentages of all tokens.

Unmarked handshapes $(1,2,3,4$, and 6$)$ were most frequent totalling $79.86 \%(n=1,110)$ of tokens. Interestingly the marked handshape-5 was more frequent than unmarked handshape-6, due to depictions of grasping or handling an item of a thin shape. The other 13 marked handshapes were rare, ranging downwards from $2.66 \%(n=37)$ to $0.07 \%(n=1)$.

Table 4-1 Handshape Types and Frequency for Right-Hand and Left-Hand

\begin{tabular}{|c|c|c|c|c|c|}
\hline & $\begin{array}{l}\text { Handshapes } \\
\text { (HS) }\end{array}$ & Right-Hand & Left-Hand & Total & $\begin{array}{l}\text { Percentage } \\
\text { of tokens }\end{array}$ \\
\hline 1. & & 280 & 248 & 528 & 37.99 \\
\hline 2. & & 128 & 105 & 233 & 16.76 \\
\hline 3. & & 102 & 57 & 159 & 11.44 \\
\hline 4. & & 77 & 52 & 129 & 9.28 \\
\hline 5. & & 57 & 36 & 93 & 6.69 \\
\hline 6. & & 34 & 27 & 61 & 4.39 \\
\hline 7. & & 20 & 17 & 37 & 2.66 \\
\hline 8. & & 18 & 5 & 23 & 1.65 \\
\hline 9. & & 17 & 9 & 28 & 2.01 \\
\hline
\end{tabular}




\begin{tabular}{|c|c|c|c|c|c|}
\hline 10. & & 13 & 3 & 16 & 1.15 \\
\hline 11. & d. & 10 & 7 & 17 & 1.22 \\
\hline 12. & $\delta$ & 9 & 2 & 11 & 0.79 \\
\hline 13. & & 5 & 3 & 8 & 0.58 \\
\hline 14. & tiv & 4 & 2 & 6 & 0.43 \\
\hline 15. & & 4 & 2 & 6 & 0.43 \\
\hline 16. & $A=E$ & 4 & 1 & 5 & 0.36 \\
\hline 17. & & 3 & 2 & 5 & 0.36 \\
\hline 18. & & 2 & 2 & 4 & 0.29 \\
\hline 19. & $A$ & 2 & 1 & 3 & 0.22 \\
\hline 20. & $c$ & 1 & 0 & 1 & 0.07 \\
\hline 21. & fen & 1 & 0 & 1 & 0.07 \\
\hline 22. & & 1 & 0 & 1 & 0.07 \\
\hline
\end{tabular}




\begin{tabular}{|l|l|l|l|l|l|}
\hline \multicolumn{5}{|c|}{ Table 4-2 Handshape Types and Frequency for Right-Hand and Left-Hand (continued) } \\
\hline & Indeterminate & 12 & 7 & 19 & 1.37 \\
\hline & Total & 802 & 588 & 1,390 & 100.00 \\
\hline
\end{tabular}

Six participants' indeterminate handshapes comprised $1.37 \%(n=19)$ of the total tokens. I expected marked handshapes to be foreign signs, but this seldom occurred. Marked handshape-11 occurred in $1.23 \%(n=17)$ of tokens, as either a one or two-handed loose formation, describing curved pig tusks, touching the cheek with a bent finger for "male" and a conventional gesture for "married" with bent fingers. Two instances of unusual handshape-17, with extended index and pinky fingers, were idiosyncratic signs for "happy" and "lobster". Overall, I found foreign signs or conventional gestures had little influence on the handshape inventory.

\subsubsection{Handshape Variation Between Individuals}

Individual statistics show that seven participants used between five to eight identified handshapes each. For example, a comparison of John and Lisa's unmarked and marked handshape inventories are seen in Table 4-2. Note their most frequent handshapes are both unmarked (handshape-1; handshape-2) but in reverse order. Moreover, neither matched participants' overall averaged handshape tokens in Table 4-1. A comparison of John and Daisy, who lived in the same village, showed their handshape inventories differed with John's five to Daisy's nine. The disparity may be related to differences in maturity, gender, topics and experiences, and/or to the effect of elicitation by discourse or stimulus materials. For example, Daisy was the elder with more experiences and subsequently a larger vocabulary, including numbers which are often marked handshapes. 
Table 4-2 Individual Lowest and Highest Handshape Inventory

\begin{tabular}{|c|c|c|c|}
\hline \multicolumn{2}{|c|}{$\begin{array}{l}\text { John's handshape } \\
\text { (x5) distribution }\end{array}$} & \multicolumn{2}{|c|}{$\begin{array}{l}\text { Lisa's } 16 \text { handshape }(x 16) \\
\text { distribution }\end{array}$} \\
\hline है। & $\begin{array}{l}63.16 \% \\
(n=12)\end{array}$ & (2) & $32.49 \%(n=77)$ \\
\hline & $21.05 \%(n=4)$ & & $16.03 \%(n=38)$ \\
\hline & $10.53 \%(n=2)$ & 8 & $15.61 \%(n=37)$ \\
\hline 8 & $10.53 \%(n=2)$ & 1 & $10.13 \%(n=24$ \\
\hline \& & $5.26 \%(n=1)$ & IIt & $8.86 \%(n=21)$ \\
\hline & & & $3.80 \%(n=9)$ \\
\hline & & \multicolumn{2}{|c|}{$\begin{array}{l}9 \text { other handshapes occurring } \\
\text { at frequencies between 1-8 } \\
\text { signs }\end{array}$} \\
\hline & & (ी) & $0.42 \%(n=1)$ \\
\hline
\end{tabular}




\subsubsection{Location}

Signs were formed in 10 locations as presented in Table 4-3 in descending frequency. Locations were almost invariably iconic or motivated by the referent.

Table 4-3 Location and Frequency of Use

\begin{tabular}{|l|l|l|}
\hline Location description & Number & $\begin{array}{l}\text { Percentage of } \\
\text { total signs }\end{array}$ \\
\hline Neutral Space & 512 & 59.95 \\
\hline Facial area or neck & 100 & 11.71 \\
\hline Torso (touching it), not head & 57 & 6.67 \\
\hline Above the Neutral space & 47 & 5.50 \\
\hline Head, (not the face) & 32 & 3.75 \\
\hline Arm (not hand) is used as a base & 31 & 3.63 \\
\hline Wider than the Neutral space (lateral) & 30 & 3.51 \\
\hline Below Neutral space & 29 & 3.40 \\
\hline Legs are touched or used & 12 & 1.41 \\
\hline $\begin{array}{l}\text { Back of body or behind the jawline, or } \\
\text { behind the signing space in front }\end{array}$ & 4 & 0.47 \\
\hline Head and Face & 0 & 0.00 \\
\hline Total & 854 & 100.00 \\
\hline
\end{tabular}

Neutral location is the front mid-torso area, from hip level (some participants sat during data collection) to head height, used in $59.95 \%(n=512)$ of signs by all participants. Neutral was likely motivated by depictions of working with items in front of the body and were predominantly two-handed and non-symmetrical (see Figure 4-15). 
Figure 4-15 Neutral Location

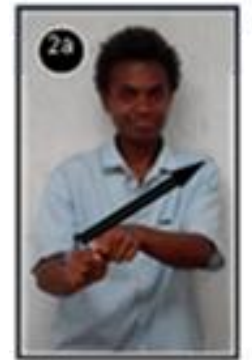

(i) speedboat

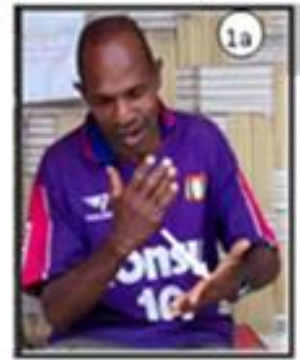

(ii) cacao

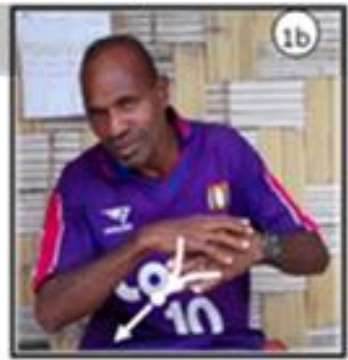

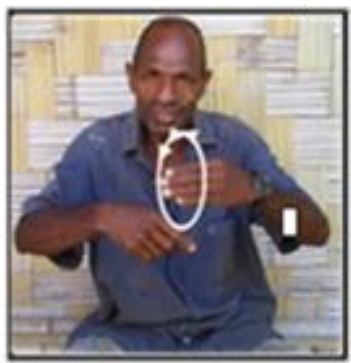

(iii) rolling leaves

Face location is on the face (or neck) and used in $11.71 \%(n=100)$ of signs by 11 participants. Face was motivated by either: (i) features of the referent, such as for "man/father", whereby the finger strokes the cheek (beard or stubble); or (ii) the place related to the meaning, such as for "fever", with hand touching the forehead to test for temperature (see Figure 4-16).

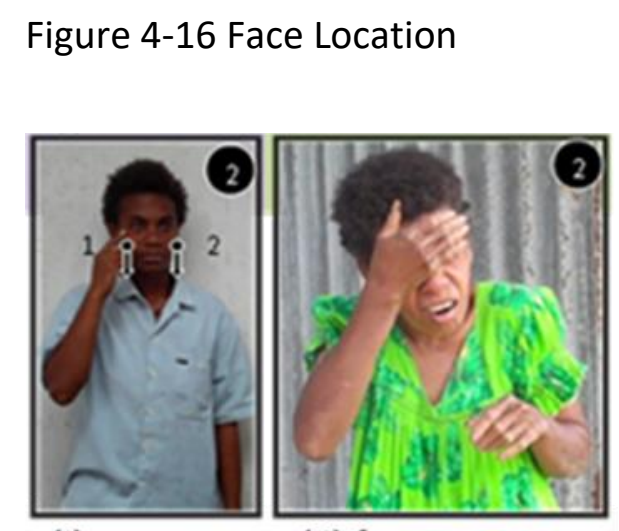

(i) $\operatorname{man}$

(ii) fever

Torso location (touching the torso) was used in $6.67 \%(n=57)$ of signs by 12 participants. Apart from personal pronouns "me/I", Torso was motivated by use of instruments, such as a "thermometer" (armpit), or for "doctor", placing a stethoscope (chest) (see Figure 4-17). 
Figure 4-17 Torso Location

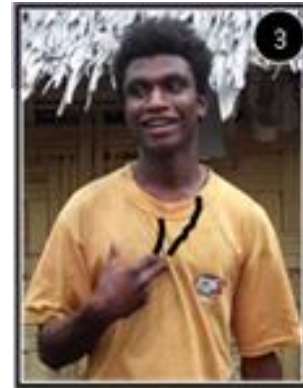

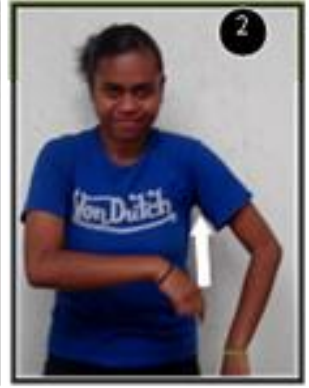

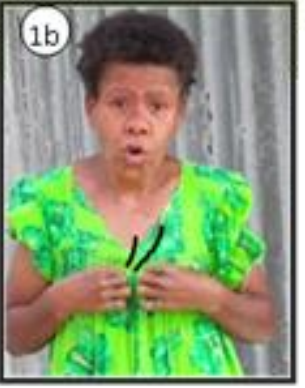

(iii) doctor

(i) me
(ii) thermometer
n.




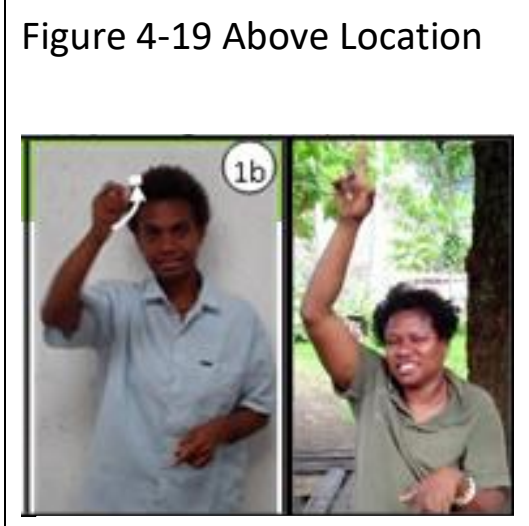

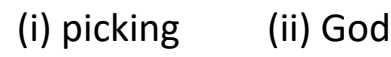

Head location (not the face) was used in $3.75 \%(n=32)$ of signs by 12 participants. Frequently the Head location was physically or metaphorically iconic. For example: (i) "deaf" signs were all ear located; (ii) hair twirling for "girl" indicated Ni-Vanuatu female hair styling; (iii) hair flattened for "European" (see Figure 4-20); and (iv) animal signs with two-handed symmetrical signs marking horns and/or ears (see Figure 4-34 i).

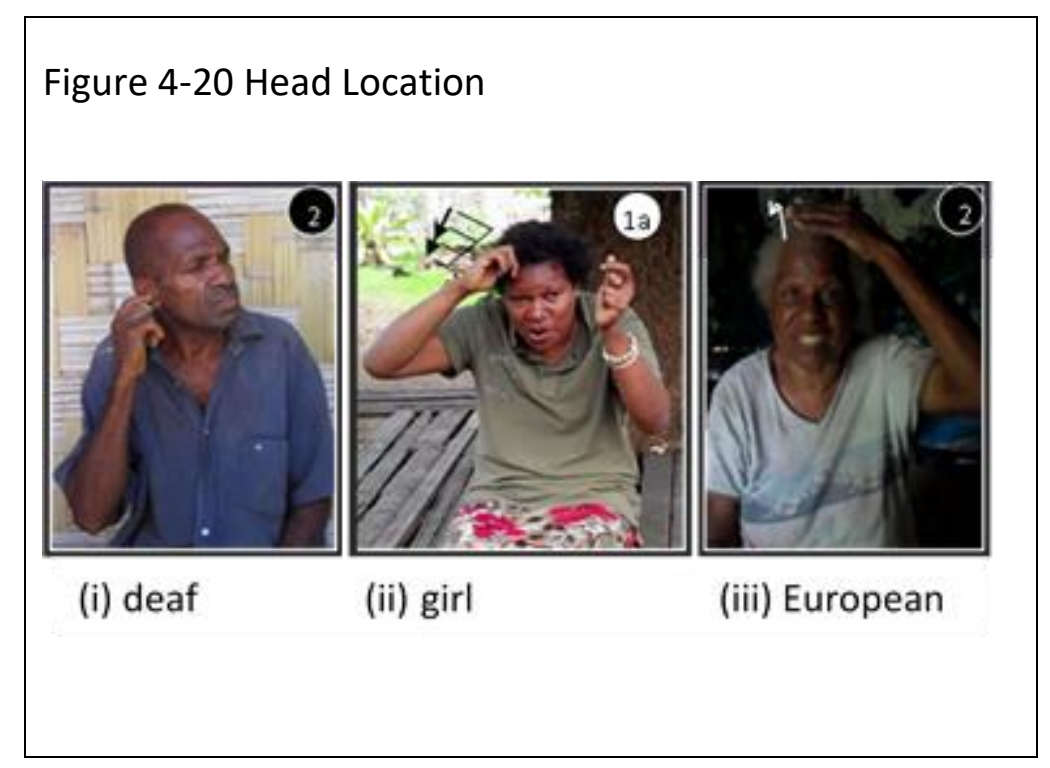

Wide location goes beyond Neutral when the arm is fully extended; it was used in $3.51 \%$ $(n=30)$ of signs by eight participants. For example, Édouard's "slingshot" with an extended arm. 
Arm location was use of the non-dominant arm as a base for the dominant hand, and it was used in $3.63 \%$ ( $n=31)$ of signs by eight participants. The Arm was used to represent either an arm, an animal or an inanimate object (see Figure 4-21). For example: (i) receiving an "intravenous line"; (ii) the "fish" caught by the hand; and (iii) a tree that the "green tree lizard" ascended.

Figure 4-21 Arm Location

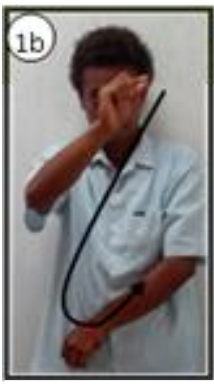

(i) an arm

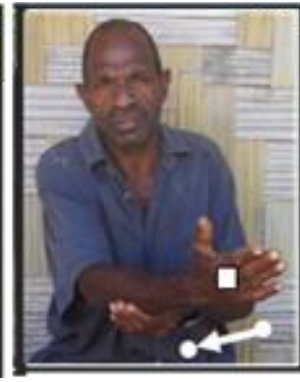

(ii) an animal

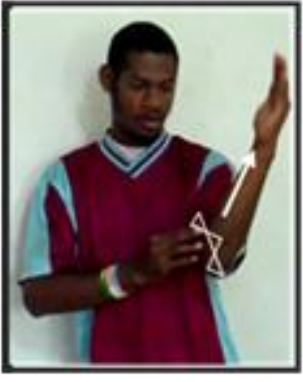

(iii) an inanimate object

Below location is below hip height, but not touching the legs, and is used in $3.40 \%(n=29)$ of signs by nine participants. Most instances depicted performing an action on objects below hip level, such as picking food grown at ground level, holding instruments or making items. For example: (i) "octopus"- depicts two sticks used to prod it from amongst rocks; (ii) "sago palm" - depicts roof sections constructed from sago leaves on the lap; and (iii) "flippers"depicts flippered feet swimming with arms hanging (see Figure 4-22).

Figure 4-22 Below Location

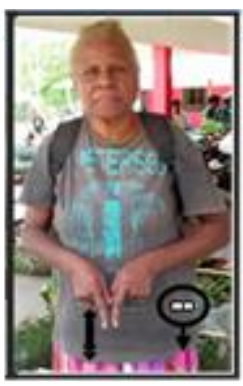

(i) octopus

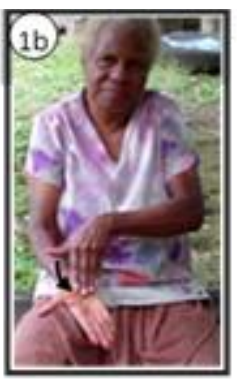

(ii) sago palm

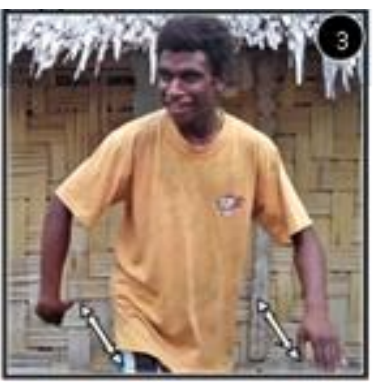

(iii) flippers 
Legs location is on the leg/s and used in $1.41 \%(n=12)$ of signs by seven participants. Most frequently Legs had constructed actions performed either on or around the leg/s. For example: (i) cricket thigh pads (see Figure 4-13 i); and (ii) weaving materials in the lap.

Back location is either behind the signer's jawline, or on the back of the body, and used in $0.47 \%(n=4)$ of signs by three participants. Behind was motivated by use of objects or space (see Figure 4-23). For example: (i) Paul depicted a "gecko" path on a wall behind his seated position (for convenience); (ii) Grace depicted "dead" in a whole-body enactment; and (iii) Serah located injections on the buttocks.

Figure 4-23 Back Location

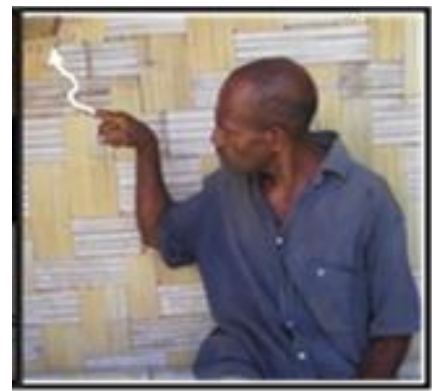

(i) convenience

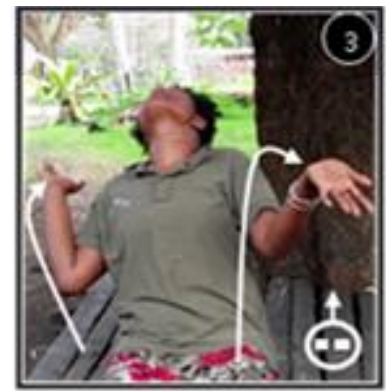

(ii) mimesis

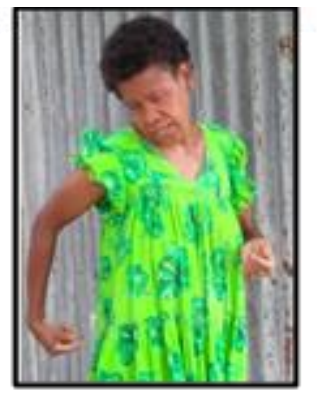

(iii) actual location

Head and Face location could occur in a manual sign with movement, but no instances were found.

\subsubsection{Location Variation Between Individuals}

Neutral and Head locations were used by all participants. Neutral occurred most frequently in individual lexicons, ranging from $38.46 \%$ of signs $(n=10)$ to $71.15 \%$ of signs $(n=37)$, whereas Head was infrequent, ranging from $1.92 \%$ of signs $(n=1)$ to $7.32 \%(n=3)$. Torso was the second most frequent location, but one participant did not use this location in the data. Two participants' location distributions are shown in Table 4-4. 
Table 4-4 Individual Lowest and Highest Location Distribution

\begin{tabular}{|l|l|l|l|}
\hline \multicolumn{2}{|l|}{ Hillary's Location (x5) Distribution } & Serah's Location (x9) Distribution \\
\hline Neutral & $40.00 \%(n=6)$ & Neutral & $58.97 \%(n=69)$ \\
\hline Torso & $26.67 \%(n=4)$ & Face & $12.82 \%(n=15)$ \\
\hline Below & $20.00 \%(n=3)$ & Torso & $11.11 \%(n=13)$ \\
\hline Head & $6.67 \%(n=1)$ & Wide & $5.13 \%(n=6)$ \\
\hline Above & $6.67 \%(n=1)$ & Head & $4.27 \%(n=5)$ \\
\hline & & Arm & $3.42 \%(n=4)$ \\
\hline & & Above & $2.56 \%(n=3)$ \\
\hline & & Legs & $0.85 \%(n=1)$ \\
\hline & & Below & $0.85 \%(n=1)$ \\
\hline
\end{tabular}

Of a possible 11 locations, the maximum number used by any single participant was nine and the minimum was five.

\subsubsection{Movement}

Movements in signs almost invariably mimicked real-world properties of the referent, such as an animate being's actions, handling or appearance of objects (such as in the harvesting process, food preparation), or outlining an object's shape/exterior (such as the sea, or animals). However, other types of finger movements were also observed: internal movement (opening and/or shutting); an internal movement combined with another movement; and finger wriggling.

\subsubsection{Internal Movements}

Internal movements were used in $2.08 \%(n=17)$ of signs by eight participants. These movements depicted either internal movements of an agent's hand performing a real action, or something external from themselves, such as an animal's body part, an element (water, fire), or an object's movements (see Figure 4-24). For example: (i) Yonathon's "passport" sequence contained a two-handed outlined camera shape, whilst one finger clicked the camera shutter to signify the passport photo; (ii) Renjo's "whale" used internal flexing of the fingers to depict water spouting from the blowhole. 
Figure 4-24 Internal Finger Movements

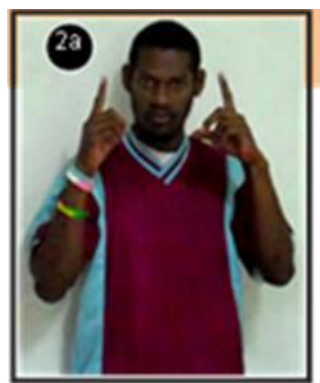

(i) hand action - click

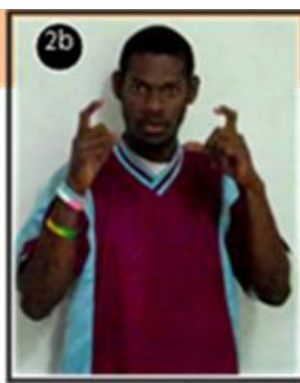

(ii) element - flex

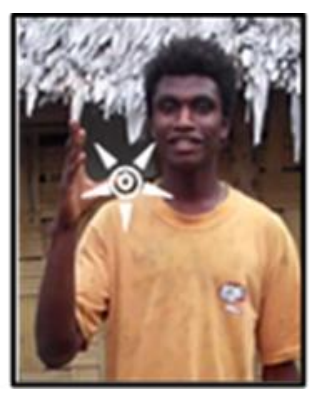

Three participants combined internal finger movements with a secondary whole hand movement (path) (see Figure 4-25). For example: (i) Edna's "boat moving" depicted a onehanded flat handshape alternately bent, moving in a forward path; (ii) Serah's "coconut milk" depicted hands squeezing (the coconut fibre) whilst moving across an imaginary laplap (a local food); and (iii) Paul's "crab" depicted claws, by both hands opening and shutting the fingertips to the thumbs, whilst moving the formation downwards. In almost all cases, movement is mimetic.

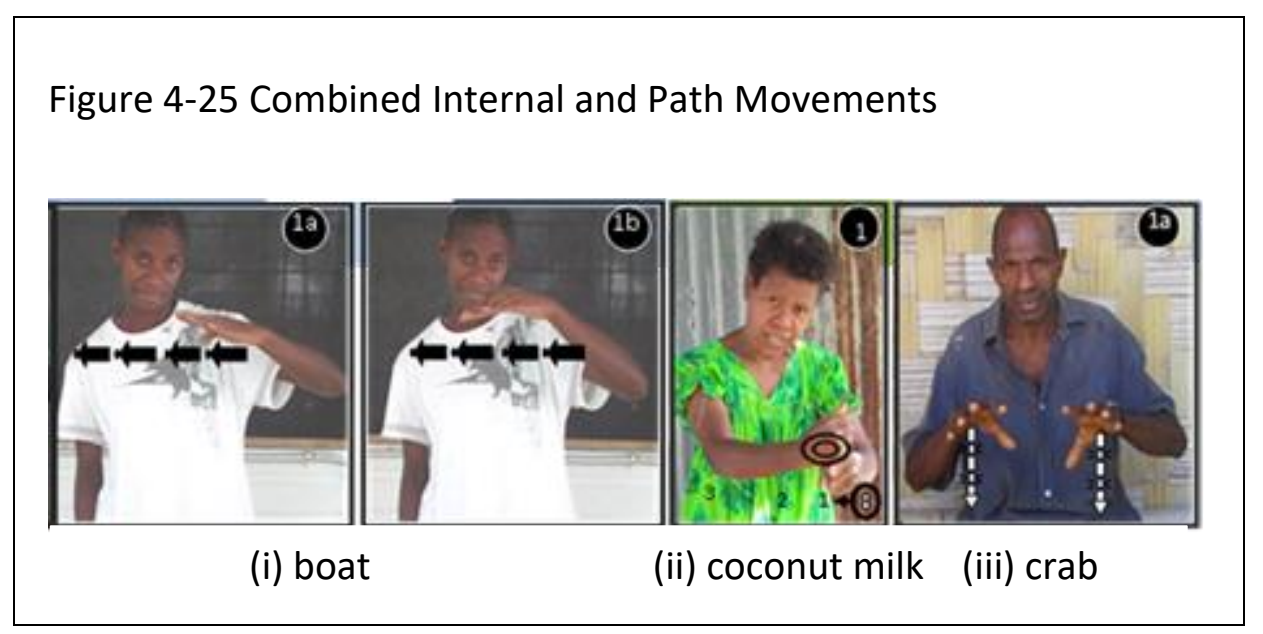

Wriggling was slightly less frequently used than internal movements, present in $1.84 \%$ $(n=16)$ of signs used by six participants, who had prior foreign sign language contact (two signs appeared foreign). Generally, wriggling depicted either: (i) leg movements, such as "spider" running; (ii) different animal body parts (i.e., not legs), such as "snail" tentacles; 
and (iii) in one instance an inanimate movement - "pandanus leaves falling down" with a secondary downward movement (see Figure 4-26).

Figure 4-26 Wriggling Movements

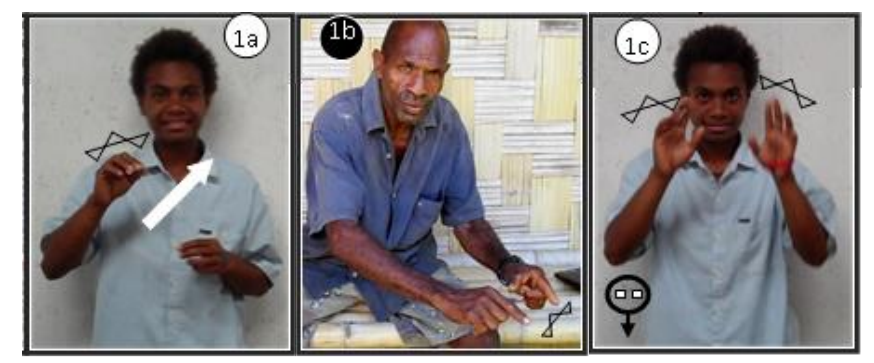
(i) legs
(ii) tentacles
(iii) leaves

\subsubsection{Differing Movements in Two-Handed Signs}

Two instances occurred of signs with symmetrical handshapes but different movements on each hand; these were two forms for "pumpkin", where the dominant hand performed blade actions, whilst the non-dominant hand rotated. These signs depict peeling a pumpkin with a bush knife (see Figure 4-27).

Figure 4-27 Differing Simultaneous Hand Movements

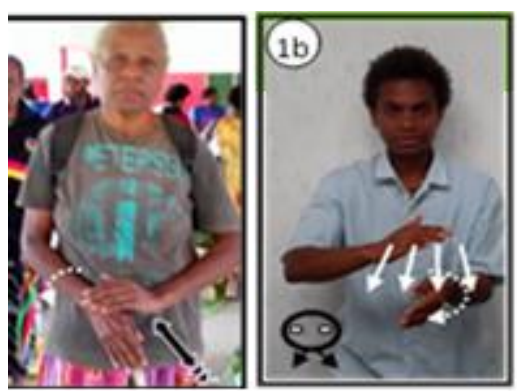

(i) peeling pumpkin

The precision of handshapes and movements as stable parameters of signs is difficult to ascertain in participants whom I visited once and/or had limited data collected, however, the fact their signs are highly iconic supports consistency. I met with two participants several times, and after comparison of their individual data concluded they were generally consistent in their respective sign production, albeit repetitions slightly vary. However, 
overall, insufficient data is available to determine whether all participants had precision or stability in handshape and movement elements of their signs.

\subsection{Signed Sequences}

Signed sequences, where several signs described one item or meaning, were generally prompted by stimulus materials rather than discourse. Sequences tended to describe the object first, then additional information, which may indicate rudimentary compounds (see section 4.8). For example, participants were often consistent in identifying distinctive features first: (i) gender was defined by either facial hair, breasts or hairstyle and then sometimes a height specifier added; (ii) animals were identified by tusks, horns or ears, then some participants depicted how the animal walked or flew; (iii) edible items were often depicted by SASSs, then descriptions of how the item was processed by picking, cutting or peeling, then possibly eaten. Across the data, $66.64 \%$ of total meanings were expressed by a single sign by all participants (see Figure 4-28). Only $10.53 \%$ of meanings were expressed using two signs by all participants, and $2.60 \%$ of meanings were expressed using three or more signs by eight participants.

Figure 4-28 Number of Signs per Meaning Average

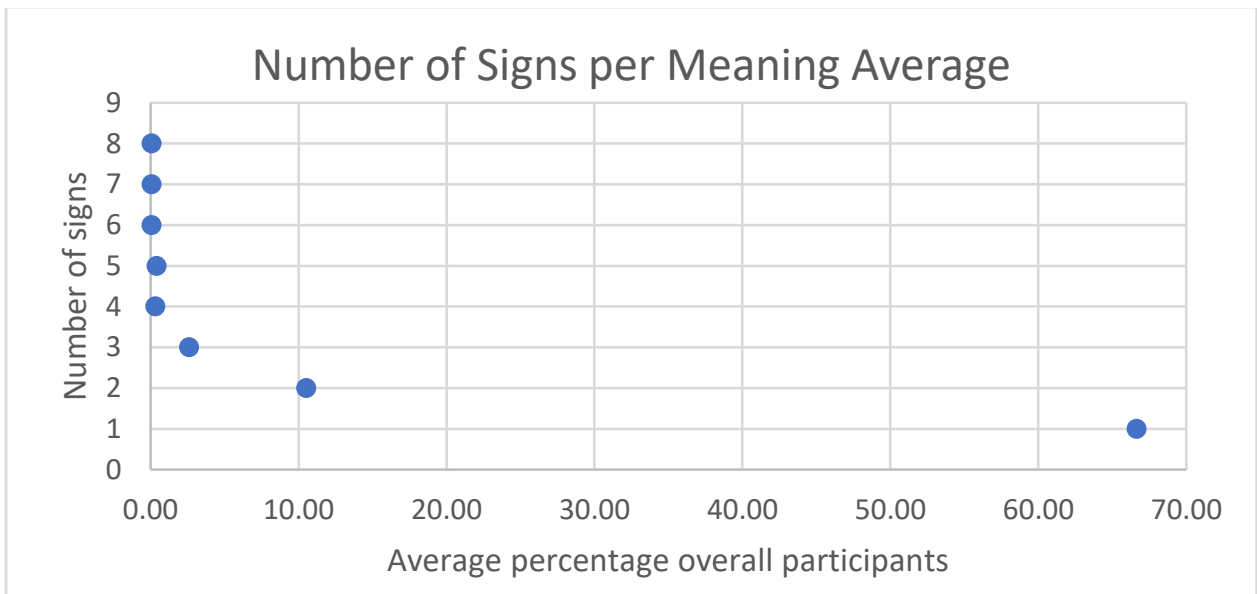

The few exceptionally long sequences were mimetic, describing the preparation of raw materials.

\subsection{Depicting Strategies}

Depicting strategies were evident in $75.62 \%(n=645)$ of total signs $(n=854)$. Categorisation of depicting signs resulted in six types, initially based on Padden et al. (2013) (see section 2.1.2), however, later "constructed actions", "body part - animal", "entity" and "element" 
forms were added. Strategies for depiction are presented in order of descending frequency in Figure 4-29.

Figure 4-29 Depicting Sign Type Strategies and Usage

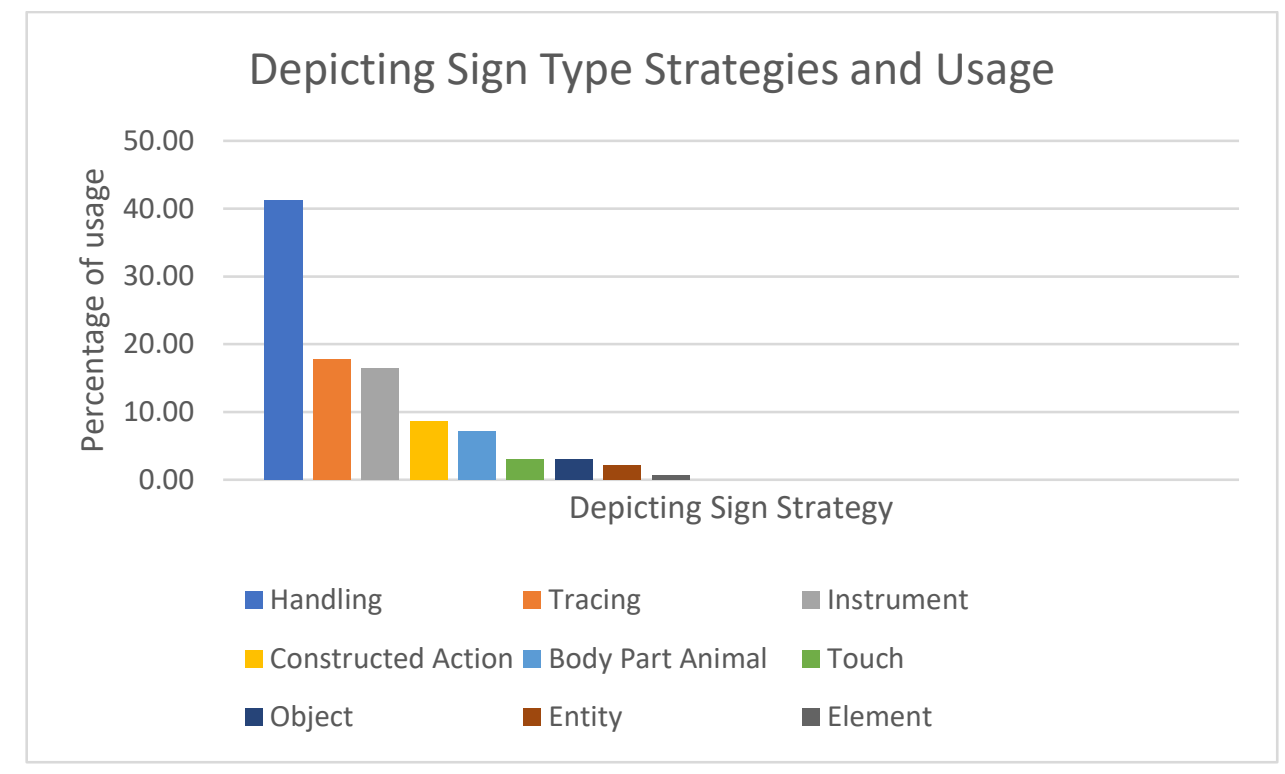

Handling strategy, representing grasping and/or using an object through mimetic movements was most frequent, used in $40.93 \%(n=264)$ of signs by all participants. Handling was the preferred strategy for inanimate objects but occurred minimally for animate objects. For example: (i) "green coconut" - different sequences related to opening and drinking the contents; (ii) "apple" - picking by hand; (iii) "rice" - washing by rubbing the palms together; (iv) "bread" - kneading dough; (v) "market" - food being prepared then sold at the market; (vi) "crab" - handling a knife to kill it; (vii) "horse" - handling the reins to control it; and (viii) "fire" - holding pieces of husk to the mouth to blow upon sparks (see Figure 4-30). 


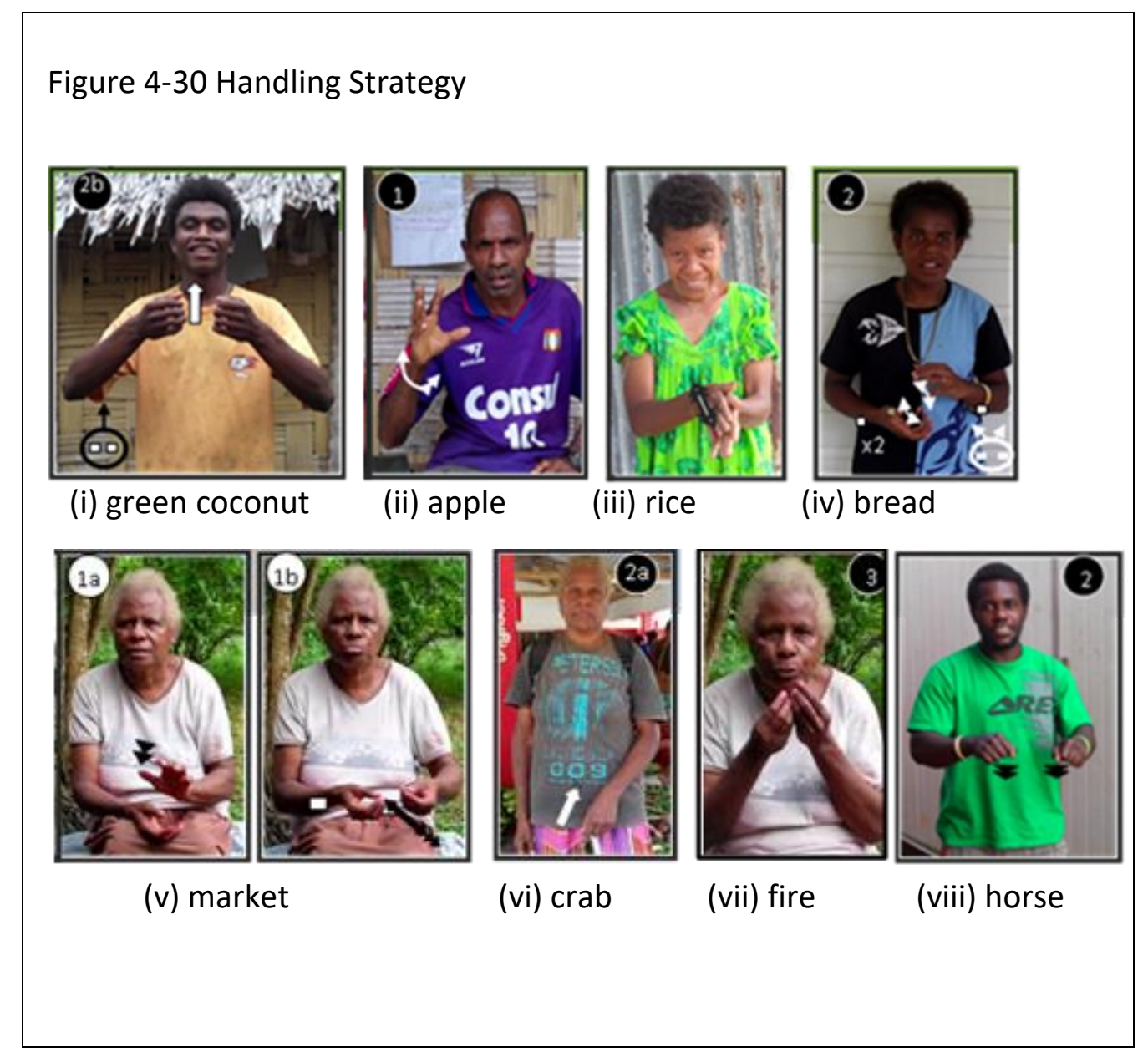

Depictions of picking food used handshapes motivated by the object's size and shape, and locations represented the height at which it grows (although signed at hip level or above, remaining within the signing space). For example, "beans" are picked at head height, in contrast to ground level food items that are signed at hip height - "watercress", and "manioc", which is depicted as being tugged from the ground (see Figure 4-31).

Figure 4-31 Handling Strategy - food collection
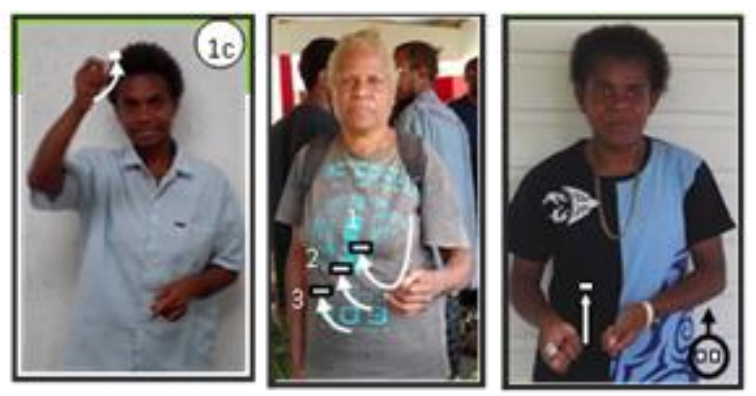

(i) picked high (ii) picked low (iii) tugged out 
Signs referring to "water" consistently used handling strategy, depicting how water is obtained (except for "bottled water" which used an object handshape) (see Figure 4-32).

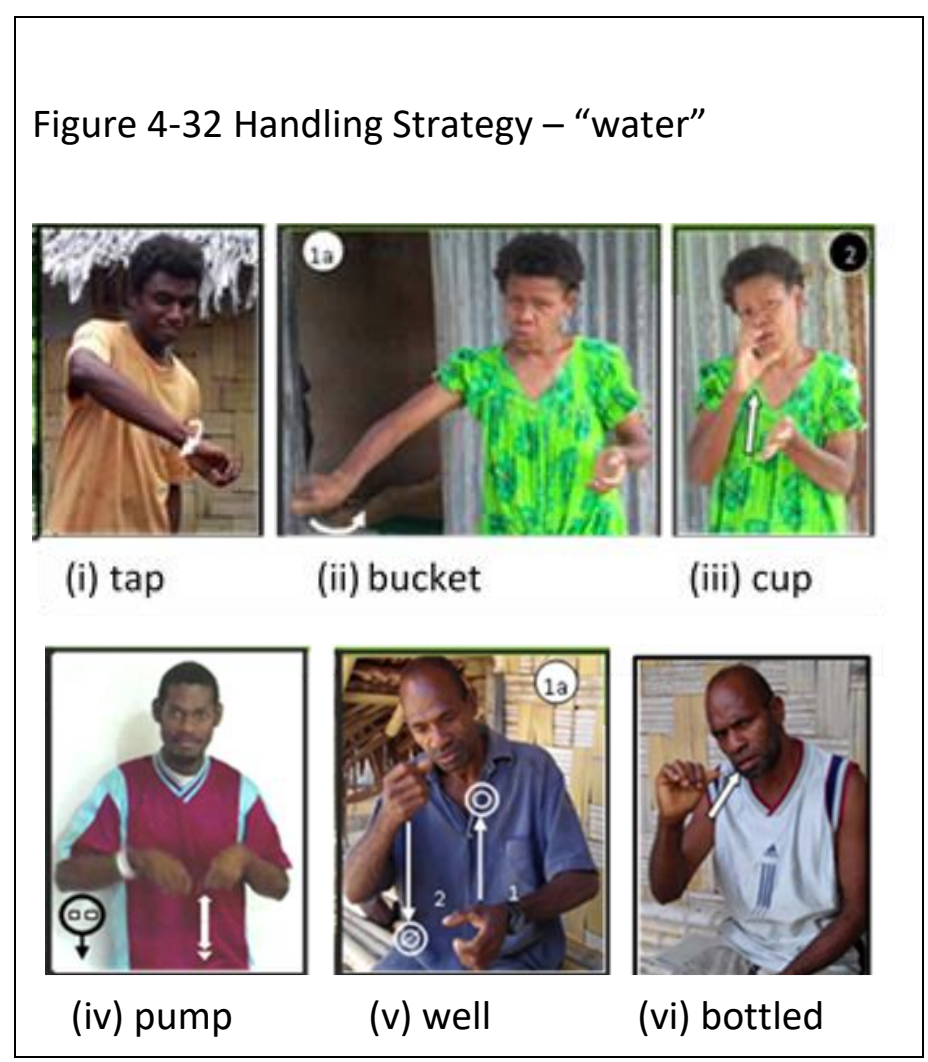

Tracing strategy, in which the object is outlined (i.e., a SASS), was second most frequent, used in $17.83 \%$ ( $n=115)$ of signs by 11 participants. For example: (i) animate - "dolphin" nose traced; (ii) inanimate - "statue" eyes and body patterns traced; (iii) plant - "laplap-leaf" positions traced onto imaginary ground; (iv) food - "egg" traced in circular outlines onto the palm; ( $v$ ) state of being - "pregnant" traced an enlarged belly protruding from their torso (see Figure 4-33). 
Figure 4-33 Tracing Strategy

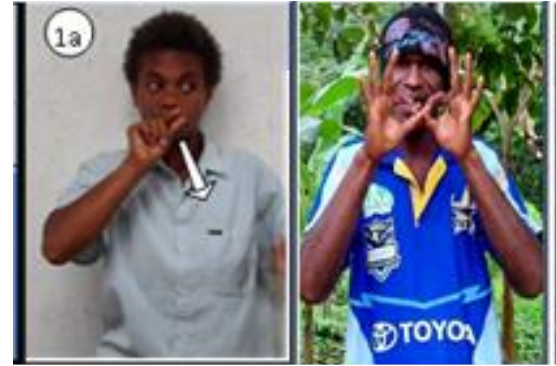

(i) dolphin

(ii) statue

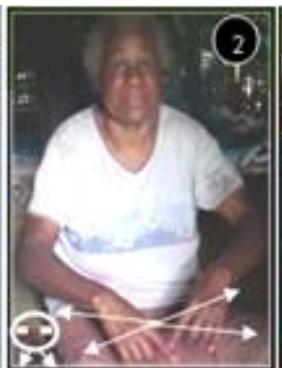

(iii) leaves

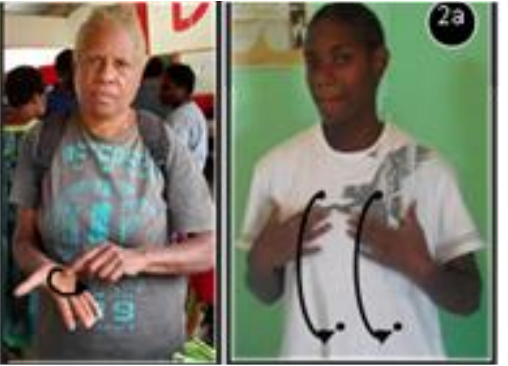

(iv) egg

(v) pregnant

Tracing strategy was also second most frequent for animal signs with $21.78 \%(n=22)$ of these motivated by protruding features. For example: (i) Lisa's "flying fox" - ears outlined on her head; and (ii) Yonathon's "kingfisher" - an outlined long beak from his face, then its flight path traced (see Figure 4-34).

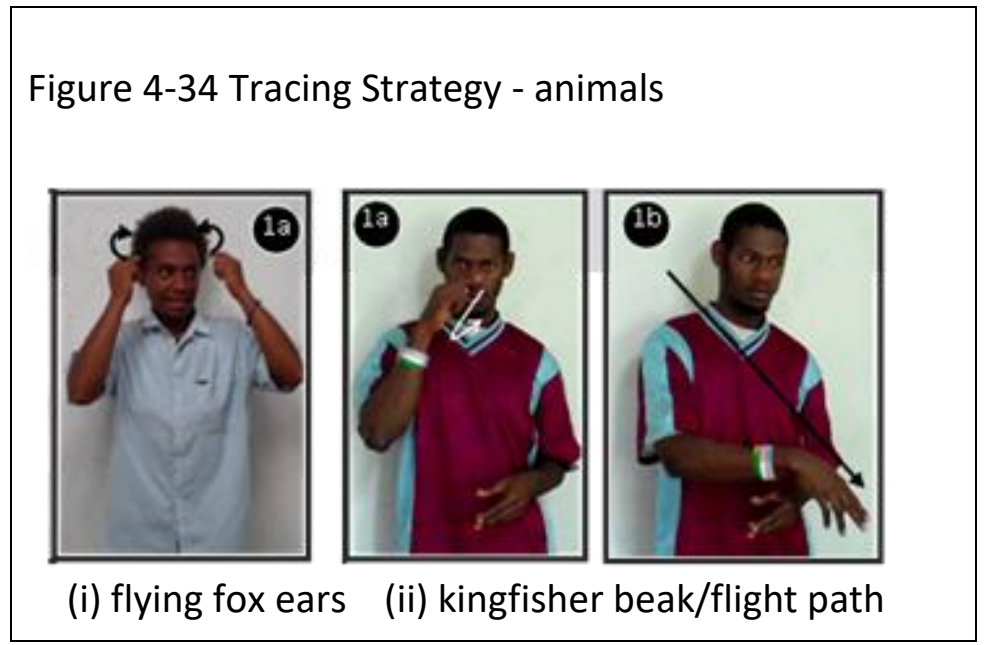

Instrument strategy, where the handshape represents an instrument's shape and is accompanied by a mimetic, repetitive action, was third most frequent, and used in $16.39 \%$ ( $n=107$ ) of signs by 11 participants. Instrument formations were either single signs for a large or small knife, within a sequence to identify a food item, or used singly for a food item (see Figure 4-35). For example: (i) "bush knife"- the full hand as the blade; and (ii) "apple"identified by a picking instrument used at tree height. One participant used both instrument and handling strategies to depict knives. 
Figure 4-35 Instrument Strategy - knives

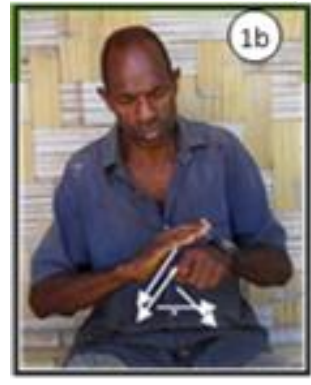

(i) bush knife

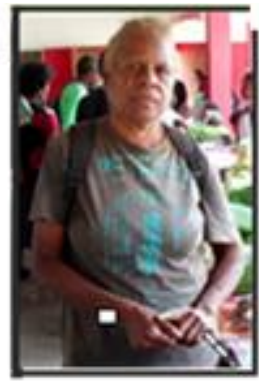

(ii) small knife

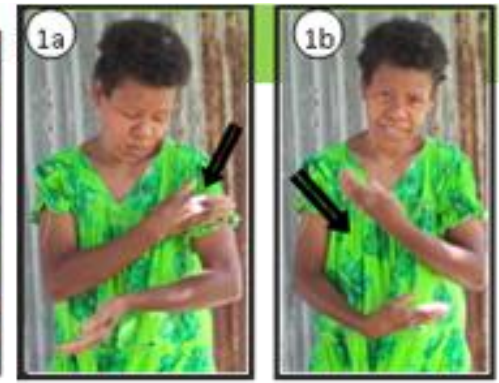

(iii) knife applied to the body

Constructed action strategy (mimetic enactment) was fifth most frequent depicting strategy, used in $8.68 \%$ ( $n=56$ ) of signs by 10 participants. For example: (i) "sleep" - with one or two hands placed on or near the cheek, like children sleeping on mats ( $n=4)$; (ii) "police"a salute ( $n=2$ ) (see Figure 4-13 iii). Signers used constructed action to depict different fishing methods (see Appendix D): (i) by spear; (ii) by line and gently jerking it, then a stronger upward action; and (iii) by spear-gun, holding the gun lengthwise, then pressing the trigger.

Body Part of an Animal was coded for signs when the hands represent a discrete part of an animal's body (moving or not moving), used in $7.13 \%(n=46)$ of all signs by nine participants. For example: (i) legs (e.g., crab, bullock); (ii) wings flying (e.g., flying fox, bird) (see Figure 4-36); (iii) sting or bite actions (e.g., hornet, mosquito, centipede); and (iv) horns or tusks (e.g., pig, goat) (see Figure 4-37).

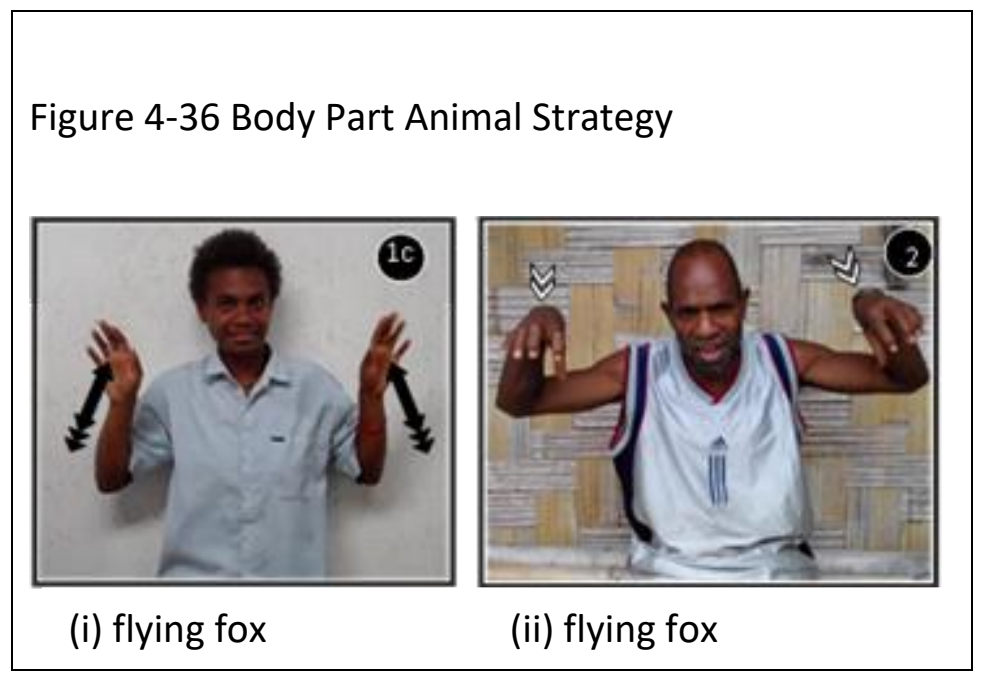


Figure 4-37 Variants for "pig"

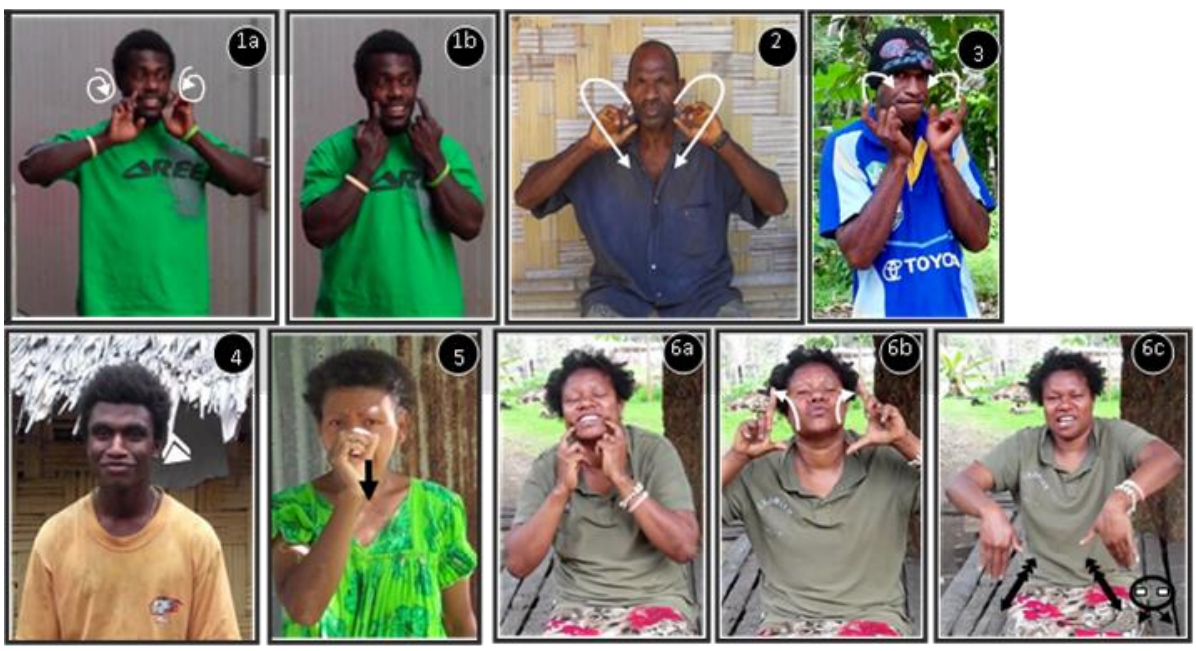

Touch strategy describes signs that touched the body to indicate a literal location, used in $3.10 \%(n=20)$ of signs by eight participants. However, I realised that some touching was metaphorical, and therefore likely conventional gestures. For example, "think" is a touching of the forehead, therefore metaphorically linked to the brain, but likely copied from other people.

Object strategy describes signs that represent a feature of an object's shape without an associated action, used in $3.10 \%(n=20)$ of signs by nine participants. For example, (see Figure 4-38): (i) "tree" - a stationary upright forearm and hand; (ii) "key" - a bent finger, to represent the shape and/or hanging up of a key. 
Figure 4-38 Object Strategy

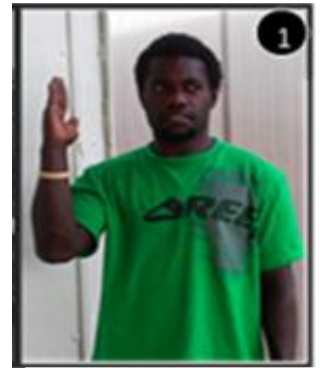

(i) tree

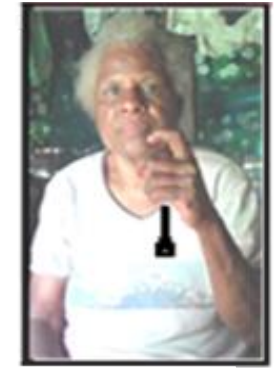

(ii) key

Entity is a depicting strategy that represents a whole human, animal or object entity, used in 2.02\% ( $n=13$ ) of signs by six participants. For example: (i) Serah's "person-go-come"; (ii) Lisa's "dolphin" diving through the sea; (iii) Paul's "ship" coming alongside a wharf; and (iv) John's "truck" negotiating winding roads (see Figure 4-39).

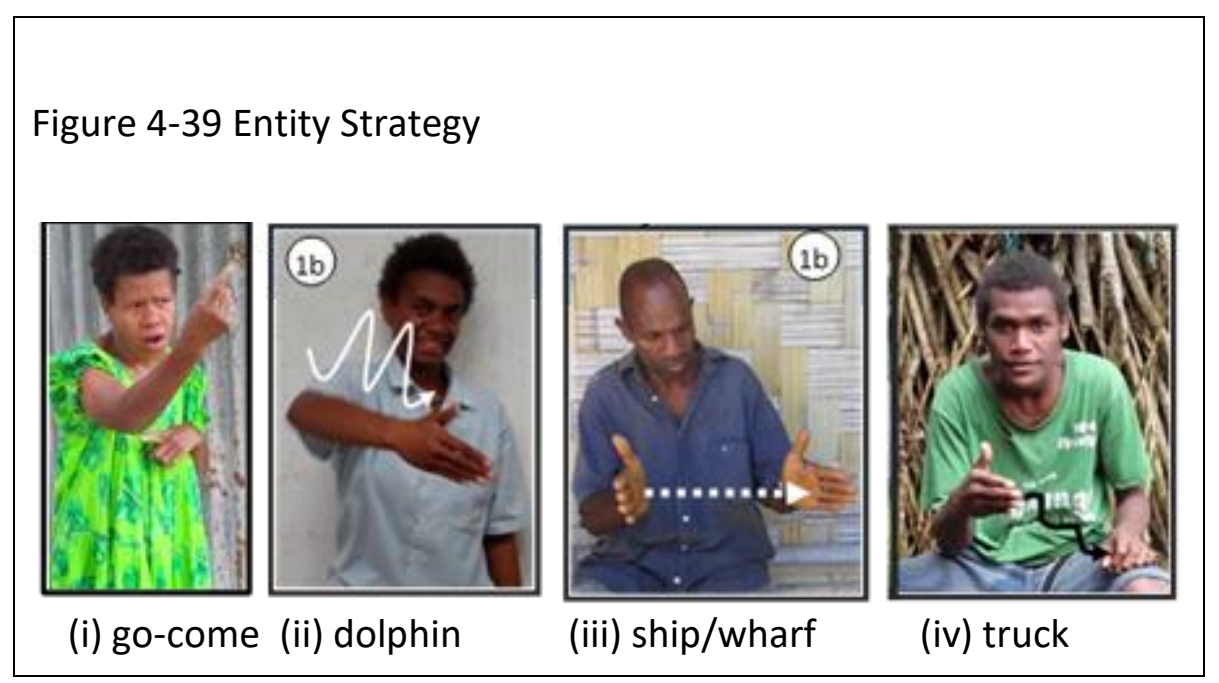

Element strategy depicts qualities of natural elements (e.g., fire, water), used in $0.62 \%(n=4)$ of signs by three participants. For example: (a) "fire" - hands move up and down slightly for flames; and (b) "whale" - hand depicts water exiting the blowhole (see Figure 4-40). 
Figure 4-40 Element Strategy

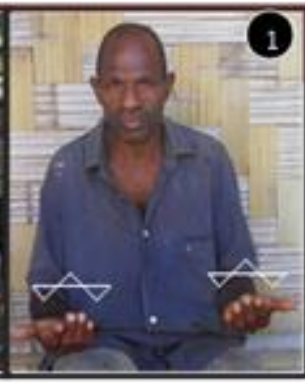

(i) fire

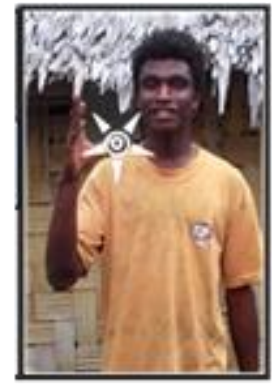

(ii) whale

\subsection{Noun-verb Distinctions ("Nouns")}

This section considers whether there is evidence to distinguish signs with noun-like or verblike properties in utterances. As previously noted, in established sign languages (see section 2.2.3), noun-verb differences are often marked by truncated and partially repeated movements for nouns, whereas verbs tend towards larger movements with more repetitions. Evidence of consistent distinctions between nominal from verbal reference were observed in some (if not all) participants, which will be described next.

\subsubsection{Representation of Objects ("Nouns")}

Overall, it was rarely possible to allocate a clear "noun" or "verb" status to signs, however, there were hints that some signers made distinctions. Signs produced in response to pictures of objects generally depicted handling or use of the object (i.e., were more verblike), the sequence of actions often had reduced movements that seemed more noun-like. For example: (i) "spring onion" - a single upward movement of being picked; and (ii) "octopus"- repeated, restrained movements showing sticks being used to force an octopus to leave its hole in the rocks, (which in reality likely takes more than two stabs to persuade it to leave). When wings were the visual motivation for a sign, such as Paul's "chicken" and "flying fox", there tended to be one short (noun-like) repetition of the movement. However, in a sequence final position, such as Lisa's "flying fox", flying was depicted with two or more repetitions suggesting a possible verb clause (Tkachman \& Sandler, 2013).

Some participants used reduced constructed actions to name things. For example, in response to a stimulus photo of a turtle swimming under the sea, Hillary used her hands to 
make small flipper movements close to the body, with a slight head movement, in a nounlike manner; in contrast, Lisa produced a full body enactment, giving a more literal portrayal of the turtle's swimming action (see Figure 4-41). As mentioned in Chapter 3, these different forms of representation may have reflected both differing lexical repertoires, and/or differing understandings of the elicitation task: to "describe" what was happening in the picture, or to identify the main object in the picture by "naming" it.

Figure 4-41 Constructive Action - "turtle"

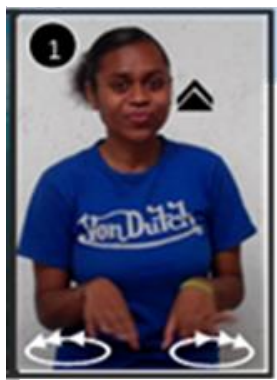

(i) restrained actions

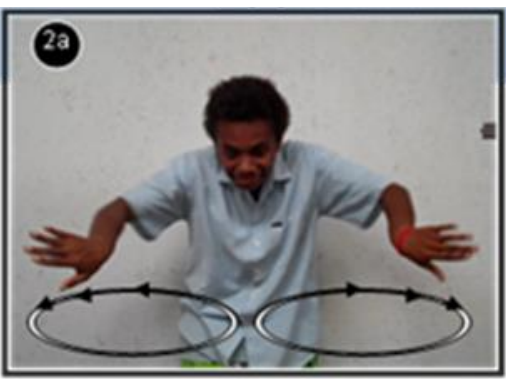

(ii) unrestrained actions

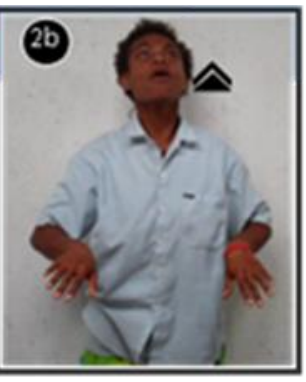

Another strategy observed for nominal reference was a type of depicting compound, used to categorise people. For example, "twirled hair" and "height" meant "girl", whereas "facial hair" and "height" meant "boy".

In several instances Grace used compound-like sequences for place names - first producing an iconic action associated with the place, then pointing to its location (see Figure 5-1 Line 1c). Similarly, Daisy repeated her combination of depicting signs "tuluk" and "pay" for "market" three times which demonstrated reduced repetitions and movements. However, with the limited data available it is unknown whether this form of noun distinction is consistent.

In sum, reference to objects assumed shared knowledge between interlocutors of visual features and/or associated actions that motivate the sign's form. Objects were often depicted with restrained movements, which could suggest a noun-like status, but further analysis is needed to confirm this. 


\subsubsection{Representation of Actions ("Verbs")}

I found little evidence that participants used lexicalised verbs. For example, variants of "eat" depicted forms that varied according to the food items' form and handling, (see Figure 4-42).

Figure 4-42 Variants for "eat"

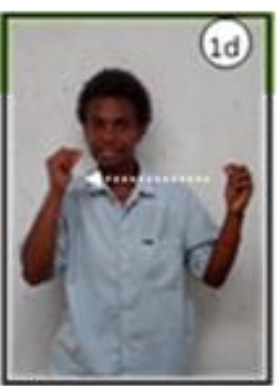

(iv) eat bean

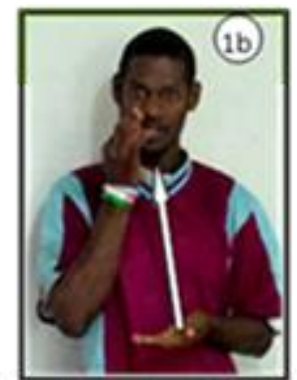

(v) eat tree lolly

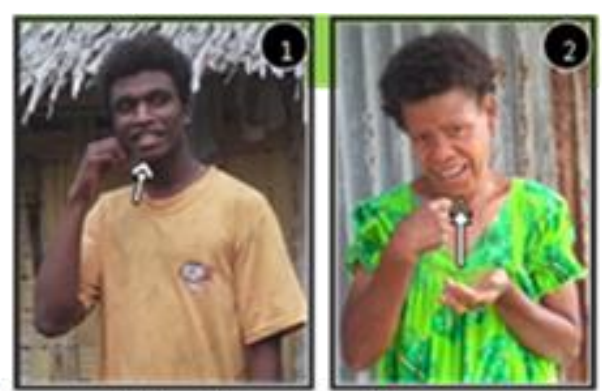

(vi) eat from a plate

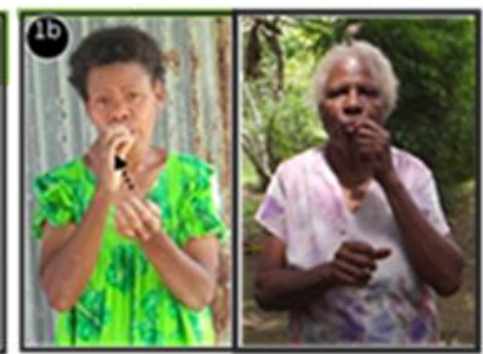

(ii) eat mango

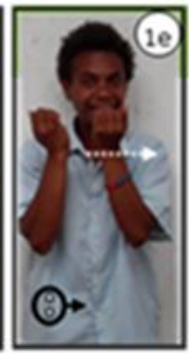

(iii) eat corn

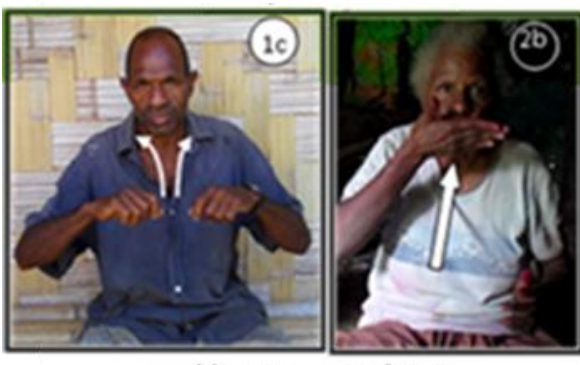

(i) eat grapefruit

Actions were usually expressed through a sequence of constructed action/mimesis (sometimes whole-body enactments), rather than discrete signs per se. For example: (i) "walk" or "swim"- Edna's hands alternated movements appropriately and her torso moved accordingly, whilst for "football" she fully enacted arm and leg movements in kicking the ball; (ii) bathing is usually performed by scooping water from a bucket to throw over oneself, and accordingly Edna and Serah's mimesis is rubbing their hair, then face and torso in a truncated manner, whereas Paul used a less elaborate form depicting quickly throwing water at the face, which perhaps functioned more like a "verb" in his lexicon; (iii) Hillary expressed "to get hurt" with a constructed action sequence of punching her non-dominant hand, then adopting the role of recipient of the punch by cringing defensively with a pained expression (see Figure 4-43 iii). It is difficult to say if any of these depictions of actions have grammatical status as verbs. 


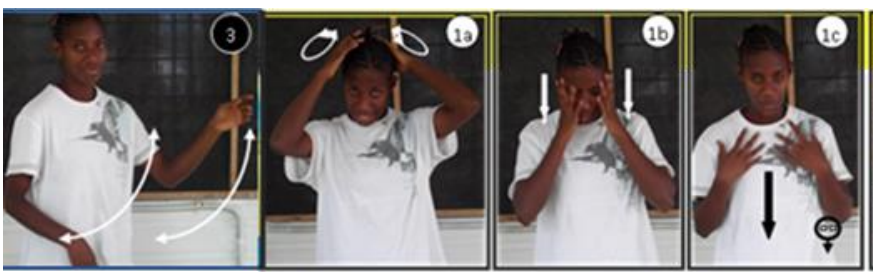

(i) walking

(ii) bathe

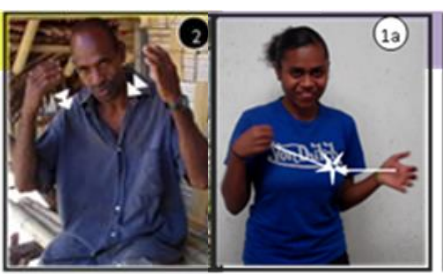

(iii) hurt

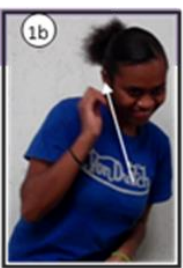

A few examples of possible noun-verb distinctions occurred in the data. Firstly, Grace produced three references to "plane" and "plane-flying", using whole body enactment, holding her slightly bent arms out from her body. The first instance had stationary arms and hands, whereas the other two instances used the same formation, but her hands flapped twice, suggesting the action of flying (bird-like rather than the action of plane wings). The first appears noun-like and the latter verb-like. Secondly, Paul produced the same wholearm formation for "plane" although his arms alternately dipped slightly, suggesting the motion of a plane, however having established this as a referent, he then switched to a onehanded entity form with a horizontal flat handshape to depict the plane flying downwards to land. This (pro)form combines (pro)noun and verb properties, similar to the use of entity classifiers in conventional sign languages.

In sum, preliminary observations suggest that objects and actions are expressed in a wide variety of ways. Distinctions between the form of noun and verb signs may exist for some concepts in the vocabulary of some individuals, but further analysis (and more controlled data) would be required to show whether these distinctions are patterned.

\subsection{Summary of Observations About Lexicon}

Analysis of form and meaning of signs indicates that participants' individual lexicons are restricted in size and conceptual range, and that forms of expression are more idiosyncratic than shared or conventionalised, in conditions of scarce contact between deaf individuals. Signs that exhibited a degree of shared form across participants and/or islands appeared to be similarly visually motivated by the referent or conventional gestures rather than through 
contact and dissemination. Although foreign signs have been introduced to some deaf adults, their relative isolation has prevented dispersal.

A large proportion of meaning is expressed through mimesis and gestural components, pointing signs, depicting signs and some conventional gestures. Moreover, interlocutors require shared contextual knowledge of referents (objects, activities, people, locations) to decode the meaning of most signs due to their visually motivated and deictic character. Furthermore, few abstract concepts were identified in the data.

Regarding the form of signs, most were produced in locations that conform to the parameters of village sign languages (i.e., a larger, more flexible signing space than that of established urban sign languages). Locations often held iconic/deictic relevance, and apart from Neutral and Head locations that were used by all participants, individuals range of locations for signs varied. Participants used two-handed formations twice as frequently as one-handed formations. Of two-handed formations, the prevalent form was symmetrical handshapes with symmetrical movements. Whole body enactments were used infrequently overall.

Analysis of the "sub-lexical" parameters of signs shows that handshapes were loosely formed and appeared less important to meaning than movement. Both marked and unmarked handshapes were used, with 22 different handshapes identified. Unmarked handshapes were most common. Additionally, most movements were iconic (mimesis) of the referent's real-world movement properties. Signs contained few internal movements, and even fewer combined simultaneously with path movement. Furthermore, wriggling movements were used only by signers exposed to foreign sign languages, although this may be coincidental, and predominantly depicted the actions of animate entities.

Precision or stability of handshapes and movements was difficult to ascertain since there was little opportunity to observe repeated use of the same item; many responses to stimulus (either pictures or referents visible in the context) appeared to be an improvised depiction (involving an extended sequence of gestures), rather than a regularly used form to symbolise the meaning. However, a few participants showed consistency of sign production over several occasions, suggesting that these individuals had more signs that were lexicalised in their personal repertoire. In these cases, consistency of sign form seemed to 
be associated with individuals' opportunity to communicate regularly with an interlocutor, such as a hearing child or sibling who shared their communication system.

The data shows possible evidence of formal distinctions between signs that express nominal reference and those that express actions, although this is not consistent. Truncated nounlike movements and compounding strategies were used by some participants. Objects are often referred to by sequences that depict actions associated with their use (e.g., the preparation of a food item), their actions (if animate), or depict a visual characteristic such as shape, size or salient feature (such as breasts for females). "Verb-like" signs tend to be expressed by mimesis or constructed action, including whole body actions.

The next chapter describes the social context and language profile of three selected participants and presents some analytical observations about features of their discourse. 


\section{Discourse Features of Three Participants}

Systematic analysis of the syntactic or discourse characteristics of utterances across all participants is beyond the scope of this thesis, which focuses chiefly on describing their lexicon. Nonetheless some features of their language use are explored here. This section purposefully samples and reports some preliminary observations on the discourse characteristics of three participants: Grace, Paul and Serah. They were chosen for their diversity in circumstances and gender. Ethnographic sketches introduce their respective circumstances, followed by comments on their response to the elicitation process and features of their use of signs in spontaneous discourse. A comparison of their capacity to relate information about their lives reveals similarities and differences in their vocabularies and discourse organisation.

\subsection{Grace's Ethnographic Sketch}

We encountered a woman when out walking in a remoter part of the village, near the beach, one Saturday. She was collecting firewood, solitary in her work. We waved, and she approached us. She made unusual noises and gestured; I reasoned she was likely deaf. It was difficult to estimate her age due to her damaged eye, and dirty, torn clothing. She appeared pleased that I tried to talk with my hands. She pointed back at the path we came down and towards the sea, several times. We waved goodbye and left. I looked for her every day when walking my circuit of the village.

Months later, I saw her outside the Co-op store between the market and the Provincial Offices. She was wearing the same clothes. She pointed up and down the hill and waved good bye.

Months later, again, a woman working up at the Provincial Offices offered to introduce me to the family of a deaf woman who was said to sign. After several follow up visits and delays, permission was finally granted to meet her father. We walked down the road that I had walked down almost daily since arriving. We entered a small village, shaped like a large compound behind the trees, just off the only road. The buildings were typical bamboo and natanggura rooved dwellings. I was taken near to one house, and introduced to an elderly man, and his wife. After a polite interrogation he reluctantly gave permission for me to meet with Grace. It was all very uncomfortable. Discussion about whether her deafness was from birth or acquired through illness left the matter unresolved. Grace was fetched, and I 
recognised her from the beach and the Co-op; she wore the same clothes. This time Grace was reluctant to sign to me, as extended family watched us. Her brother suggested I come back the next week, so we arranged this.

As I walked into their compound again, through another entry point, there was little grass to be seen, but a bamboo platform encased the trunk of a large tree. Hungry looking dogs came closer to check me out. I attracted a posse of children in various states of dress, preschoolers carrying babies. They watched us working when Grace and her brother Frank arrived. Grace had a new second-hand outfit on, her shirt inside out. Frank expected Grace and I to understand and communicate with each other directly - because we both signed. Frank tried to explain to Grace that I wanted to film her signing - this took time. I was moved at his gentleness and patience with her. Frank spoke Bislama and then spoke with gestures, but when this was not effective in communicating our intention to Grace, he resorted to miming a version of my request. Eventually, Grace sat on the bamboo platform, and responded to Frank's promptings.

Grace listed her siblings, four brothers and a sister, using defining features to "name" them, such as a stomach scar, and her sister as fat, with smooth hair. Grace counted siblings first on her fingers and then on her toes - this included their children. She mentioned mama and a leg amputation. Grace has no husband but tells me her babies are buried there. (Frank translates, "Two boys and two girls.") This is important to her, as she gets up to physically make me turn and look towards their graves. I look, and she again indicates the hospital and her babies dying there.

Eventually the topic changed from past trauma to her sister's wedding the day before. She indicated that one brother went in a plane above us, heading south (to Port Vila). There was dancing, then guitar music and they dressed in their best clothes. She described pigs by their tusks, running. It rained as they paddled in a canoe and bailed water out - the sun was crying, she said. They went to church and there were long speeches. I think she is telling us about praying to God in the sky and that Mama's dead now, after a leg amputation, which happened over the hills there. She describes the coffin. Frank translates - her mama's father (grandfather) is dead now and their mama lives elsewhere. It is evident much shared contextual knowledge is essential for comprehension of Grace's signs. They have this shared 
knowledge; I do not. But it is apparent that the traumatic events of her life are recurrent throughout her story and appear unresolved in her heart and mind.

\subsubsection{Grace's Elicitation Process}

Grace's multilingual brother, Frank, mediated for me, standing to my right. I could not see him at the same time as we faced Grace who was seated. From the periphery I saw Frank simultaneously gesture and speak to her. Some of his gestural signs were caught on camera and showed similarity to Grace's basic signs, although "mama” was different. Frank's gestures were inadequate to convey my request, so he enacted this. Grace sat down, seemingly familiar with being instructed, and copied his raised hand gesture. I asked via Frank how many brothers Grace had and after a small delay she signed four which was accurate. Occasionally, Frank gave the gist or background to Grace's utterances; generally, they lacked the capacity for specific questions or detailed discourse.

\subsubsection{Grace's Discourse Features}

Grace was the only participant who consistently produced vocal noises with signs; from my observations I think Frank took topic clues from her pointing rather than from vocal sounds. Grace's 12-minute discourse contained approximately 295 signs (tokens) with 37 types that had consistent form-meaning; some were used multiple times (e.g., individuals' name signs = 11; $\mathrm{HEIGHT}$ (of person) =20; MAN =11), either relevantly or repetitively. During the transcription process (i.e., assigning meaning to her signs), meaning was reasonably clear after considering visual motivation and/or her brother's comments. Grace's discourse lacked cohesive structure and seemed to mostly consist of fragments rather than a series of connected idea units (except for one passage) (see Figure 5-1). Also, her references (to place, person, events) were opaque to me without prior knowledge of the contextual references, some of which Frank supplied. Basic concepts were expressed without a timeframe that I could discern. For example, Grace's wedding description lacks chronological or narrative order, perhaps reflecting that she only identified aspects that were visually salient to her, such as guitars, pigs running around, and dancing, rather than preparations.

Grace paused between utterances in two ways. Either by simply lowering her hands, or by holding counting signs (e.g., "first" and "fifth") whilst she looked around, distracted or thinking. This pause type was repeatedly interspersed (randomly) in one lengthy passage (75 
signs) (see Figure 5-1 Line 1d), where Grace pointed to her fingers (and toes) as a listing device (not always systematically), which created a measure of cohesion in recounting extended family members.

Reference to specific persons was difficult. Grace repeatedly used what appeared to be a personal name sign, a compound of HAIR-SMOOTHED and FAT (see Figure 5-1 Line 1d), but it was unclear whether she was referring to: (i) her sister; or (ii) her sister's female children; (iii) her sister's adult female children: or (iv) all of these. Elsewhere, Grace used HAIRTWIRLING with HEIGHT-short to mean "girl", and it was unclear (to me) who the referent was, without knowing individuals' gender, age or height.

Figure 5-1 Discourse Transcription Sample - Grace

\begin{tabular}{|c|c|c|c|}
\hline GLOSSING KEY & $\begin{array}{l}\text { CAPS = gloss for sign; } \\
\text { lower-case = } \\
\text { description of } \\
\text { meaning; } \\
\text { (lower case) = } \\
\text { approximation of } \\
\text { likely meaning; }\end{array}$ & $\begin{array}{l}\text { PT = pointing } \\
\text { PT-lowercase = } \\
\text { pointing to a location } \\
\text { (usually identified by } \\
\text { clozure); }\end{array}$ & $\begin{array}{l}/ / \text { = pause; } \\
\text { SIGN, = a pause or } \\
\text { lengthening of the } \\
\text { sign; } \\
+ \text { = sign repetition; } \\
\text { SIGN^SIGN = } \\
\text { compound } \\
\text { "SMALL CAPS" = gesture } \\
\text { /FIII/ = mouthing }\end{array}$ \\
\hline Participant & \multicolumn{3}{|c|}{ Transcriptions, Translation or Transliteration } \\
\hline Grace 1a: & \multicolumn{3}{|c|}{$\begin{array}{l}\text { //BABY PT-grave BABY PT-grave BURY BABY BURY PT-grave// BABY PT- } \\
\text { grave// }\end{array}$} \\
\hline Translation 1a: & \multicolumn{3}{|c|}{$\begin{array}{l}\text { (My) baby - there (in the grave), (I) buried baby, there baby buried } \\
\text { there (in the grave). }\end{array}$} \\
\hline Grace 1b: & \multicolumn{3}{|c|}{ // “WAITING" BURY+ // BURY PT-grave BURY BABY SMALL// } \\
\hline Translation 1b: & \multicolumn{3}{|c|}{ (After a time) buried. (I) buried in the grave there (my) small baby. } \\
\hline
\end{tabular}




\begin{tabular}{|l|l|}
\hline \multicolumn{2}{|l|}{ Figure 5-1 Transcription Sample - Grace (continued) } \\
\hline Grace 1c: & $\begin{array}{l}\text { //INJECTION PT-hospital INJECTION PT-hospital INJECTION FIVE } \\
\text { INJECTION FIVE INJECTION DEAD PT-hospital// }\end{array}$ \\
\hline Translation 1c: & $\begin{array}{l}\text { (Baby had) an injection there (at the hospital), an injection there (at } \\
\text { the hospital), five injections, then dead there (at the hospital). }\end{array}$ \\
\hline Grace 1d: & $\begin{array}{l}\text { // FIRST, AMPUTATION-mid-thigh+++ FIRST AMPUTATION-mid-thigh } \\
\text { MAMA SECOND MAN HEIGHT-higher-than-head SECOND HEIGHT- } \\
\text { higher-than-head SECOND HEIGHT-nose-level MAN THIRD HAIR- } \\
\text { SMOOTHED^FAT+ THIRD FAT^HAIR-SMOOTHED FOURTH ... }\end{array}$ \\
\hline $\begin{array}{l}\text { Transliteration } \\
\text { 1d: }\end{array}$ & $\begin{array}{l}\text { First, leg amputation, first, leg amputation mama, second, man adult, } \\
\text { second, adult, shorter man, third, sister, sister, third, sister, fourth ... }\end{array}$ \\
\hline
\end{tabular}

Grace's pointing and eye gaze were consistently aligned. Deixis accounted for $21.69 \%(n=64)$ of her signs, and of these, $92.18 \%(n=59)$ referenced real-world directions, usually performed ipsilaterally (i.e., using the arm located closest to the real-world reference) (see Figure 5-1 Lines 1a, 1b and 1c). Real-world referents for deixis were identified either by Frank's interpretation at the time, or later by extrapolating from my knowledge of the discourse context. For example, Frank identified the location of hospital (the place her babies died), the plane's flight path towards Port Vila (where one brother lived), and I knew the direction of the market, Litzlitz and the village over the hills, when she pointed accordingly. Some pointing accompanied name signs when repetitively pointing at a brother's hut, which may have been intended to identify the person, rather than the place. In contrast, only $7.81 \%(n=5)$ of pointing signs were discourse references, and these were where Grace pointed metaphorically to God directly above and then signed PRAY. However, this metaphorical deixis was likely copied from family, rather than self-generated, in contrast to her deixis which referenced real-world locations. Grace pointed to another part of the sky for the "sun" and signed CRY RAIN repeatedly, and to the hospital several times, a place of significant events. Also, Grace stretched her whole body to varying levels to convey a place's distance; for example, the village over the hill required turning her whole body towards the hills and almost standing up, with her arm outstretched too. 
Overall, shared contextual knowledge was essential to approximate Grace's intended meaning, although I suspect her brother's intermittent translation reflected his partial comprehension at times. Nonetheless, perceived ambiguity in Grace's discourse may result from her inadequate cohesive strategies, my lack of shared contextual knowledge, and my knowledge of her idiolect (individualised vocabulary), or a combination of these.

\subsection{Paul's Ethnographic Sketch}

An American Peace Corp volunteer, Ricky, arranged permission with the extended family of a deaf couple for me to visit them. I travelled an hour to meet with Ricky, then we walked down the dusty road to Paul and Susan's place. Paul was about 40-years-old, confident, smartly dressed, lean and proud of his home. Remarkably, Paul wore a watch. Their section looked well maintained, with bright tropical flowers and hedges, all bush-knifed into orderly divisions. Several basic single-room dwellings, made from bamboo and natanggura leaves, had a bleached appearance, and were randomly situated. One was a cook-house with a fire. Paul perched on a split-bamboo platform in front of one building, whilst Ricky sat and talked with interested observers next to him. Paul and I spent the next hour attempting to understand each other. Despite my best intentions I occasionally used NZSL signs. We used props including photos, a world map and a camera. He proudly pointed out two raised concrete graves that stood exposed nearby - his parents' resting place. Paul conveyed that malaria caused his deafness when he was young. Oddly, Susan had not yet appeared. After about an hour, Paul was willingly filmed signing a brief monologue. Unfortunately, with the usual distractions of surrounding noise from people talking, comprehension of his story mostly escaped me at the time.

Afterwards, Paul took us to see their vegetable gardens and a well. Next, we ventured further back through trees onto the beach, where he fished, opposite a small island. The sea channel looked deep and momentarily inviting, until Paul described how many people had died from shark attacks in recent years. Etiquette restrained me from bringing out my videocamera again to record this account. We said our goodbyes and Ricky and I returned to await my truck ride. We discussed the strangeness of Susan's absence, despite our arrangement and how, without her presence as another female to accompany me, the meeting was culturally inappropriate. While we awaited the truck Susan suddenly appeared. She was dressed tidily, but most of her teeth were missing. Susan sat down, held my hand, 
and signed a little with me. Later, Ricky surmised that Paul had decided it was safe to allow Susan to meet me.

Later, reviewing the video, I unravelled Paul's story, drawing on information I gleaned during our hour's negotiation of communication. Paul, in a simple manner, told of five months fruit-picking work in New Zealand. He expressed bewilderment at the small payment for fruit-picking compared to his local cacao and copra work. An unexpected discovery in the narrative was Paul's sign expressing "month", which traced the moon's path. It seemed there was more to be learnt from him.

Subsequently, I arranged the next meeting with Susan's cousin. During this visit Susan was shy; she gave a few signs, and then disappeared.

On my third visit I took my Vanuatu sign dictionary proof sheets to show Paul, and when he saw his "month" sign with an accompanying picture clue, his face lit up in satisfaction at being understood.

\subsubsection{Paul's Elicitation Process}

The introductory visit to Paul was mostly spent working out communication between us, assessing how much mutual comprehension might exist. On further visits I used photos to elicit concepts I was seeking for the dictionary. On the second visit, Paul's youngest son, Daniel, was home and mediated questions for me. For example, I requested Paul's permission to film him - he agreed. Additionally, I explained why I was creating the dictionary, which by the expression on Paul's face he did not fully understand. Daniel is multilingual, and his loosely formed signs flowed with little hesitation in expressing himself which suggests he is a regular interlocutor in Paul's idiolect.

\subsubsection{Paul's Discourse Features}

Paul was generally silent when signing, although occasionally a word was verbalised, such as plen (plane) and tawi (male relative). Paul's 48-second recorded passage from our first meeting contained 36 signs (tokens) with only six types repeated (HOUSE=3; ME=2; MONEY=2; THINK=2; GIVE=2; STAY=2). The transcription process was relatively straightforward, considering the visual motivation for many signs and our previous communication. However, a "palms-up" gesture apparently had several meanings - (see Figure 5-2 Lines 1a and 1b). His discourse was cohesively structured, and utterances 
contained between one to 15 signs, including counting months (see Figure 5-2 Line 1a). Paul used a single time sign and his narrative was organised logically and chronologically. At the end, he turned his palms facing downwards to mark the end of his discourse.

Paul's pauses between utterances occurred in two ways. Firstly, and consistently, by lowering his hands, and secondly, in two instances, by holding a palms-up question sign (suggesting a rhetorical "what"), before adding further information (see Figure 5-2 Lines 1a and $1 b)$.

Figure 5-2 Discourse Transcription Sample - Paul

\begin{tabular}{|l|l|}
\hline Paul 1a: & $\begin{array}{l}\text { //PT-sky MONTH FIVE PT-ONE-TWO-THREE-FOUR-FIVE COME-BACK } \\
\text { PT-New Zealand PACK-APPLES MONEY GIVE-ME WHAT-palms-Up? SMALL } \\
\text { "HEADSHAKE"// }\end{array}$ \\
\hline $\begin{array}{l}\text { Translation } \\
\text { 1a: }\end{array}$ & $\begin{array}{l}\text { For five (whole) months (I) packed apples (in New Zealand), (I) came back } \\
\text { and cannot believe how little money (I) was given. }\end{array}$ \\
\hline Paul 1b: & $\begin{array}{l}\text { //ME STAY THINK WHAT-palms-up?// ME PT-plantation COPRA// } \\
\text { CACAO// GIVE-ME BIG MONEY// }\end{array}$ \\
\hline Translation & $\begin{array}{l}\text { (In future) I think I will stay (here) -why? My plantation (work) processing } \\
\text { copra and cacao earns more money. }\end{array}$ \\
\hline
\end{tabular}

Paul's pointing and eye gaze were consistently aligned. Deixis accounted for $22.22 \%(n=8)$ of his signs, and $87.50 \%(n=7)$ of these pointing signs referenced real-world directions and were generally performed ipsilaterally. These referents were identifiable either by the physical presence of the locations (visible houses) or extrapolated from my contextual knowledge of the plantation, and the location of New Zealand relative to Malakula; although his pointing in New Zealand's direction also vaguely aligned with Malakula's airport, so I was unsure whether the destination or the departure point was indicated. In contrast, only $12.50 \%$ ( $n=1)$ of pointing signs were Path referenced (i.e., tracing a path), when he traced the moon's celestial path to convey "month" (see Figure 5-2 Line 1a). 
Paul inconsistently used pursed lips to express "small" items. In two instances he negated a proposition with a headshake, once consecutively (following the signed phrase) and once simultaneously with signs.

Overall, Paul's discourse was comprehensible at lexical, phrasal and discourse level, although shared contextual knowledge was essential to understand deictic references, and for comprehension of his idiolect.

\subsection{Serah's Ethnographic Sketch}

On three different days, I took long walks up the hill to look for Serah, a deaf woman I had heard worked at the hospital. On the third day she is there, and a colleague fetches her. Serah is smartly dressed and looks about 35 years-old. She takes me into a room, out of sight of her colleagues, and we attempt to communicate in signs. I briefly show her video clips I have collected from deaf people. We arrange to meet on her next day off, so she describes her address and writes her sister-in-law's phone number down for me. The address is vague, although Vanuatu generally lacks street numbers and names.

On the agreed day I catch the bus to her village. Across the field, behind the trees I find Serah, dressed in a lovely Island dress. There is no husband. I wait by Serah's house. The walls and roof are rusty unpainted corrugated iron, without windows, and just inside the door the earth floor is covered with sacking. Electricity is not evident. I am not invited inside, but this is customary. Serah lives on her brothers' large section. Their homes are smart Western-styled concrete buildings, with raised floors, iron rooves, mosquito-netted glass windows. Several frangipani trees are in flower and under the closest one we are joined by Nicola, her teenage daughter, a sister-in-law with toddlers and babies in tow, who all sit on pandanus mats to watch us.

Serah begins her story. I see a time sign - BEFORE - to introduce a timeframe. Serah became deaf as a three year-old seriously ill with a high temperature. Her parents sent her overseas for an education - she signs and mouths "school", "Fiji". Serah says her parents are "dead", and her sign is unique with its graceful articulation, which contrasts with the throat slitting gesture used by others. Serah turns to the dogs' barking, points, and signs DOG in NZSL. I try to communicate directly with her, one of my hands still holding the video-camera, and her eyes slide to her daughter for clarification. When I ask about Serah's work, she describes it 
with gentleness and love, how she helps new mothers learn baby care. Despite our audience's cacophonous noise, I find I comprehend most of her story. The various stimulus photos elicit signs and sometimes a sequence from Serah. She and Nicola discuss what other stories to tell and seem to communicate well, although with some clarifications. I thank everyone and leave to catch the next bus.

Months later, I see Serah going to work and stop for a quick chat. After the initial greetings we struggle to communicate. In contrast to answering set questions, responding to prompts and recounting stories of the past, it seems that perhaps casual conversations are outside her usual discourse repertoire.

\subsubsection{Serah's Elicitation Process}

Immediately apparent to me is that Serah has sign language capacity to answer specific questions, albeit mediated by Nicola (her daughter), so I ask about her life and work. Serah considers this, then starts her stories. Nonetheless, while recording, maintaining focus is challenging for me, as Nicola repeatedly yells in Bislama and the sister-in-law instructs the children in their vernacular. We proceed to elicitation of signs using photo stimuli, resulting in minor confusion over some details, but overall Serah's responses are straightforward.

\subsubsection{Serah's Discourse Features}

Although soundless when signing, Serah occasionally mouthed words (e.g., Fiji; baby). Serah's "Life description" is 1-minute 42-seconds, contains 63 signs (tokens) with 14 types repeated (e.g., $M E=8$; Palms-up=4; shivering-shaking=4; FINISH=3; BABY=3). Serah's "Work description" is 42-seconds, contains 56 signs (tokens) with 7 types repeated (e.g., ME=9; $\mathrm{GOOD}=3 ; \mathrm{WORK}=3 ; \mathrm{MAMA}=2 ; \mathrm{BABY}=2$ ). Transcribing her signing was relatively straightforward although translating some parts required clozure on my part, drawing on the likely visual motivation for signs (see Figure 5-3 Line 1b). Extraordinarily, Nicola's interpretation kept pace with Serah's signing. Again, my mediator was multilingual, but also confident moving between oral languages and their shared signs.

Serah's discourse was cohesively structured, with connected utterances from one to 23 signs in length, sequenced both logically and chronologically. She announced topics before further explanations (see Figure 5-3 Line 1a). For example: (i) "ME DEAF", then explaining how she became deaf; and (ii) "ME WORK", then describing her work responsibilities. She 
held both palms facing outwards at chest height to mark she had finished answering each question (see Figure 5-3 Lines 1a and 1e). Serah correctly fingerspelled her job, N-U-R-S-E AI-D-E, sweeping her hands downwards between words. Significantly, Serah, was the only participant seen to directly question me or their interlocutor. She signed WHAT (palms-up) to me with furrowed brows, then she pointed at me and swept her point and eye-gaze around to her daughter which indicated, "tell her what you said to me again", and awaited Nicola's signed rendition of my question.

Figure 5-3 Discourse Transcription Sample - Serah

\begin{tabular}{|c|c|}
\hline Serah 1a: & $\begin{array}{l}\text { //ME DEAF, ME BABY BEFORE BABY CHILD-small THREE YEAR THREE// WHAT-palms- } \\
\text { up // }\end{array}$ \\
\hline Translation 1a: & I became deaf, before as a baby only three-years-old. It happened. \\
\hline Serah 1b: & $\begin{array}{l}\text { /doctor/ } \\
\text { USE-STETHOSCOPE-ON-CHEST // SHIVERING-SHAKING USE-STETHOSCOPE-ON-CHEST } \\
\text { SHIVERING-SHAKING INJECTION IN-RIGHT-BUTTOCK, IN-LEFT-BUTTOCK, IN-LEFT-ARM, IN- } \\
\text { RIGHT-ARM }\end{array}$ \\
\hline Translation 1b: & The doctor examined me and gave me injections in my buttocks and arms \\
\hline Serah 1c: & EARS-BLOCKED, WHAT FINISH, DEAF FINISH GROW-UP FINISH// \\
\hline Translation 1c: & My ears were blocked, it happened, I was deaf and grew-up deaf. \\
\hline Serah 1d: & //PT-Fiji// PT-here NOTHING PT-Fiji// STAY PT-Fiji// TWELVE GO-COME++++ \\
\hline Translation 1d: & $\begin{array}{l}\text { Fiji there, not here but in Fiji. I stayed in Fiji twelve (years) going backwards and } \\
\text { forwards. }\end{array}$ \\
\hline Serah 1e: & GROW-UP THINK WHAT, ME WORK PT-hospital PALMS-UP// \\
\hline Translation 1e: & When I finished I thought what now - I'll work at the hospital. \\
\hline
\end{tabular}

In two instances Serah used complex two-handed constructions, holding a sign on either her non-dominant or dominant hand in position whilst information was added by the other hand. For example: (i) with a right-handed sign HIGH-temperature held static, she negated with a headshake and signed NOT on the left hand; and (ii) with her non-dominant left-hand enacting holding a baby, her dominant right-hand "wrap(ped)" the baby, then while the left- 
hand (baby) is held static, she signs MOTHER with her right-hand, then uses both hands to convey GIVE-baby-to (the mother).

Serah's pauses are marked differently from other participants in that she consistently holds both hands to her torso, sometimes interlocked whilst thinking, before the next utterance. It is likely that Serah's use of FINISH is a completive aspect marker, expressing or emphasising that an event did occur (Figure 5-3 Line 1c).

Serah's pointing and eye gaze were consistently aligned. In her Life description deixis (pointing signs) accounted for $12.50 \%(n=7)$ of her signs $(n=56)$, and $85.71 \%(n=6)$ of these referenced real-world directions. In her Work description, deixis accounted for $10.34 \%(n=6)$ of her signs $(n=58)$, and $83.33 \%(n=5)$ referenced real-world directions. Only one displaced reference to her work in front of her occurred; although her relaxed manner suggests this could be gesticulation. Deictic signs in Serah's two narrative recordings average $11.14 \%$. Her pointing was generally performed ipsilaterally. In contrast, to other participants, Serah identified all locations by naming the referent, with a sign and by mouthing (consecutively). Additionally, one instance of deixis was accompanied by a headshake to negate the phrase ("not here") (see Figure 5-3 Line 1d). This appears to be a grammatical construction that is common in many established sign languages and may result from her experience in Fiji. Overall, the grammatical structures in her texts - in terms of word and clause order, topic marking, negation, connective use of "WHAT-palms-up" - have many of the features expected in a user of NZSL or another conventional sign language and show more complexity and cohesion than the other two participants profiled here.

Transcribing Serah's discourse presented few difficulties regarding meaning, although shared contextual knowledge was essential for comprehension, and communication ambiguities with Nicola were few in her discourse. Serah's discourse had a few more complex constructions rather than just individual signs sequenced into utterances. Furthermore, Serah's borrowed signs, such as a BEFORE (NZSL/ FJSL), and fingerspelling were used accurately, which suggests some literacy and a larger language repertoire than the other two participants. 


\subsection{Discourse Features Summary}

All three participants may have been exposed to spoken language prior to becoming deaf; confirmation was not possible. Two participants described the cause of their deafness. The discourse elicitation process included specific questions and free expression, assisted by multilingual mediators. However, participants' extent of shared signs with interlocutors differed; Serah and Paul who had older children, seemed to have greater language capacity in sign than Grace, and Serah more than Paul. Additionally, Serah and Paul's discourse appears to be logically segmented by pauses, although sometimes in different ways.

Overall, participants used few grammatical features as to be expected with home sign. There were few discourse markers; connectors were only observed in Serah and Paul's discourse. Paul and Serah occasionally used non-manual gestures that appeared linguistic, and the conventional questioning "palms-up" gesture, as a connector or rhetorical question. Serah used some relatively complex two-handed constructions, with interaction between different elements of meaning on dominant and non-dominant hands. Pointing signs were used by all three participants; for Grace and Paul comprising an average of $22.63 \%$ signs, indexing mostly by real-world directions. In contrast, Serah averaged $11.42 \%$ of pointing signs, with referents consistently identified by other signs as well as real-world direction, which increased comprehensibility.

Of the three, Grace's communication was least conventional and structured, consequently the most difficult to decipher, and required a high level of contextual knowledge for her interlocutor to decode her intended meaning and even then, it was ambiguous. Paul's discourse was more logically structured although it still required considerable negotiation of meaning between interlocutors. Serah's signing was the most comprehensible without close contextual knowledge, in terms of lexicon and discourse structure.

The next chapter will discuss some of the social, lexical, and grammatical features reported in chapters four and five, and compare these to other home sign and emerging sign language situations described in the literature. 


\section{Discussion}

\subsection{Introduction}

The aims of the research were firstly, to identify the sociolinguistic context experienced by deaf people in Vanuatu; secondly, to describe the repertoire and characteristics of signs used by the deaf participants; thirdly to determine the degree of similarity of signs between participants and to consider how this may reflect individuals' opportunities for contact with other deaf people and signing interlocutors; fourthly, to investigate how features of the signs used by Ni-Vanuatu deaf individuals may align with characteristics of home signs and emerging sign languages documented elsewhere. These four aims were accomplished by considering deaf individuals within their social and physical environments, the nature of their communication with interlocutors, and documenting their individual lexicons. Analysis indicates that all participants used home signs, and characteristics of these (including signing space, sign formation parameters, depicting strategies and some usage properties) are compared with those in the literature on home signs and if applicable, emerging sign languages. Overall, signs that were documented from the 19 deaf individuals span a limited range of concepts and include a small number of foreign signs and apparently conventional gestures.

\subsection{The Sociolinguistic Context of Participants}

The individual situations of participants show experiential similarities, but this observation must be qualified by the extent to which I, as a foreigner, can understand deaf people's lives by, at most, three brief encounters with each person. To comprehend a deaf person or deaf group's reality requires daily living in their village for a substantial time to form an accurate picture (Kuster, 2012; Nyst, et al., 2012). In meeting with deaf people, as I moved about Malakula and further afield, we usually drew a crowd of villagers who voiced ideas to the participants. This attention perhaps gave the misleading impression that deaf people were socially integrated.

Nonetheless, living in Vanuatu for two years, and engaging with participants in the contexts of rural and village life and within primary and adult education contexts gave me a more informed and critical perspective on their sociolinguistic context. I observed a degree of social isolation irrespective of where they lived, and this impression was reinforced on the occasions that I witnessed encounters between deaf people, in which I observed a lack of 
mutual communication with one another. The threads of isolation wind deeply into participants lives with strands from language, education, work and geographical isolation. My impression of the participants' life circumstances was that they all experienced degrees of vulnerability and social marginalisation, and in some cases, personal trauma.

Language isolation is a typical experience of participants resulting from their inability to access and acquire their family and community's multiple spoken languages, and the scarcity (usually absence) of other sign language users. This exclusion from conventional language leads to a disadvantaged status in all aspects of their lives, as is common for deaf individuals within hearing communities (Woll \& Ladd, 2003). Without the existence of an established, shared sign language(s) in Vanuatu, nor opportunity to participate in collective deaf education or family settings where intergenerational transmission of a sign language may occur, each deaf isolate creates their own home signs to use with interlocutors (Brentari \& Coppola, 2013; Goldin-Meadow, 2003). Home sign lacks the discourse depth that hearing people are accustomed to and only people who know the deaf person's life and experience intimately can comprehend their communication (Goldin-Meadows and Feldman 1977; Kegl et al. 1999). Home signers in this study had limited capacity to use a conventional language in this way and were thus precluded from fully taking part in their society, including cultural traditions and religious life, apart from observational and experiential knowledge which may or not be accurately constructed in their minds. A comparable situation to these participants has been described in rural Nicaragua, Mexico and in Rennell (Solomon Islands), where only a few family members or friends acquired the home sign of deaf isolates (Haviland, 2013; Kuschel, 1973; Le Guen, 2012; R. Senghas, 1995). The inherent isolation of participants' lives means they cannot create a fully functional language on their own, therefore shared knowledge of their lives is requisite to comprehending their discourse, albeit few mediators gave full details of the home signers' meaning, likely due to incomplete information conveyed in discourse (Goldin-Meadow \& Feldman, 1977; Kegl et al., 1999; R. Senghas, 1995). Participants' limited family communication echoes Elena Gonzáles' observation of her deaf sibling in Nicaragua being "unknown" to her, through lack of shared language (Polich, 2005).

Pejorative attitudes towards deaf people in Vanuatu were apparent, reflected, for example, in the use of the term "nambut" (deaf and dumb), and the limited social opportunities and 
roles available to them. A similar situation was described for a deaf isolate in Rennell, who experienced unsuccessful marriage attempts with hearing women (Kuschel, 1973). In Nicaragua, societal acceptance of deaf children and adults varied, between inclusion and employment, to being hidden from public view due to shame, including serious abuses (Polich, 2005; R. Senghas, 1995). Similarly, deaf Ni-Vanuatu experiences range widely: I saw some deaf people who were loved and respected family members, and others who appeared to have been abused, particularly women who were unpartnered mothers. Of course, mutual language barriers and cultural constraints prohibited me from deeply exploring and confirming these impressions, either directly with deaf individuals, or with their associates (nearly always family members). However, two-thirds of Ni-Vanuatu women reportedly experience physical or sexual violence, and international studies show that the rate of gender-based violence against deaf and disabled women is two to three times higher than average, due to disparities in communication, information and personal agency (Anderson et al., 2011; Kvam, 2004; Nosek, Howland, Rintala, Young, \& Chanpong, 2001; Sobsey \& Doe, 1991; Vanuatu Women's Centre, 2011).

Evidence of full inclusion in society, such as education, economic activities, occupations, marriage and raising families, and making decisions and choices in all those areas, is considered a key to empowerment of deaf peoples' lives; for deaf Ni-Vanuatu who I encountered, this varied to extremes (Polich, 2005). The absence of shared language marginalises deaf Ni-Vanuatu in these areas of life, comparable to Nicaragua's rural deaf isolates and the Solomon Island's Rennellese isolate (Kuschel, 1973; Polich, 2005).

Education in Vanuatu has variable importance depending upon parental attitudes, educational experience and/or wealth (UNICEF \& Republic of Vanuatu, 2014). Government policies support full inclusion of children with disabilities into the education system, but in practice (at the time of this study) no funding was provided for extra support. Two deaf women I encountered in this study who had significantly more education than their deaf contemporaries, either had parents who were educated professionals, and/or could afford appropriate overseas education, which significantly elevated their employment outcomes (Serah employed as a nurse aid and Hillary self-employed as a seamstress). Participants were disadvantaged by the fact that little, if any, accessible deaf education existed, or exists now, compared to their hearing peers educated in the village. While disability organisations 
SFA, VSDP and DPA have attempted to introduce sign language to some schools, the effects for deaf children have been negligible. Generally, I met families appreciative of sign language courses for their children, but they often lacked understanding of the importance of learning sign themselves and of the language acquisition difficulties that deaf children face in a multilingual context. Therefore, deaf children without competent interlocutors do not receive increased interactions which improve language opportunity.

Employment for participants was mainly subsistence farming, and a few participants diverged from this norm. For example, a small number of deaf people I met had different work, which suggests social equity, but whether their pay is equivalent to hearing workers is unknown. Although they participate in the physical routines of subsistence living, during these activities deaf individuals are generally excluded from surrounding conversations, decisions and traditional knowledge of the immediate and wider community.

Few participants lived independently of family, regardless of their employment. Only four out of 19 participants that I met had married. This suggests that participants are excluded from assuming key social roles and statuses, which may reflect parental and societal belief that deaf children (particularly females) retain child-like status into adulthood, as described in Nicaragua (Polich, 2005). A gender divide exists in Vanuatu culture, whereby some deaf males participated in paid employment and were more at liberty to move around for work than deaf females, who mostly continued to live at home into adulthood, as in Nicaragua (Polich, 2005). I subsequently observed that this pattern was also typical in PNG, until Callan Services ran workshops for deaf adults to discuss the meaning and responsibilities of marriage, which led to some deaf people establishing relationships and families (Personal Communication, James Knox, November 27, 2017). The few participants in my study who were engaged in raising families and earning incomes lived independently from their parents, although with extended family, which brought relatively more inclusion in society; although extended family and/or tribal oversight constrains personal autonomy for all $\mathrm{Ni}$ Vanuatu (Regenvanu, 2005).

In sum, in 2012, the overall sociolinguistic context experienced by participants, and generally likely for deaf $\mathrm{Ni}$-Vanuatu, is characterised by relative linguistic isolation from society which affects all aspects of their inclusion in society. Similarities exist between these participants and other isolated rural deaf people of Nicaragua and the Solomon Islands. A 
few participants have achieved better economic status through education, in one case outside Vanuatu, and in others through access to resources obtained by individual parents.

\subsection{Deaf Identity and Social Networks}

When the Vanuatu situation is compared to the world's urban and rural communities, few similarities exist apart from correspondingly having deaf individuals, (Polich, 2005; de Vos, 2012). Geographical separation of deaf individuals is a key barrier to the creation of a deaf identity based on regular social contact and a shared means of communication, which usually occur among deaf children who have the capacity for language creation, and deaf youth as they develop social skills and networks (Kegl et al., 1999; Lane et al., 1996; Polich, 2005; Sandler, 2012; Woll \&Ladd, 2003). Recently in PNG, where the conditions for deaf people are similar, Callan Services established a residential school for deaf children; subsequently a deaf language community began to emerge. However, this emerging sense of collective identity challenged strong tribal allegiances, and when students refused to return to their homes, to comparative language and social isolation, the residence at the school was closed, its future unknown (Personal Communication, Michael Lulu, February 2014).

Important contextual factors required for sign language development among Vanuatu's deaf isolates are currently weak. International influence has brought about changes in government policy for social integration of people with disabilities, including deaf people, through educational access. NZ and Australian volunteers have raised awareness on deaf issues in disability NGOs, which has resulted in some change for individual deaf children. Events which include deaf people of all ages might in time contribute to or birth a sense of deaf identity and shared language (Polich, 2005) but the economic and logistical factors constrain this.

\subsection{Characteristics of Vanuatu Home Signs}

Similarities exist in the lexical and grammatical features of signs in this data and those of other home signs, emerging sign languages, or occasionally established sign languages. These features are discussed in this section. A brief discussion on the range of concepts, signing space, deixis uses and iconicity in sign parameters inherent to participants' home signs is covered next. 


\subsubsection{Range of Concepts}

Participants expressed a limited range of concepts, and fewer than child home signers described by Goldin-Meadow (2003). The few participants who occasionally mouthed or whispered a word, may have had prior exposure to spoken language and included some known concepts in their sign creation; research shows postlingually deaf people introduce signs for concepts previously encountered (Dufour, 1992, as cited in Emmorey \& Reilly, 1995). Some participants may have had few concepts, resulting from delayed language acquisition, which can impede cognitive development (Morford \& Hänel-Faulhaber, 2011).

Few participants used time concepts, with little evidence of reference to past, present and future in discourse or elicitation, similarly to Nicaragua's rural home signers but contrary to home signers in USA (Goldin-Meadow \& Feldman, 1977; Polich, 2005). Whether participants' elicited time signs were nonce or used regularly in everyday discourse was generally unconfirmed. Nevertheless, most participants' village upbringing, without school knowledge and experience, is a different context in which to develop concepts compared to a Western home signer with intentional parental and educator language input in a time focussed society (Goldin-Meadow, 2003; Green, 2014; Nyst et al., 2012).

Evidence of metaphorical timelines was not found, and the three participants who used a celestial timeline (pointing to the sun's location at sunrise, noon and sunset, and the moon's path for month) varied in direction and handshape of their signs. Clock time was generally not an important construct in everyday life; for instance, on Malakula (the location of four participants), mobile phones arrived in 2008 , and as people did not wear watches, this may have been the first time they had access to the time of day in hours and minutes. Time constructs based on celestial movements are reflected in home signs or emerging sign languages in other traditional cultures, particularly those close to the equator, such as Kagobai's pointing to the sun's position (de Vos, 2012; Kuschel, 1974). In this study, it is unknown whether community gestures influenced the celestial time referents that participants used; although Yucatec Mayan home signers share many community gestures, they do not share the celestial line used by Yucatec Mayan hearing people (Le Guen, 2012). Paul was the only deaf person to mention a deaf friend and perhaps their interaction, or his overseas work experience, led to his expressions for time. Four participants marked time in 
discourse with signs, and related events chronologically, a strategy common to Yucatec Mayan home signers and Indonesian Kata Kolok signers who also lack lexical time markers (Kendon, 1980; Le Guen, 2012; Meir, Sandler, Padden, \& Aronoff, in-press).

Kinship terminology signs are limited, which is similar to Yucatec Mayan home signers and other signers in rural contexts (Nyst, 2007a, \& Shuman, 1980 as cited in de Vos \& Pfau, 2015), but apparently contrasts with the complexity of Kagobai's relationship vocabulary in Rennell (Kuschel, 1974). Although the kinship topic per se was not raised with participants, signs usually indicated a generic male or female identity. For example, a sign might refer to the person's mother and all related women, and/or women, with few separate signs to distinguish the female relationships. This may reflect local family norms in which children are raised by the community (Regenvanu, 2005). Participants' idiosyncratic signs for male, man or father, had the common referent of facial hair which was also Kangobai's referent (Kuschel, 1974).

Name signs referring to individuals were used by two participants, based on their distinguishing features; similarly, Kagobai's father's name sign depicted his tattoo (Kuschel, 1974). These were single or compound signs, likewise, Kangobai's name signs were mostly single signs, with some comprising two or three elements (Kuschel, 1973; Hunsicker \& Goldin-Meadow, 2013). Insufficient data was collected to establish if name signs are frequently used, as by deaf people elsewhere (McKee, 2001; R. Senghas, 1995), however, communicative context is a determining factor: name signs develop when interlocutors regularly need to refer to mutually known individuals, (who are not visibly present), and in the case of these Vanuatu signers, the level of such interaction appears limited.

Participants' affirmations were head nods and eyebrow raising, also conventional in the local hearing community, whereas negation (other than foreign signs), was expressed by the headshake that is commonly used in established sign languages (de Vos \& Pfau, 2015).

Few participants were seen to ask questions (such as using a palm-up gesture). This mirrors observation of deaf children in Yucatec Mayan villages, whose signing skills were constrained by little interaction apart from imperative commands from family members (Le Guen, 2012). 


\subsubsection{Vocabulary Size and Stability}

Participants' vocabularies varied in size but were experientially limited, as expected in home signers (Kegl et al., 1999: Kuschel, 1973). Other factors potentially contributed to documentation of small vocabularies, such as individuals' few previous opportunities to "converse", and likely reticence to publicly sign in front of fellow villagers or a foreigner, as also noted by researchers in Nicaragua (Polich, 2005) and Rennell (Kuschel, 1973).

It is expected that participants' gestures have become more sign-like and consistently produced over time with reduction in movements, similarly to young home signers in North America (Morford, Singleton \& Goldin-Meadow, 1995), however, there is no diachronic data to confirm this. Generally, signs sampled in the lexicon were not spontaneously created in discourse, although some are productive, but became systematic through repetition, and they may differ in part from other home sign formational criteria (Goldin-Meadow, 2003; Morford, et al., 1995). Nonetheless, participants signs can be used combinatorically with prosodic pauses, such as the Z Family and the Al-Sayyid Bedouin signs use, and therefore, fall between "language-like" and "signs" on Kendon's Continuum (Armstrong, Stokoe \& Wilcox, 1995; Goldin-Meadow, 2003; Haviland, 2013; McNeill, 2005). Those participants with sufficient data collected mostly demonstrated consistent use of form and meaning, while some had several forms for one meaning.

A characteristic of home sign is the lack of integrated use of manual and non-manual elements. Therefore, hands were the main articulators, other than constructed action/mimesis and conventional gestures that used non-linguistic head movement (de Vos \& Zeshan, 2012; Sandler, 2012). Non-manual actions were rarely seen to modify signs or gestures, which aligns with the first generation of signers described in the development of ABSL (Sandler, 2012). Participants who did use non-manual modifiers, likely learnt this from contact with other sign language users, such as Serah at school in Fiji, and Paul, who mentioned a deaf friend, of unknown background. These two, unlike the others, also had children who were competent and regular interlocutors in their home signs, which was perhaps a contributing factor to their greater discourse capacity and fluency than other participants. 


\subsubsection{Signing Space}

Signing space was utilised similarly to Nicaraguan home signers and Kata Kolok village signers (de Vos, 2012; Kegl et al., 1999), but quite defined in contrast to an American deaf child and Kagobai (Hunsicker \& Goldin-Meadow, 2013; Kuschel, 1974). For example, although Kagobai's sociolinguistic context was shared with participants (Kuschel, 1974), he breached any notion of signing space with frequent mimesis. In contrast, these participants' few signs located below the signing space held iconic import.

\subsubsection{Formational Characteristics of Signs}

A third of all participants formations were two-handed symmetrical signs, as expected in home signs (Kegl et al., 1999). One-handed formations were slightly fewer, excluding deictic signs (see section 4.5.2). Some participants also presented two-handed asymmetrical signs, (up to $24 \%$ ), which can be considered more sign-like than gesticulation, which is rarely asymmetrical (Singleton, et al., 1995). While their use could suggest development towards sign language (Kegl et al., 1999), it is more likely that this participant (with 24\%) had daily tasks that required use of tools which motivated many asymmetric depicting forms (e.g., holding and acting upon an object). This contradicts Kendon's (1980) hypothesis that the Enga deaf woman had few asymmetric signs because of her simple lifestyle.

During discourse, Serah's use of a negation sign on the non-dominant hand, interjected between two signs on the dominant hand, may reflect Sandler's (2012) observation based on fourth generation ABSL signers, that this type of non-dominant hand use only occurs when signing "becomes automatic" (p. 297). If this claim is correct, complexity in Serah's signing reflected her earlier and more extensive interaction with other signers at school in Fiji, and possibly in adult life with her daughter.

\subsubsection{Iconicity}

The data collected mainly depicted familiar objects and activities, and the signs are highly iconic, often in several if not all four parameters. The degree of iconicity is high compared to intergenerational lexicons which become increasingly arbitrary over time (Morford, et al., 1995; Pfau, 2016). 


\subsubsection{Three Main Parameters of a Sign}

Overall the handshape inventory was 22 handshapes, although individuals used from five to 16 handshapes, in contrast to the expected 12 handshapes for home signers (Morford, et al., 1995). Participants with more frequent interaction opportunities had larger inventories, albeit marked handshapes were used minimally, and some were likely nonce formations for the purpose of depicting particular objects or actions (Brentari \& Eccarius, 2011; van der Kooij \& Crasborn, 2016). Two participants from the same location had significantly different handshape inventory sizes (5 and 9). However, several factors may have influenced this, such as elicitation by free expression versus pictures, topics of activities versus objects, and gendered work differences. However, it is most likely that the lower inventory contained mostly unmarked handling formations, in contrast to the larger inventory's higher number of marked handshapes, including object handshapes and quantifiers (i.e., extended digits for counting which result in marked handshapes) (Hunsicker \& Goldin-Meadow, 2013).

The six most frequently used handshapes were, surprisingly, not all unmarked, as might be expected (Johnston \& Schembri, 2007). This finding is influenced by handshapes that depict the handling of objects (see section 6.4.5), which contrasts with an American home signer's and ABSL signers' preference for handshapes representing the object rather than handling (Hunsicker \& Goldin-Meadow, 2013; Padden et al., 2013). Nonetheless, even established sign languages have different handling or object handshape preferences, such as NZSL and ASL respectively (Padden et al., 2013). Overall, my impression was that participants' handshapes were less important or defined compared to the information carried by movement. This contrasts with the view that handshapes are the most defining parameter of signs (Hunsicker \& Goldin-Meadow, 2013; Johnston \& Schembri, 2007), and points to the gradient or unconventional status of these home signs.

Movements were mostly iconic to the referent, that is mimicking real-world actions (GoldinMeadow, 2003). Few internal hand movements were found, and finger wriggling was used only by participants with previous foreign sign language contact, and in depiction of body movements (cf. Kagobai's "coconut crab" with finger wriggling; Kuschel, 1974), and in some element signs (e.g. water), also seen in established sign languages (Johnston \& Schembri, 2007). 
The location of signs was typically iconic, related to real-world actions (Kendon, 1980). Neutral location, the natural position of the hands, was most frequent - comparable to Enga signs, but less than in ASL (Kendon, 1980; Pfau, 2016). Head or Face located signs were minimal (3.75\% and $11.71 \%)$, mainly occurring in enactments of a person or an animal's head. This finding contrasts with the high percentage of Head or Face locations used in established sign languages; therefore, for these participants, the theory that many signs tend to be located on the head and face for ease of visual perception may be irrelevant (Kendon 1980; van der Kooij \& Crasborn, 2016). Participants used few metaphorical locations, and those used may be sourced from conventional gestures. Metaphorical gestures require language and abstract thinking, which can be problematic for some home signers (Goldin-Meadow, 2003; Morford \& Hänel-Faulhaber, 2011).

\subsubsection{Nominal Reference}

Preliminary analysis reveals some evidence of rudimentary noun-verb distinctions in several forms, similarly to home signers in Nicaragua, Mexico and America (Haviland, 2013; Hunsicker \& Goldin-Meadow, 2013; Kegl et al., 1999). For some participants insufficient data was collected to form an opinion, and part of speech is typically rather ambiguous in home sign and young sign languages (Haviland 2013; Kegl et al., 1999).

Nominal reference was expressed in either single signs or sequences, and some participants' data suggests the beginning of compound forms, similarly to Nicaraguan home signers (Kegl. et al., 1999; Meir et al., in-print). As home signers, participants will have frequently encountered the need to extend their lexicon to specifically reference a new idea or object presented in their daily lives, which is how compounding strategies develop, such as pointing and adding an iconic action, and/or SASS (Goldin-Meadow, 2003; Kegl et al., 1999; Meir et al., in-print). One participant demonstrated reduction in the articulation of a compound, albeit lacking consistency and smoothness in formation, but nonetheless clearly a nominal construction (Kegl. et al., 1999; Meir et al., in-print). The following five characteristics of nominal reference were identified in the data.

Firstly, in signed language generally, nouns often contain short movements possibly partially repeated, performed closely to the body, in contrast to slightly larger movements in verbs (Tkachman \& Sandler, 2013). Some participants were consistent in identifying objects with reduced movements while other participants were not, which likely reflects their number of 
interlocutors and frequency in conversing (Padden, 2011; Trudgill, 2012). This form of marking nouns, particularly reduced movements, intersects with other noun marking distinctions.

Secondly, some nouns were simply SASS, either singly or in sequence (Haviland, 2013; Meir et al., in-print). Occasionally a height indicator seemed to represent age or authority rather than size, as described in Kangobai's signs (Kuschel, 1974), and height specifiers were frequently in final position, for example "male height-tall" (Meir et al., in-press).

Thirdly, other studies of young sign languages suggest that the use of a quantifier with a sign indicates its noun status (Haviland, 2013; Meir et al., in-print). In this study, two instances were found of iconic signs (identifying a nominal referent) followed by a quantifier.

Fourthly, a few participants identified places with combinations of an iconic sign and pointing, with deixis in final position, although researchers have noted differences in other home signers' sequences (Goldin-Meadow, 2003; Haviland, 2013: Meir et al., in-print).

Fifthly, a few participants' used handshapes to represent a whole entity, similarly to Kangobai (Kuschel, 1974). These handshapes made nominal reference to a person, animal or inanimate object, and usually also expressed further information such as path and manner of actions, or relative location.

Thus, the data show that nominal reference was marked in various ways by some participants. Further analysis is needed to identify if other patterns exist, for instance, whether noun compounds contain consistencies relevant to types of objects. Distribution and consistency of strategies could also contribute to description of home sign and emerging sign languages.

\subsubsection{Depicting Sign Strategies}

This section discusses the productive depicting strategies found in the data; these were distinguished as Handling, Tracing, Instrument and Body Parts. A key source for this analysis was Padden et al.'s (2013) study which investigated a typology for how sign languages of different historical ages tend to depict actions that involve the use of tools and objects. However, I discovered that the typology of strategies outlined in that study did not fully account for my data, because in the material culture of Vanuatu, tool or object use is relatively limited in the everyday activities most participants described; many actions and 
processes are performed directly with the hands. I added other categories in response to data observations, including Body Parts (exclusive to Animals), Entity and Element forms drawn from other typologies of productive sign types (Sutton-Spence \& Woll, 1999). Nonetheless, the data revealed all except two participants favoured handling strategy over the eight other strategies coded (see Error! Reference source not found.).

Handling strategy (grasping an object while performing a canonical action), featured strongly in the data, as participants described the predominantly practical, subsistence tasks of their everyday lives. This real-life context, and the elicitation materials, produced a dataset that contrasts with the American child home signer and ABSL signers (Hunsicker \& Goldin-Meadow \&, 2013; Padden et al., 2013). For example, food is rarely spontaneously mentioned as a topic in discourse, but food items featured in the stimulus materials, prompting descriptions of cultivation and preparation processes using mainly handling depictions, with some commonalities to Kuschel's (1974) data. For example, most participants in elicitation used handling forms to depict the water source types of pump, well, bucket, tap, and cup. However, different strategies for identifying water sources is comparable to Kagobai's object form for drinking cup water, and tracing form with a swallowing movement for "bush pool" water (Kuschel, 1974, p. 70-71).

Tracing strategy was second most frequent, and commonly used by home signers (Hunsicker \& Goldin-Meadow, 2013). Instrument strategy, (depicting features of an object while performing a canonical action), was third most frequent, although four participants never or rarely used this strategy. Bush knives are the predominant instrument in daily tasks and most participants used instrument forms in two-handed constructions that focus on how a knife blade (represented by the dominant handshape) acts upon another object, such as processing fruit and vegetables. In contrast, handling strategy was preferred to express onehanded depictions of acts of using a bush knife, such as "grass cutting" or manipulating another object in relation to the knife, such as "sharpening the bush knife".

Depicting Body Part of an Animal was used in nearly $50 \%$ of animal signs, whether moving or not, which contrasts with the Mexican Z Family's preference to depict handling of the animal or a feature unique in dealing with that animal (Haviland, 2013). Some participants included a sequence which depicted a body part, then mimesis of the animal walking or running, although these were unrefined compared to animal walking patterns described in 
Kata Kolok (de Vos, 2012). Like Mexican home signers' depiction of a "neck-wringing" action to refer to "chicken" (Haviland, 2013), several participants identified an animal by depicting the manner of its killing, such as stabbing a "crab", or by slapping their forearm for “mosquito", like Kagobai (Kuschel, 1974).

Overall, the main depicting strategy was handling, which correlates to neither the American home signer nor ABSL signers, who demonstrated greater use of instrument strategies (Hunsicker \& Goldin-Meadow, 2013; Padden et al., 2013). This finding indicates that deaf isolates in this particular context draw heavily on mimetic actions as an expressive strategy, and also suggests that the physical and material context for communication (e.g., degree of tool use in everyday life) needs to be considered in categorising the type of signs or depicting strategies that will develop.

\subsubsection{Deixis}

Participants' deixis most frequently identified real-world direction of a place, person, or occasionally an object, and their eye gaze was consistently aligned to the direction which makes it lexical, as similarly identified in Kata Kolok and ABSL signers' deixis (de Vos, 2012; Meir et al., in-press; Singleton et al., 1995). Three participants' data was analysed for use of real-world direction, discourse reference and path movement to compare with other deaf isolates. Firstly, Paul and Grace's deixis averaged $22.63 \%$, of signs which is below the average frequency of pointing signs observed in other studies of home signers, such as six American deaf children who averaged $51.33 \%$, and two elderly deaf adult siblings who averaged 32\% (Goldin-Meadow \& Feldman, 1977; Torigoe \& Takei, 2002). Secondly, Serah's deixis averaged $11.42 \%$ over two discourse clips, substantially lower again. These lower frequencies may reflect differences in the data collection and communication context, or that the Vanuatu participants were drawing on other resources for reference.

Several features of deixis were apparent. Firstly, deixis was expressed using several handshapes, but predominantly used a loose pointing handshape, sometimes influenced by the previous sign's handshape. Secondly, varying levels of body engagement related to expression of relative distance of locations (de Vos, 2012). Thirdly, compounding deixis with iconic signs for places and people was observed (see section 4.8.1) (Coppola \& Senghas, 2010). When places and people are given name signs a reduction in deixis is likely if they are not compounded into the sign name (Meir et al., in-print). However, increased lexical use of 
deixis, such as for personal pronoun referencing, seems to require a greater number of deaf interlocutors than were present around participants, as seen in the increasing use of lexicalised deixis across Nicaraguan cohorts on the continuum from home sign towards more conventional ISN (Coppola \& Senghas, 2010). Fourthly, most deixis was performed ipsilaterally, similarly to other home signers and village sign languages (de Vos, 2012; Pfau \& Baker, 2016). Further exploring some of these observations is beyond the scope of this thesis, but further comparison of deictic features with other comparable studies might establish whether participants' deixis exhibit more linguistic features (Coppola \& Senghas, 2010; Kendon, 1980b; Kuschel, 1974).

\subsection{Degree of Sign Similarity Between Participants}

Participants live in the most linguistically diverse place in the world, they share a subsistence lifestyle, particularly when living rurally, but are individually and geographically dispersed in villages and islands. Their signs therefore differ. Similarly, some Japanese home signers share a sociolinguistic context with each other, but are isolated on rugged islands, and their signs also differ (Meir et al., in-press). Individual participants have developed their own idiosyncratic signs for communication, and due to the challenging conditions for data collection, it was not feasible to systematically cross-check for overlap in sign forms. However, the signs documented show that participants had some analogous signs, for which three reasons are considered next.

Firstly, when participants lived in the same locality there was potentially opportunity to meet and share signs. Only two situations were encountered where two participants lived in the same home or village. The married couple's individual home signs were excluded, due to insufficient data. The two participants in the same village are unlikely to have spent much time together, due to age and gender differences, and few analogous signs between them were identified, and qualitative differences in the complexity of their signing were noted (see section 4.2).

Two participants from different islands produced the same form for "fish caught", similar to a conventional gesture for "catch" (Personal Communication, Kolika Markie, June 2018).

Secondly, some signs shared common visual referents. Although participants may have selected different features to highlight in their variants, which would be contextually 
comprehensible; shared experience was key to comprehension between Nicaraguan home signers and their interlocutors (R. Senghas, 1995). Sign variants are common at any level of sign language development (Meir et al., in press). A few similar sign forms were produced by participants in Malakula and Efate, but these were iconic and/or likely conventional gestures.

Thirdly, most participants have incorporated into their lexicon conventional gestures from their communities, albeit these are unresearched yet, but villagers frequently communicated with gestures in stores or to people passing on trucks.

Although few participants used quantifiers, data suggests that numbers one to five mirror conventional gestures, similarly to Yucatec Mayan signers (Safar, 2017). These had some inconsistency in use or formation, which suggests some participants may have limited understanding of the associated meaning and form. Contact with participants was insufficient to establish whether and how other conventional gestures may be in use in their daily interactions.

In sum, the degree of similarity of sign forms across participants is low, suggesting that their vocabularies are more idiosyncratic than shared, as might be expected given the spatial and social circumstances of their lives. 


\section{Conclusions}

The main contribution of this thesis is to provide a first documentation and description of the signs created and used by deaf individuals in Vanuatu. The specific aims of the research were as follows: to establish the sociolinguistic context experienced by deaf people in Vanuatu; to identify the repertoire and characteristics of signs used by the deaf participants; to compare features of participants' individual signs with the characteristics of home signs and emerging sign languages; and to consider the degree of similarity and potential similarity of signs between participants and how this reflects individuals' opportunities for contact with other deaf people and signing interlocutors. The limitations of this study are that field methodology for data collection was developed in situ as conditions allowed, rather than systematically pre-planned, although opportunistic data collection did result in random sampling of participants in their natural home contexts. This study in a Melanesian context contributes knowledge and understanding of isolated deaf signers, emphasising that no one person has exactly the same context, experiences, or resulting language features as another isolated deaf signer. Furthermore, this study contributes evidence on the range and characteristics of home signs and emerging sign languages.

\subsection{The Sociolinguistic Context for Deaf Ni-Vanuatu}

The sociolinguistic context for deaf Ni-Vanuatu confirms that language isolation leads to marginalisation from community and society. Vanuatu as an archipelago of 83 islands, naturally isolates deaf people from each other geographically, which is a difficult contextual barrier to the potential development of a shared sign language. The Vanuatu Government's international agreements cover accessibility for deaf people. However, until these policies are implemented at all levels of Vanuatu society deaf isolates will continue to be marginalised. Although attitudes per se were not investigated in this study, it was apparent through my interactions over two years that pejorative attitudes towards deaf people within their family and/or their village significantly constrain their prospects of inclusion in society.

Vanuatu's oral language diversity, with multilinguals and plentiful gestures imply that deaf people might draw on these resources to communicate with family and friends. Nevertheless, each deaf participant had created their own home signs, an incomplete language, to communicate with a small circle of family and friends, who may or may not share their system. 
Education is generally inaccessible to deaf children within the Vanuatu education system.

Deaf people historically have been excluded from education by inaccessible communication, parental disinterest, and teachers untrained in deaf children's educational needs.

Nonetheless, education contributed to the few paid employment opportunities that were evident in participants' lives. Traditionally, many hearing children leave their home islands and congregate in boarding schools around the archipelago, which with sufficient training and funding, could also be a model for deaf education.

Work opportunities in rural contexts are comparable to other community members of the same gender. Few participants were married, and those with older children had interlocutors competent in their home sign. Deaf men's greater freedom often allowed them to move around the islands in contrast to deaf women who remain home based. Observation suggested that deaf women are even more vulnerable to the systemic abuse that Ni-Vanuatu women experience. Participants often shared contextual factors, such as agricultural work, minimal or no schooling, and low social differentiation, which elsewhere has supported integration of deaf people into rural communities; however, from my observations participants did not experience true integration.

\subsection{Sign Characteristics}

The study established that these home sign lexicons were limited in quantity and conceptual range, and that shared background knowledge was essential for comprehension. Few participants expressed time concepts, and some presented their information chronologically. Deixis was predominantly real-world orientated. Their idiosyncratic formations were articulated within a defined signing space. Iconicity in signs was high, and made strong use of mimesis, which meant that sign parameters were often iconic to the referent; therefore, movement and location held more import. Overall, 22 handshapes were documented, and the predominant handshapes were unmarked, although individuals' inventories varied significantly. Most participants preferred the handling strategy for depicting signs, with individual variations. Some evidence of noun-verb distinction was noted in the repertoire of some participants. When this data was compared with studies of other home signers, in either similar or substantially different sociolinguistic contexts, it showed similarities and differences, which suggests that factors in the physical and social context will contribute to varying language outcomes. 


\subsection{Conditions for a Shared Sign Language}

In Vanuatu, multiple barriers have precluded development of a shared sign language and any form of deaf community. Firstly, few connections between these participants existed, as few shared a village or locality, and a lack of shared communication between those who did meet was evident. Notwithstanding the methodological limitations of the research, participants' lexicons suggested few common signs resulting from either within village contact, incorporation of conventional gestures, or the high level of iconicity that motivates the form of home signs. Sign iconicity within a shared context could support mutual comprehension, although this was untested across participants in this study. Secondly, social organisation in Vanuatu reinforces familial interaction with extended family rather than external relationships, therefore the concept of a group of deaf people identifying and forming social bonds with each other, in preference to family, is unlikely to occur naturally. Thirdly, although there are some policy and practical efforts to progress this, societal attitudes towards people with disabilities generally contribute to the currently low social status of deaf $\mathrm{Ni}$-Vanuatu in terms of opportunities for language, education, employment and meaningful social roles. Few opportunities exist for deaf individuals to gather together, and consequently little prospect currently exists for a Vanuatu sign language to develop spontaneously. 


\section{Appendices}

A. SFA Letter of Consent 2012

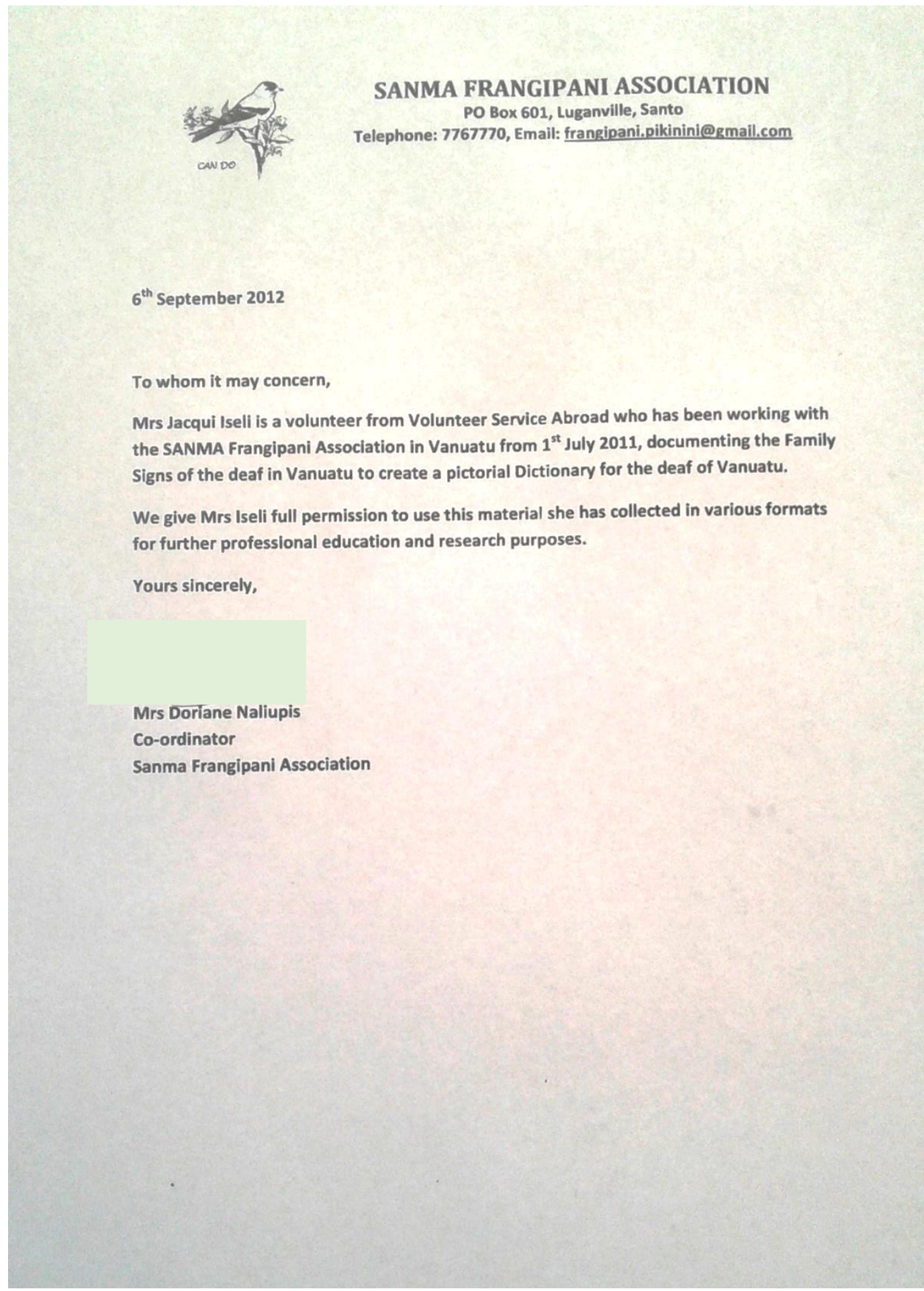


B. SFA Letter of Consent 2017

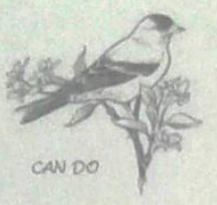

\title{
SANMA FRANGIPANI ASSOCIATION
}

P. O Box 601, Luganville, Santo

Telephone: 5623088 , Email: frangipani.pikinini@gmail.com

$12^{\text {th }}$ May 2017

\author{
TO WHOM IT MAY CONCERN
}

On behalf of the Sanma Frangipani Association board member, I do hereby grant permission for Jacqueline G. Iseli to conduct the research title "Homesigns and Emerging Sign Language of Some Nambut (Deaf) Ni-Vanuatu at the Sanma Frangipani Association .

Yours faithfully,

Doriane Naliupis

Coordinator 
C. Participants' Location, Gender and Approximate Age

\begin{tabular}{|c|c|c|c|c|}
\hline Country & Province & Islands & Locations & $\begin{array}{l}\text { Participants (gender, } \\
\text { approximate age) }\end{array}$ \\
\hline \multirow[t]{11}{*}{ Vanuatu } & \multirow[t]{2}{*}{$\begin{array}{l}\text { SANMA } \\
\text { Province }\end{array}$} & \multirow[t]{2}{*}{$\begin{array}{l}\text { Espiritu } \\
\text { Santo }\end{array}$} & Luganville & $\begin{array}{l}\text { Yonathon }(\mathrm{M}, 17) \\
\text { Hillary }(\mathrm{F}, 21) \\
\text { Maryann }(\mathrm{F}, 18)\end{array}$ \\
\hline & & & South Santo & $\begin{array}{l}\text { Lisa }(F, 22) \\
\text { Edna }(F, 20)\end{array}$ \\
\hline & $\begin{array}{l}\text { PENAMA } \\
\text { Province }\end{array}$ & Ambae & $\begin{array}{l}\text { Nambangahake } \\
\text { Nataluhanggle } \\
\text { Lombanga }\end{array}$ & $\begin{array}{l}\text { Jean-Marie (M, 34) } \\
\text { John }(M, 50+) \\
\text { Rosemary }(F, 40+)\end{array}$ \\
\hline & \multirow{5}{*}{$\begin{array}{l}\text { MALAMPA } \\
\text { Province }\end{array}$} & \multirow{5}{*}{$\begin{array}{l}\text { Malakula } \\
\text { Vao } \\
\text { Ambrym }\end{array}$} & Lakatoro, & Grace $(F, 40+)$ \\
\hline & & & Atchin & $\begin{array}{l}\text { Paul (M, 40+) } \\
\text { Susan (F, 40+) }\end{array}$ \\
\hline & & & Louuni & $\begin{array}{l}\text { Daisy }(F, 54) \\
\text { John }(M, 17)\end{array}$ \\
\hline & & & Vao & Jeanine $(F, 25+)$ \\
\hline & & & Ulei & Renjo (M, 20) \\
\hline & \multirow[t]{3}{*}{$\begin{array}{l}\text { SHEFA } \\
\text { Province }\end{array}$} & \multirow[t]{3}{*}{$\begin{array}{l}\text { Efate } \\
\text { Ifira }\end{array}$} & Port Vila & $\begin{array}{l}\text { Édouard (M, 20+) } \\
\text { Jane }(F, 20+)\end{array}$ \\
\hline & & & Pango & Serah $(F, 35+)$ \\
\hline & & & Ifira & Isabella $(F, 19+)$ \\
\hline
\end{tabular}


D. Stimulus Photo List Sample

\begin{tabular}{|l|l|l|}
\hline Type & Photo & Description \\
\hline People & Father & Man, with child walking \\
\hline Feelings & Sad & Woman with child hugging her \\
\hline State of being & Pregnant & Boy sitting with head in hand \\
\hline Places & Island & Pregnant woman standing in profile \\
\hline Actions & Pretending & Photo from plane looking down on whole island \\
\hline House & Boy bent over with a walking stick pretending to be old; \\
\hline Food & Groom & Woman standing with broom inert by side \\
\hline Animal & Gecko & Tied up and hanging from pole \\
\hline Custom & Statues & Gecko on wall \\
\hline Medical & Sick & Carved statues stacked lying on the ground \\
\hline Transport \& & Woman blowing her nose with tissue \\
\hline
\end{tabular}


E. Dictionary Page 83 Seascape Sample
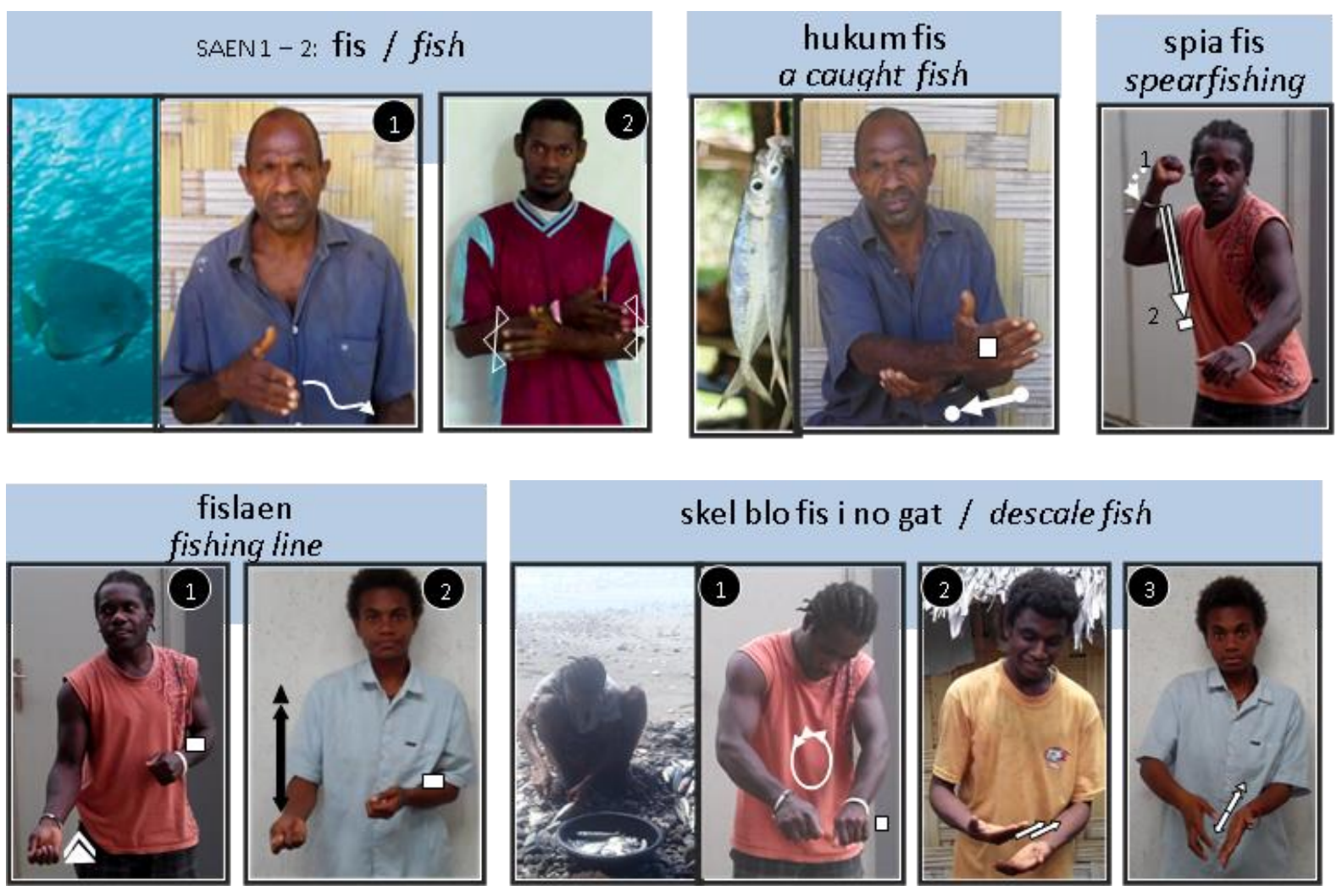

All photos of signs being performed are taken by myself and/or copied from "Storian wetem han olgeta" (Iseli, 2012). The original symbols in these sign illustrations were adapted, with permission, from "A Concise Dictionary of New Zealand Sign Language". Kennedy, G. et al. (Eds). Bridget Williams Books 2002. 
F. Glossary

\begin{tabular}{|l|l|}
\hline Bislama & English \\
\hline Famli & Family \\
Haosgel & Maid \\
Kastom & Custom \\
Man or woman Vanuatu & Ni-Vanuatu \\
Nambut & Deaf and dumb \\
Natangurra & Sago palm \\
Tuluk & Cassava pudding \\
\hline
\end{tabular}

G. Acronyms

\begin{tabular}{|l|l|}
\hline Acronyms & Meaning \\
\hline ABSL & Al-Sayyid Bedouin Sign Language \\
ASE & Adamarobe Sign Language \\
ASL & Australian Signed English \\
AusAID & Australian Agency for International Aid \\
Auslan & Australian Sign Language \\
DPA & Disability, Promotion and Advocacy \\
FJSL & Fijian Sign Language \\
ISN & Idioma de Señas Nicaragūense- \\
MS & (Nicaraguan Sign Language) \\
NGO & Melanesian Sign \\
NZAID & Non-governmental organisation \\
NZSL & New Zealand Agency for International Aid \\
SASS & New Zealand Sign Language \\
SFA & SANMA Frangipani Association \\
VNSO & Vanuatu National Statistics Office \\
VSDP & Vanuatu Society for Disabled People \\
\hline
\end{tabular}


H. ELAN Controlled Vocabulary Lists and Codes

\begin{tabular}{|c|c|c|c|}
\hline \multicolumn{2}{|l|}{ ELAN Tiers } & \multicolumn{2}{|c|}{ Controlled Vocabularies } \\
\hline $\begin{array}{l}\text { Handshapes (HS) } \\
\text { Right-Hand (RH) } \\
\text { Left-Hand (LH) }\end{array}$ & Description & $\begin{array}{l}\text { Code: } \\
\text { Auslan } \\
\text { handshape } \\
\text { name }\end{array}$ & $\begin{array}{l}\text { Table 4-2 } \\
\text { equivalent } \\
\text { name }\end{array}$ \\
\hline & Handshape types were Auslan & B-Flat & Handshape-1 \\
\hline & for coding in ELAN and Excel & A-Fist & Handshape-2 \\
\hline & (ELAN, 2018; Johnston, 1989). & G-Point & Handshape-3 \\
\hline & During analysis these were & 5-Spread & Handshape-4 \\
\hline & converted into handshape & 11-Write & Handshape-5 \\
\hline & numbers (e.g., handshape-1). & O-Round & Handshape-6 \\
\hline & & C-Cup & Handshape-7 \\
\hline & & 6-Good & Handshape-8 \\
\hline & & L-Gun & Handshape-9 \\
\hline & & H-Spoon & Handshape-10 \\
\hline & & X-Hook & Handshape-11 \\
\hline & & F-Okay & Handshape-12 \\
\hline & & 12-Salt & Handshape-13 \\
\hline & & V-Two & Handshape-14 \\
\hline & & 3-Eight & Handshape-15 \\
\hline & & W-Three & Handshape-16 \\
\hline & & Џ-Animal & Handshape-17 \\
\hline & & Y-Ambivalent & Handshape-18 \\
\hline & & 8-Middle & Handshape-19 \\
\hline & & K-Perth & Handshape-20 \\
\hline & & I-Bad & Handshape-21 \\
\hline & & Y-Rude & Handshape-22 \\
\hline & & Unsure & Indeterminate \\
\hline
\end{tabular}




\begin{tabular}{|c|c|c|c|}
\hline \multicolumn{4}{|c|}{ Appendix H. ELAN Controlled Vocabulary List and Codes (continued) } \\
\hline $\begin{array}{l}\text { Depicting Sign (DS) } \\
\text { Type; } \\
\text { RH and LH }\end{array}$ & Description & $\begin{array}{l}\text { Code } \\
\text { (dominant } \\
\text { hand only) }\end{array}$ & Example \\
\hline \multirow{6}{*}{$\begin{array}{l}\text { Major DS Types. } \\
\text { Padden et al., } 2013 \\
\text { (pp. 294, 295) } \\
\text { Iconicity patterns. }\end{array}$} & $\begin{array}{l}\text { Handling: "Grasping an } \\
\text { imaginary object while } \\
\text { performing a canonical action" }\end{array}$ & $\mathrm{H}$ & Vanuatu broom \\
\hline & $\begin{array}{l}\text { Instrument: "Depicting features } \\
\text { of an object while performing a } \\
\text { canonical action" }\end{array}$ & 1 & Rake \\
\hline & $\begin{array}{l}\text { Object: "Depicting features of } \\
\text { an object with hands with no } \\
\text { action" }\end{array}$ & 0 & Bottle of water \\
\hline & $\begin{array}{l}\text { Tracing: "Depicting an outline of } \\
\text { an object's shape or } \\
\text { dimensions" }\end{array}$ & $\mathrm{T}$ & Spider \\
\hline & $\begin{array}{l}\text { Touch: "Touching on or near the } \\
\text { body where the object is } \\
\text { typically found" }\end{array}$ & Tch & Flippers \\
\hline & $\begin{array}{l}\text { Body Part: "Holding up a part of } \\
\text { the body where an object is } \\
\text { found" }\end{array}$ & BP1 & No examples \\
\hline \multirow[t]{4}{*}{ Added codes. } & Animal Body Part: & $\mathrm{BPa}$ & Rooster's beak \\
\hline & $\begin{array}{l}\text { Constructed action: Mimetic of } \\
\text { person or animal }\end{array}$ & CA & Walking \\
\hline & Entity & $\mathrm{E}$ & Person \\
\hline & Element & $\mathrm{El}$ & Fire \\
\hline \multirow[t]{2}{*}{$\begin{array}{l}\text { Not DS types but } \\
\text { coded for statistical } \\
\text { purposes. }\end{array}$} & $\begin{array}{l}\text { Conventional gestures and } \\
\text { foreign signs (further broken } \\
\text { down into NZSL and MS) }\end{array}$ & C & Good \\
\hline & Anything not coded in DST & 0 & \\
\hline
\end{tabular}




\begin{tabular}{|c|c|c|c|}
\hline \multicolumn{4}{|c|}{ Appendix H. ELAN Controlled Vocabulary List and Codes (continued) } \\
\hline $\begin{array}{l}\text { RH Deixis or } \\
\text { LH Deixis }\end{array}$ & Description & Code & Example \\
\hline \multirow{4}{*}{$\begin{array}{l}\text { Pointing at a place, } \\
\text { person or object. }\end{array}$} & Real-world direction & RWdir & Place \\
\hline & Following a path & Path & Moon \\
\hline & Discourse referent & DisRef & Hospital \\
\hline & Ambiguous or unclear & $A m b$ & None \\
\hline \multirow[t]{12}{*}{ Sign Location } & Description & Code & Example \\
\hline & Neutral space & $\mathrm{N}$ & Copra \\
\hline & Facial area or neck & Face & Man \\
\hline & Head (not the face) & Head & Girl \\
\hline & Torso (touching it), not head & $\mathrm{TnH}$ & Woman \\
\hline & Above the Neutral space & Above & Apple \\
\hline & Below the Neutral space & Below & Flippers \\
\hline & $\begin{array}{l}\text { Wider than the Neutral space } \\
\text { (lateral) }\end{array}$ & Wide & Slingshot \\
\hline & Arm (not hand) is used as a base & Arm & $\begin{array}{l}\text { Green tree } \\
\text { lizard }\end{array}$ \\
\hline & Legs are touched or used & Legs & Football \\
\hline & $\begin{array}{l}\text { Back of body or behind the } \\
\text { jawline, or behind the signing } \\
\text { space in front }\end{array}$ & Back & $\begin{array}{l}\text { Injection to } \\
\text { buttocks }\end{array}$ \\
\hline & Head and Face & $\mathrm{HnF}$ & No examples \\
\hline \multirow[t]{3}{*}{ NMF Mouth } & Description & Code & Examples \\
\hline & Mouth pursed & $\mathrm{Mp}$ & Small \\
\hline & $\begin{array}{l}\text { Suggestion of a mouthed word } \\
\text { aligned to meaning }\end{array}$ & Oral & Fiji \\
\hline \multirow[t]{3}{*}{ NMF Function } & Description & Code & Examples \\
\hline & Affect & Aff & Few examples \\
\hline & Modifier & Mod & Few examples \\
\hline
\end{tabular}




\begin{tabular}{|c|c|c|c|}
\hline \multicolumn{4}{|c|}{ Appendix H. ELAN Controlled Vocabulary List and Codes (continued) } \\
\hline $\begin{array}{l}\text { Sign Formations } \\
\text { (Articulators) }\end{array}$ & Sign description & Code & Example \\
\hline \multirow{8}{*}{$\begin{array}{l}\text { How many hands used } \\
\text { or NMF only, including } \\
\text { sign types. }\end{array}$} & No hands, NMF only & 0 & Pig \\
\hline & One handed & $1 \mathrm{H}$ & Watercress \\
\hline & Two handed & $2 \mathrm{H}$ & Lock up \\
\hline & Two handed symmetrical & $2 \mathrm{HS}$ & Watermelon \\
\hline & Two handed non-symmetrical & $2 \mathrm{HnS}$ & Descale fish \\
\hline & $\begin{array}{l}\text { Two handed alternating the } \\
\text { same actions }\end{array}$ & $2 \mathrm{Halt}$ & Bird walking \\
\hline & $\begin{array}{l}\text { Hands with NMF } \\
\text { (NMS is old terminology) }\end{array}$ & HwNMS & $\frac{\text { neg }}{\text { HERE }}$ \\
\hline & Whole body used & WB & Police \\
\hline Number of parts & Description & Code & Example \\
\hline \multirow{3}{*}{$\begin{array}{l}\text { Number of signs in the } \\
\text { sequence or when } \\
\text { NMF is solely used for } \\
\text { a meaning. }\end{array}$} & Single sign or NMF & 1 & Pig \\
\hline & Two signs & 2 & Turtle \\
\hline & Three or more signs & $3+$ & Coffin \\
\hline
\end{tabular}




\section{References}

Anderson, M., Leigh, I., \& Samar, V. (2011). Intimate partner violence against Deaf women: A review. Aggression and Violent Behavior, 16, 406. doi:10.1016/j.avb.2011.02.006 Applebaum, L., Coppola, M., \& Goldin-Meadow, S. (2014). Prosody in a communication system developed without a language model. Sign Lang Linguist, 17(2), 181-212. doi:10.1075/sll.17.2.02app

Armstrong, D., Stokoe, W., \& Wilcox, S. (1995). Gesture and the Nature of Language. Cambridge, England: Cambridge University Press.

Bamberg, M. (1987). The acquisition of narratives: learning to use language. New York, NY: Mouton de Gruyter.

Bates, E., Marchman, V., Thal, D., Fenson, L., Dale, P., Reznick, J., . . Hartung, J. (1994). Developmental and stylistic variation in the composition of early vocabulary. In K. Perera, G. Collis, \& B. Richards (Eds.), Growing points in child language. Cambridge, England: Cambridge University Press.

Blok, G. (2013). A descriptive grammar of Eastern Lawa. (Master of Arts in Linguistics Linguistics), Payap University, Chiang Mai. Retrieved from https://inter.payap.ac.th Brentari, D., \& Coppola, M. (2013). What sign language creation teaches us about language. Wiley Interdisciplinary Reviews: Cognitive Science, 4(2), 201-211. doi:10.1002/wcs.1212

Brentari, D., \& Eccarius, P. (2011). When does a system become phonological? Potential sources of handshape contrast in sign language. In R. Channon \& H. van der Hulst (Eds.), Formational Units in Sign Languages (pp. 125-150). Berlin, Germany: De Gruyter Mouton.

Channon, R., \& van der Hulst, H. (2011). Introduction: Phonetics, Phonology, Iconicity and Innateness. In R. Channon \& H. van der Hulst (Eds.), Formational Units in Sign Languages (pp. 1-15). Berlin, Germany: De Gruyter, Inc.

Clarke, M., Leach, M., \& Scambary, J. (2013). Reconciling custom, citizenship and colonial legacies: Ni-Vanuatu tertiary student attitudes to national identity. Nations and Nationalism, 19(4), 715-738. doi:10.1111/nana.12009

Coppola, G., \& Senghas, A. (2010). The emergence of deixis in Nicaraguan signing. In D. Brentari (Ed.), Sign Languages: A Cambridge Language Survey (pp. 26). Cambridge, England: Cambridge University Press. 
CRIN. (2017). Vanuatu Children's Rights. Retrieved from https://www.crin.org/

Crowley, T. (2000). The language situation in Vanuatu. Current Issues in Language Planning, 1(1), 47-132.

Crowley, T. (2003). A New Bislama Dictionary (2nd ed.). Port Vila, Vanuatu: Pacific Languages Unit.

David, J. B., Edoo, B. B., Mustaffah, J. F. O., \& Hinchcliffe, R. (2009). Adamarobe-A 'Deaf Village. British Journal of Audiology, 5(3), 70-72. doi:10.3109/00381797109075543

Davis, J. E. (2011). Discourse features of American Indian Sign Language. In C. B. Roy (Ed.), Discourse in Signed Languages (Vol. 17, pp. 179-217). Washington, DC: Gallaudet University Press. Retrieved from https://muse-jhu-edu.ezproxy.aut.ac.nz de Vos, C. (2012). Sign-Spatiality in Kata Kolok: how a village sign language of Bali inscribes its signing space. (PhD), University of Radboud, Nijmegen, The Netherlands. de Vos, C., \& Pfau, R. (2015). Sign Language Typology: The Contribution of Rural Sign Languages. Annual Review of Linguistics, 1, 26. doi:10.1146/annurev-linguist-030514124958

de Vos, C., \& Zeshan, U. (2012). Introduction: Demographic, sociocultural, and linguistic variation across rural signing communities. In U. Zeshan \& C. de Vos (Eds.), Sign Languages in Village Communities (Vol. 4, pp. 2-26). Boston, MA: De Gruyter, Inc.

DESP. (2006). The Republic of Vanuatu's Priorities and Action Agenda 2006 - 2015. Vanuatu. Retrieved from https://www.adb.org.

Douglas, B. (2002). Christian Citizens: Women and Negotiations of Modernity in Vanuatu. The Contemporary Pacific, 14(1), 33. doi:org/10.1353/cp.2002.0007

ELAN. (2018) [Computer software]. Nijimegen, The Netherlands: Max Planck Institute for Psycholinguistics. Retrieved from https://tla.mpi.nl/tools/tla-tools/elan/

Emmorey, K., \& Reilly, J. (1995). Theoretical Issues Relating Language, Gesture, and Space: An Overview. In K. Emmorey \& J. Reilly (Eds.), Language, gesture, and space (pp. 118). Hillsdale, N.J.: Erlbaum.

Fiji Association of the Deaf (2007). Fiji Sign Language (FJSL) Dictionary. Suva, Fiji Islands: Fiji Association of the Deaf.

François, A. (2012). The dynamics of linguistic diversity: egalitarian multilingualism and power imbalance among northern Vanuatu languages. In International Journal of the Sociology of Language (Vol. 214, pp. 85-110). 
Gaba, E. (n.d.). Map of Vanuatu. Retrieved June 11, 2018, from

https://commons. wikimedia.org/w/index.php?curid=60143821

Geismar, H., \& Herle, A. (2010). Moving images: John Layard, fieldwork and photography on Malakula since 1914. Honolulu, Hawaii: University of Hawaii Press.

Geismar, H., Herle, A., \& Longga, N. (2007). John Layard long Malakula 1914-1915. Cambridge, England: Vanuatu Kaljoral Senta.

Goldin-Meadow, S. (2003). Hearing Gesture. Cambridge, MA.: The Belknap Press of Harvard University Press.

Goldin-Meadow, S. (2015). The impact of time on predicate forms in the manual modality: signers, homesigners, and silent gesturers. Top Cogn Sci, 7(1), 169-184. doi:10.1111/tops.12119

Goldin-Meadow, S., \& Brentari, D. (2017). Gesture, sign, and language: The coming of age of sign language and gesture studies. Behavioural and Brain Sciences, 61. Retrieved from doi:10.1017/S0140525X15001247, e46

Goldin-Meadow, S., \& Feldman, H. (1977). The development of language-like communication without a language model. Science, 197(4301), 3. doi:10.1126/science.877567

Goldin-Meadow, S., \& Mylander, C. (1983). Gestural Communication in Deaf Children: Noneffect of Parental Input on Language Development. Science, 221(4908), 4.

Green, M. (2014). The Nature of Signs: Nepal's Deaf Society, Local Sign and the Production of Communicative Sociality. (PhD Anthropology), Berkeley University, Berkeley, CA.

Haviland, J. B. (2013). The emerging grammar of nouns in a first generation sign language: Specification, iconicity, and syntax. Gesture, 13(3), 309-353. doi:10.1075/gest.13.3.04hav

Horton, L. (in-press). Representational Strategies for Symbolic Communication in Shared Homesign Systems from Nebaj, Guatemala.

Hunsicker, D., \& Goldin-Meadow, S. (2013). How handshape type can distinguish between nouns and verbs in homesign. Gesture (Amst), 175, 354-376. doi:10.1075/gest.13.3.05hun

ICDE. (2010). Vanuatu Education System. Retrieved August $3^{\text {rd }}, 2015$, but now unavailable online, from http://www.icde.org 
Iseli, J. (2012). Storian wetem han olgeta A Dictionary of Deaf Ni-Vanuatuan Signs. Port Vila, Vanuatu: Volunteer Service Abroad.

Jayaraman, T. K., \& Ward, B. D. (2006). Economic Growth in a Vulnerable Island Nation: An empirical study of the aid-growth nexus in Vanuatu. Asia-Pacific Development, 13(2), 20.

Johnston, T. (1989). Auslan Dictionary, A Dictionary of the Sign Language of the Australian Deaf Community. Petersham, N.S.W.: Deafness Resources Australia Limited.

Johnston, T., \& Schembri, A. (2007). Australian Sign Language An Introduction to Sign Language Linguistics. New York, NY: Cambridge University Press.

Kegl, J., Senghas, A., \& Coppola, M. (1999). Creation through Contact: Sign Language Emergence and Sign Language Change in Nicaragua. In M. DeGraff (Ed.), Language creation and language change: creolization, diachrony, and development. Cambridge, MA: MIT Press.

Kendon, A. (1975). Gesticulation, Speech, and the Gesture Theory of Language Origins. Sign Language Studies, 9(Winter), 24.

Kendon, A. (1980). A description of a deaf-mute sign language from the Enga Province of Papua New Guinea with some comparative discussion Part I: The formational properties of Enga signs. Semiotica, 31(1/2), 34.

Kendon, A. (1980b). A description of a deaf-mute sign language from the Enga Province of Papua New Guinea with some comparative discussion Part II: The semiotic functioning of Enga signs. Semiotica, 32(1/2), 38.

Kendon, A. (1980c). A description of a deaf-mute sign language from the Enga Province of Papua New Guinea with some comparative discussion Part III: Aspects of utterance construction. Semiotica, 32(3/4), 68.

Kennedy, G. D. (2002). A Concise Dictionary of New Zealand Sign Language / general editor, Graeme Kennedy. Wellington, N.Z.: Bridget Williams Books.

Kisch, S. (2012). Al-Sayyid: A sociolinguistic sketch. In U. Zeshan \& C. De Vos (Eds.), Sign Languages in Village Communities (pp. 365-372). Nijmegen, The Netherlands: Ishara Press.

Kuschel, R. (1973). The Silent Inventor: The Creation of a Sign Language by the Only DeafMute on a Polynesian Island. Sign Language Studies, 3, 1-27. doi:10.1353/sls.1973.0019 
Kuschel, R. (1974). A Lexicon of Signs from a Polynesian Outliner Island. Kobenhavn.

Retrieved October 24, 2017, from http://www.bellona.dk

Kusters, A. (2012). Adamarobe: A demographic, sociolinguistic and cultural profile. In U.

Zeshan \& C. de Vos (Eds.), Sign Languages in Village Communities (Vol. Sign Language Typology, pp. 6). Boston, MA: De Gruyter, Inc.

Kvam, M. (2004). Sexual Abuse of deaf children. A retrospective analysis of the prevalence and characteristics of childhood sexual abuse among deaf adults in Norway. Child Abuse \& Neglect, 28(3), 10. doi:10.1016/j.chiabu.2003.09.017

Lane, H., Hoffmeister, R., \& Bahan, B. (1996). A Journey into the Deaf-World. San Diego, Calif: DawnSignPress.

Lanesman, S., \& Meir, I. (2012). Algerian Jewish Sign Language: A sociolinguistic sketch. In U. Zeshan \& C. De Vos (Eds.), Sign Languages in Village Communities (pp. 361-364). Boston, MA: De Grouter, Inc.

Le Guen, O. (2012). An exploration in the domain of time: From Yucatec Maya time gestures to Yucatec Maya Sign Language time signs. In U. Zeshan \& C. De Vos (Eds.), Sign Languages in Village Communities (pp. 41). The Netherlands: Walter de Gruyter, Inc.

McKee, R. (2001). People of the eye. Wellington, New Zealand: Bridget Williams Books.

McKee, R., \& Vale, M. (2017). Sign Language Lexicography. In P. Hanks \& G. de Schryver (Eds.), International Handbook of Modern Lexis and Lexicography (pp. 22). Germany: Springer-Verlag GmbH.

McNeill, D. (2005). Gesture and Communication. In K. Brown, A. Anderson, \& E. K. Brown (Eds.), Encyclopedia of language and linguistics (2nd ed., pp. 58-66). Amsterdam: Elsevier.

Meir, I., Aronoff, M., Sandler, W., \& Padden, C. (in-print). Sign Languages and Compounding. 38.

Meir, I., Sandler, W., Padden, C., \& Aronoff, M. (in-press). Emerging Sign Languages. In Oxford Handbook of Deaf Studies, Language, and Education, Volume 2 (pp. 22).

Meir, R. P., \& Lillo-Martin, D. (2013). The Points of Language. Humana.mente, 24, 25. Morford, J., Singleton, J., \& Goldin-Meadow, S. (1995). The Genesis of Language: How much time is Needed to Generate Arbitrary Symbols in a Sign System? In K. Emmorey \& J. Reilly (Eds.), Language, Gesture and Space (pp. 313-332). Hove, England: Laurence Erlbaum Assoc. 
Morford, J. P., \& Hänel-Faulhaber, B. (2011). Homesigners as Late Learners: Connecting the Dots from Delayed Acquisition in Childhood to Sign Language Processing in Adulthood. Language and Linguistics Compass, 5(8), 525-537. doi:10.1111/j.1749818x.2011.00296.x

New Zealand Government. (2003). IATI Program Documents Vanuatu. Retrieved from www.mfat.govt.nz/assets/_securedfiles/Aid-Prog-docs/IATI-documents/Vanuatu.pdf Nonaka, A. (2014). (Almost) everyone here spoke Ban Khor Sign Language-Until they started using TSL: Language shift and endangerment of a Thai village sign language. Language \& Communication, 38, 54-72. doi:10.1016/j.langcom.2014.05.005

Nosek, M., Howland, C., Rintala, D., Young, M., \& Chanpong, G. (2001). National Study of Women with Physical Disabilities: Final Report. Sexuality and Disability, 19(1), 35. doi:10.1023/A:1010716820677

Nunn, P. D., Kumar, L., Eliot, I., \& Mclean, R. F. (2016). Classifying Pacific Islands. Geoscience Letters, 3(1), 19. doi:10.1186/s40562-016-0041-8

Nyst, V., Sylla, K., \& Magassouba, M. (2012). Deaf signers in Douentza, a rural area of Mali. In U. Zeshan \& C. de Vos (Eds.), Sign Language in Village Communities (Vol. 4, pp. 26). Boston, MA: De Gruyter, Inc.

Padden, C. (2011). Sign Language Geography. In G. Mathur \& D. J. Napoli (Eds.), Deaf Around the World The Impact of Language (pp. 19-37). Oxford, England: Oxford University Press.

Padden, C., Meir, I., Hwang, S., Lepic, R., Seegers, S., \& Simpson, T. (2013). Patterned iconicity in sign language lexicons. Gesture, 13(3), 287-308. doi:10.1075/gest.13.3.03pad

Panda, S. (2012). Alipur Sign Language: A sociolinguist and cultural profile. In U. Zeshan \& C. De Vos (Eds.), Sign Languages in Village Communities (pp. 353-360). Boston, MA: De Gruyter Inc.

Papua New Guinea Department of Education. (1994). Melanesian Signs For Communication With The Deaf (K. Stebbins Ed.). Port Moresby, PNG: Department of Education, Papua New Guinea.

Pfau, R. (2016). Morphology. In A. Baker, B. van den Bogaerde, R. Pfau, \& T. Schermer (Eds.), The Linguistics of Sign Languages (pp. 197-227). Amsterdam, The Netherlands: John Benjamins B.V. 
Polich, L. (2005). The Emergence of the Deaf Community in Nicaragua. Washington, DC: Gallaudet University Press.

Regenvanu, R. (2005). The Changing Face of "Custom" in Vanuatu. People and Culture in Oceania(20), 14.

Republic of Vanuatu. (2006). National Council of Chiefs Act. (No.23 of 2006). Republic of Vanuatu: Republic of Vanuatu Retrieved from www.paclii.org.

Royson, W. (2014, 2nd October). Be Alarmed! Vanuatu rates of violence against women and children. Vanuatu Daily Post. Retrieved from http://dailypost.vu/news/be-alarmedvanuatu-rates-of-violence-against-women-and-children/article_fbf9a7fb-4f4c-58f4a305-cfc8058accec.html

Safar, J. (2017). Translanguaging in Yucatec Maya signing communities. Applied Linguistics Review, 23. doi:https://doi.org/10.1515/applirev-2017-0082

Sandler, W. (2012). Dedicated gestures and the emergence of sign language. Gesture, 12(3), 265-307. doi:10.1075/gest.12.3.01san

Sandler, W., Meir, I., Padden, C., \& Aronoff, M. (2005). The emergence of grammar: systematic structure in a new language. Proc Natl Acad Sci U S A, 102(7), 2661-2665. doi:10.1073/pnas.0405448102

Schermer, T. (2016). Lexicon. In A. Baker, B. Van den Bogaerde, R. Pfau, \& T. Schermer (Eds.), The Linguistics of Sign Languages (pp. 22). Amsterdam, The Netherlands: John Benjamins B.V.

Senghas, A. (2003). Intergenerational influence and ontogenetic development in the emergence of spatial grammar in Nicaraguan Sign Language. Cognitive Development, 18(4), 511-531. doi:10.1016/j.cogdev.2003.09.006

Senghas, A., \& Coppola, G. (2001). Children Creating Language: How Nicaraguan Children Acquired Spatial Language. Pschological Science, 12(4), 6.

Senghas, R. (1995). An 'Unspeakable, Unwritable' Language: Deaf Identity, Language \& Personhood among the First Cohorts of Nicaraguan Signers. (Doctor of Philosophy PhD), Rochester University, New York, NY.

Shah, S. (2013). Sexual Offences in Vanuatu under the Light of Custom and Law: "An Avenue for Restorative Justice". Asian Journal of Criminology, 8(4), 257-275. doi:10.1007/s11417-013-9159-1 
Singleton, J., Goldin-Meadow, S., \& McNeill, D. (1995). The Cataclysmic Break Between Gesticulation and Sign: Evidence Against a Unified Continuum of Gestural Communication In K. Emmorey \& J. Reilly (Eds.), Language, Gesture and Space (pp. 287-312). Hove, England: Laurence Erlbaum Assoc.

Sobsey, D., \& Doe, T. (1991). Patterns of Sexual Abuse and Assault. Sexuality and Disability, 9(3), 16. doi:10.1007/BF01102395

Statistics NZ. (2018). Archived Health and Disability Statistics. Retrieved from http://archive.stats.govt.nz/browse for stats/health/disabilities/DisabilitySurvey $\mathrm{H}$ OTP2013/Commentary.aspx.

Sutton-Spence, R., \& Woll, B. (1999). The Linguistics of British Sign Language. Cambridge, UK: Cambridge University Press.

Tkachman, O., \& Sandler, W. (2013). The noun-verb distinction in two young sign languages. Gesture, 13(3), 33. doi:10.1075/gest.13.3.02tka

Torigoe, T., \& Takei, W. (2002). A Descriptive Analysis of Pointing and Oral Movements in a Home Sign System. Sign Language Studies, 2(3), 16. doi:10.1353/sls.2002.0013

Trudgill, P. (2012). On the sociolinguistic typology of linguistic complexity loss. Language Documentation \& Conservation, 3, 5 .

UNICEF, \& Republic of Vanuatu. (2014). Children, Women and Men with Disabilities in Vanuatu: What do the data say? : UNICEF Suva, Vanuatu Statistics Office. Retrieved from

http://reliefweb.int/sites/reliefweb.int/files/resources/Children_Women_and_Men_ with_Disabilities_in_Vanuatu.pdf.

van der Kooij, E., \& Crasborn, O. (2016). Phonology. In A. Baker, B. van den Bogaerde, R. Pfau, \& T. Schermer (Eds.), The Linguistics of Sign Languages (pp. 251-278). Amsterdam, The Netherlands: John Benjamins B.V.

Van Herreweghe, M., \& Vermeerbergen, M. (2012). Transcription. In R. Pfau \& et. al. (Series Eds.), Sign Language An International Handbook (pp. 30): De Gruyter, Inc. Retrieved from http://ebookcentral.proquest.com.

Vanuatu Women's Centre. (2011). Vanuatu National Survey on Women's Lives and Family Relationships. Port Vila, Vanuatu: Vanuatu Women's Centre. Retrieved from https://mjcs.gov.vu/images/research_database/Vanuatu_National_Survey_on_Wom ens_Lives_and_Family_Relationships.pdf 
VNSO. (2009). Vanuatu Census 2009. Vanuatu: Republic of Vanuatu. Retrieved from https://vnso.gov.vu/index.php/

Woll, B., \& Ladd, P. (2003). Deaf Communities. In M. Maschark \& P. Spencer (Eds.), Oxford Handbook of Deaf Studies and Deaf Education (pp. 151-163). Oxford, NY: Oxford University Press.

Zwitserlood, I. (2010). Sign Language Lexicography in the Early 21st Century and a Recently Published Dictionary of Sign Language of the Netherlands. International Journal of Lexicography, 23(4), 443-476. doi:10.1093/ijl/ecq031 